San Jose State University

SJSU ScholarWorks

Master's Theses

Master's Theses and Graduate Research

Spring 2010

\title{
An Analysis of Stacy Garrop's Sonnet Settings for Treble Choir and Piano
}

Kathryn Alexis Feetham

San Jose State University

Follow this and additional works at: https://scholarworks.sjsu.edu/etd_theses

\section{Recommended Citation}

Feetham, Kathryn Alexis, "An Analysis of Stacy Garrop's Sonnet Settings for Treble Choir and Piano" (2010). Master's Theses. 3759.

DOI: https://doi.org/10.31979/etd.9kx9-3ua3

https://scholarworks.sjsu.edu/etd_theses/3759

This Thesis is brought to you for free and open access by the Master's Theses and Graduate Research at SJSU ScholarWorks. It has been accepted for inclusion in Master's Theses by an authorized administrator of SJSU ScholarWorks. For more information, please contact scholarworks@sjsu.edu. 


\title{
AN ANALYSIS OF STACY GARROP'S SONNET
}

SETTINGS FOR TREBLE CHOIR AND PIANO

\section{A Thesis}

Presented to

The Faculty of the School of Music and Dance

San José State University

\author{
In Partial Fulfillment \\ of the Requirements for the Degree \\ Master of Arts
}

by

Kathryn A. Feetham

May 2010 
(C) 2010

Kathryn A. Feetham

ALL RIGHTS RESERVED 
THE DESIGNATED THESIS COMMITTEE APPROVES THE THESIS TITLED

AN ANALYSIS OF STACY GARROP'S SONNET

SETTINGS FOR TREBLE CHOIR AND PIANO

by

Kathryn A. Feetham

APPROVED FOR THE SCHOOL OF MUSIC AND DANCE

SAN JOSÉ STATE UNIVERSITY

May 2010

Brian Belet, D.M.A. $\quad$ Area Coordinator, Music Systems and Theory School of Music and Dance

Amanda Quist, D.M.A. Director of Choral Activities

School of Music and Dance

Martín Benvenuto, D.M.A. Artistic Director

Peninsula Women's Chorus, Palo Alto, CA 
ABSTRACT

\title{
AN ANALYSIS OF STACY GARROP'S SONNET SETTINGS FOR TREBLE CHOIR AND PIANO
}

\author{
by Kathryn A. Feetham
}

The purpose of this thesis is to provide a thorough and detailed analysis of Stacy Garrop's two works for treble chorus and piano, Pity Me Not (2003) and Thou Famished Grave (2006) for the purposes of providing a base for future research and study. Since Garrop's goal as she composes is to tell the story contained in the text, this analysis of her works looks closely at the approaches she takes to communicate the story to the listener. The two choral pieces are examined on several musical levels including but not limited to form, melody, harmony, register, rhythm, tempo, meter, and dynamics. Themes and broad gestures as well as small motives are identified. A short biography of the composer and an interview provides context. The works are based on two sonnets by the American poet Edna St. Vincent Millay, so the discussion includes a brief biography of the poet, an overview of sonnet form, and an analysis of the two sonnets. Finally, comparisons are made to her other settings of sonnets by Millay for mixed chorus. 


\section{ACKNOWLEDGMENTS}

First, many thanks are due to Dr. Stacy Garrop. Not only has she been gracious about the use of her music, but she has been accessible and interested in the project since its earliest beginnings.

I also owe a great deal to Dr. Brian Belet, Dr. Gordon Haramaki, and the rest of the School of Music and Dance at San José State University. Their continued support has been extremely encouraging during difficult times.

Finally, I humbly thank my parents for their help and guidance, and Luke Sanwick for his aid in the preservation of my sanity over the last two years. 


\section{TABLE OF CONTENTS}

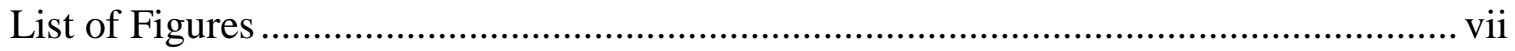

List of Musical Examples ................................................................................. viii

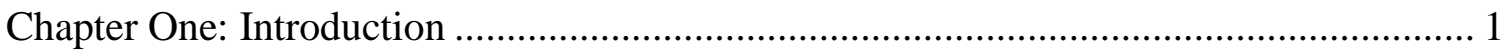

Chapter Two: Stacy Garrop .................................................................................. 4

Chapter Three: Edna St. Vincent Millay......................................................................... 7

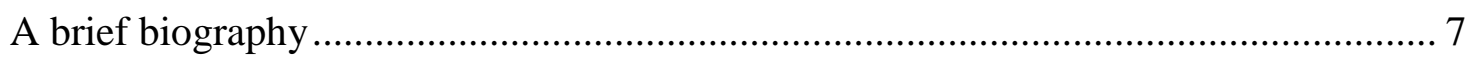

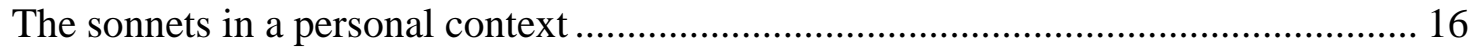

Chapter Four: Analysis of the Text.......................................................................... 19

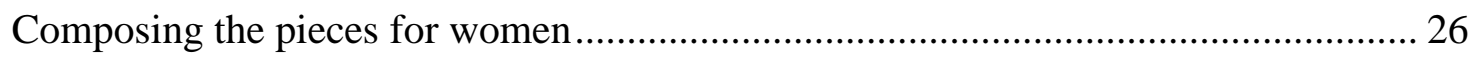

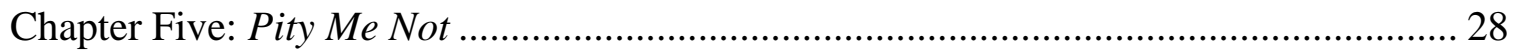

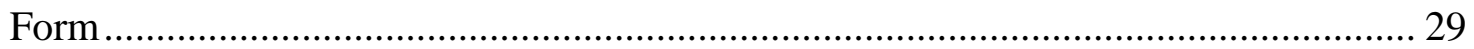

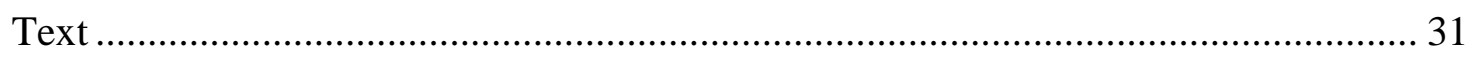

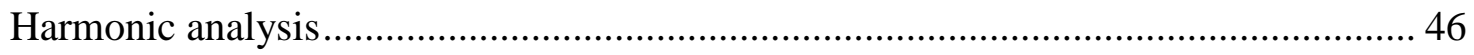

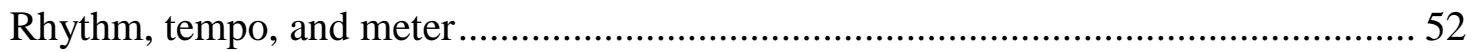

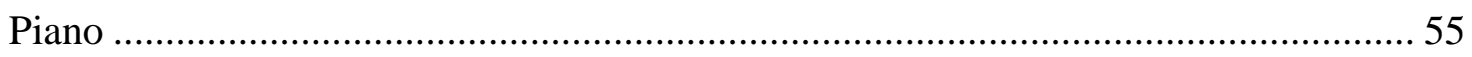

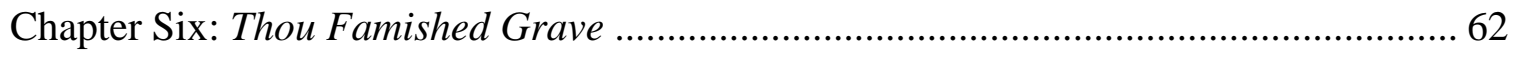

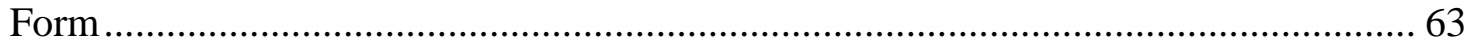

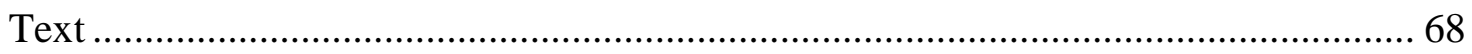

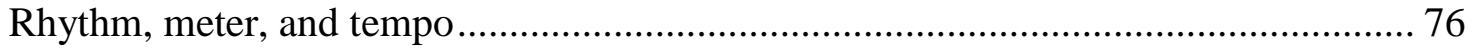

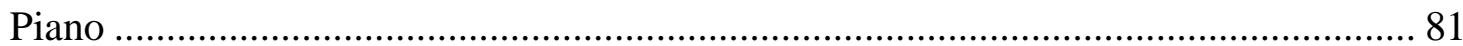

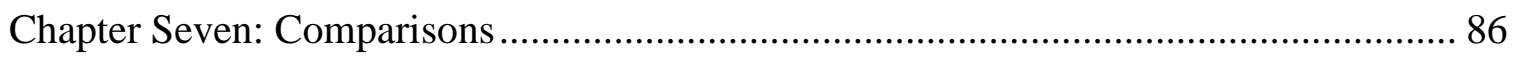

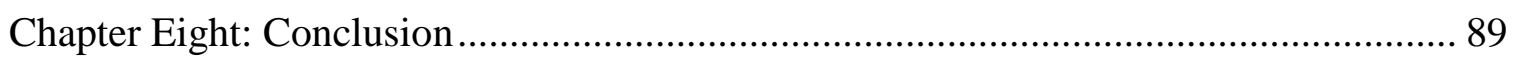

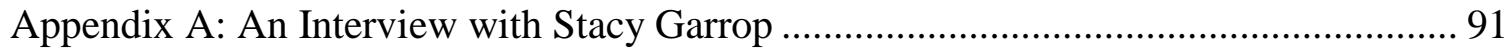

Appendix B: Supplementary Data and Analysis ......................................................... 99

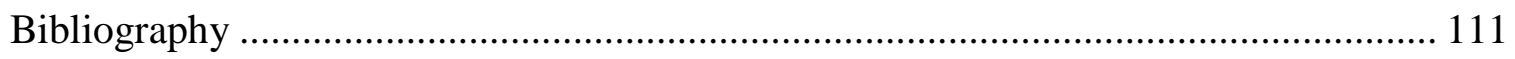




\section{LIST OF FIGURES}

Figure 1: Italian sonnet structure in "Thou famished grave, I will not fill thee yet." ....... 20

Figure 2: English sonnet structure in "Pity me not because the light of day." ................ 22

Figure 3: Vertical density in Pity Me Not mm. 12-22 ................................................. 34

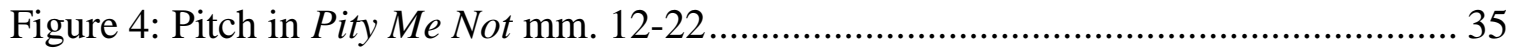

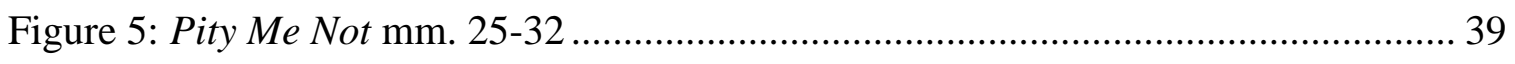

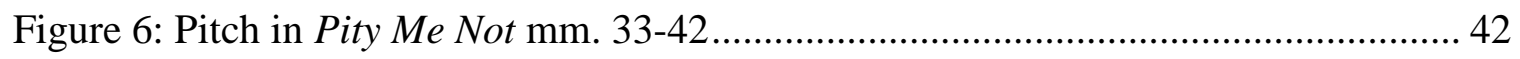

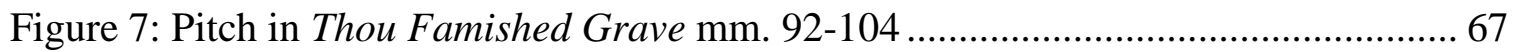

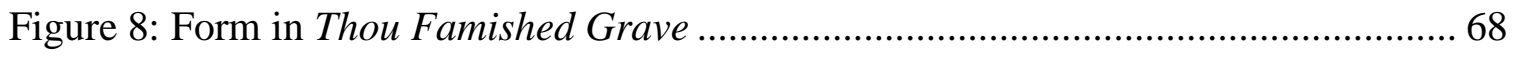

Figure 9: Pitch in Thou Famished Grave mm. 31-41 ................................................ 74

Figure 10: Pitch in Thou Famished Grave mm. 79-91 .............................................. 83 


\section{LIST OF MUSICAL EXAMPLES}

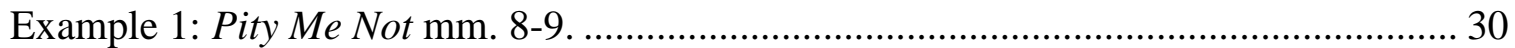

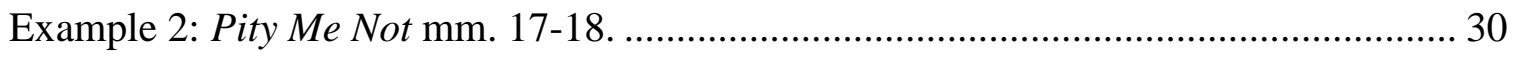

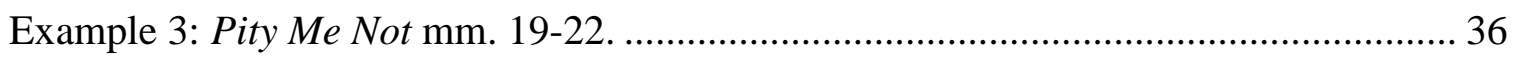

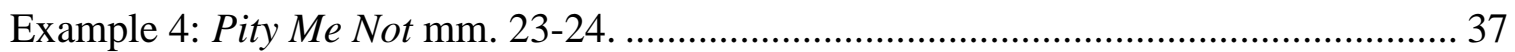

Example 5: Pity Me Not mm. 29-32 ........................................................................ 40

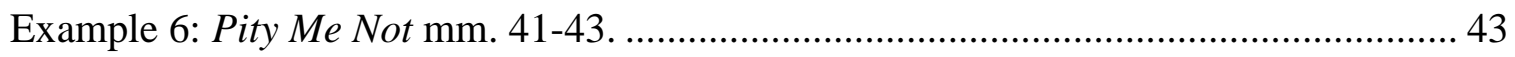

Example 7: Pity Me Not mm. 43-47 ................................................................... 44

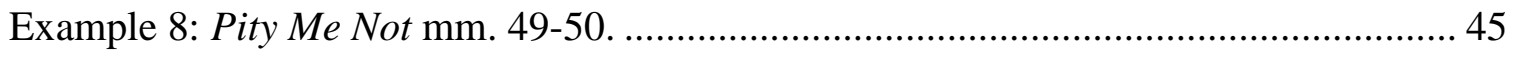

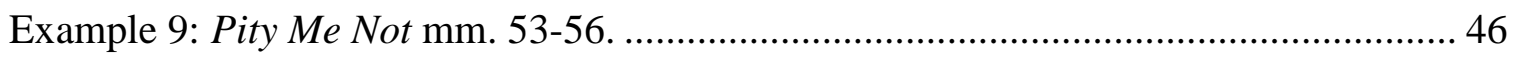

Example 10: Pity Me Not mm. 19-22 with Roman numeral analysis............................... 49

Example 11: Pity Me Not mm. 29-30 with chord root analysis...................................... 50

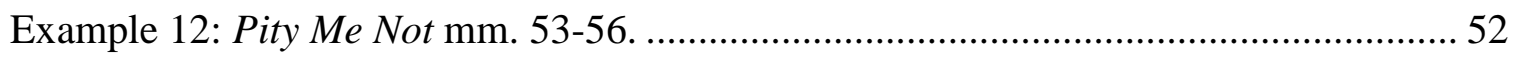

Example 13: Pity Me Not mm. 1-5 with rhythmic motive circled................................... 53

Example 14: Pity Me Not mm. 9-12 with rhythmic motives circled. ................................. 54

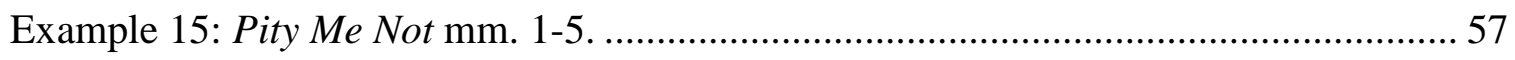

Example 16: Pity Me Not mm. 11-13. .................................................................... 57

Example 17: Pity Me Not mm. 25-28. …………………................................... 59

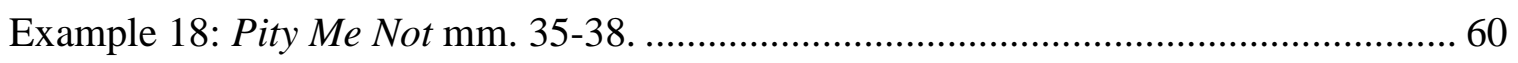

Example 19: Thou Famished Grave mm. 42-46....................................................... 64

Example 20: Thou Famished Grave mm. 21-25............................................................ 65

Example 21: Thou Famished Grave mm. 68-72....................................................... 66

Example 22: Thou Famished Grave mm. 1-3.............................................................. 69

Example 23: Thou Famished Grave mm. 10-17........................................................ 71

Example 24: Thou Famished Grave mm. 33-38 with chord root analysis...................... 73

Example 25: Thou Famished Grave mm. 23-25...................................................... 78

Example 26: Thou Famished Grave mm. 29-31......................................................... 78

Example 27: Thou Famished Grave mm. 112-117...................................................... 85 


\section{ONE \\ INTRODUCTION}

In the Introduction to his book The Cambridge Introduction to Modernism, Pericles Lewis writes about the “'hermeneutics of suspicion,' in which the apparent, or manifest, meaning of an idea or a text is thought to need decoding in order to discover another hidden, or latent, meaning, generally unknown to the original author or thinker."1 The idea appeals to music theorists who try to label and define various elements of music. Generally, music theorists have a bad reputation; it is often thought that theorists complain about unimportant musical matters without recognizing the greater effect of the piece as a whole and try to fit another's music into their own patterns, and that they do so because they are unable to compose or perform themselves. Though this petty viewpoint may be rightly ascribed to some theorists, it is unfair to claim that their work is entirely useless. An open-minded music theorist can analyze a piece of music and provide insights about its meaning by exploring technical elements that may be overlooked by a performer. In this author's view, thorough music analysis can help a performer heighten the level of art they bring to the music they are presenting. Therefore, that is the object of this thesis: to explore two pieces of music in technical detail and draw conclusions based on the findings.

Pity Me Not and Thou Famished Grave were composed by Stacy Garrop in 2003 and 2006, respectively, and are written for treble chorus and piano. For each piece, Garrop chose a sonnet written by Edna St. Vincent Millay for the text. The pieces are not

\footnotetext{
${ }^{1}$ Pericles Lewis, The Cambridge Introduction to Modernism (New York: Cambridge University Press, 2007), 18.
} 
long; Pity Me Not is performed in roughly three minutes and thirty seconds, and Thou Famished Grave is shorter at two minutes and forty-five seconds. Despite their brevity, the pieces are complex enough to warrant an intensive study of several musical elements at work.

When undergraduate music students take their classes in what is generally called theory, it is primarily to study the strict procedures of tonal harmony and voice leading and, eventually, the dissolution of those rules. Though they will be briefly discussed when relevant, an analysis of Garrop's pieces will require a different approach. The idea for this approach comes from James Tenney, a composer and theorist active during the twentieth century. He outlined the use of seven elements for music composition: "pitch, loudness, timbre, duration, temporal density, vertical density and time envelope. ${ }^{2}$ When using these elements for analysis, some of them can be quantified. Pitch will be sketched on line graphs to show the general movement of the melodies and harmonies. Loudness, or dynamics, and vertical density, or the number of notes sounding at once, can also be graphed using an area chart. The other elements will simply be discussed.

There are four objectives to the analysis of Garrop's pieces for treble chorus and piano. First, musicians studying Garrop's music may find new insights and ideas for use in their own performances, whether they are singers, pianists, or choral directors. Second, readers who are unfamiliar with Garrop's music may be inspired to hear and study more of her works, as she has written extensively for mixed chorus and for orchestra. Third, those already familiar with her music may find new reasons to enjoy

\footnotetext{
${ }^{2}$ Brian Belet, "Theoretical and Formal Continuity in James Tenney's Music," Contemporary Music Review 27, Part 1 (2008): 25.
} 
and examine it. Finally, though it cannot be expected that every conclusion in this paper will be agreed upon by every reader, it can be hoped that this analysis will spark conversation about these truly terrific pieces of music. 


\section{TWO \\ STACY GARROP}

Stacy Garrop grew up in California where funding for the arts has been scarce for decades. Even so, she managed to find several musical outlets during her childhood, beginning with piano lessons around her fifth birthday that continued throughout her undergraduate years in college. She began singing in a choir during elementary school and joined the marching band during high school, where she began playing orchestra bells and switched to saxophone during her junior year.

High school also offered Garrop the chance to take an Advanced Placement Music Theory course. The teacher was a jazz trumpeter who also taught improvisation. Garrop reminisced in an interview, "He told us to go home and write a piece of music, and that basically started my whole career because I went home and wrote a little waltz about a guy I liked."3 Though there was only one composition assignment during the class, she had enjoyed the process so much that she continued to write music on her own.

Garrop's friends and family were watching. She was introduced to H. David Hogan, a local composer and co-founder of a summer music camp in New Hampshire called the Walden School. He encouraged her to attend the camp during the summer between her junior and senior year of high school. When remembering the experience, she remarked, "By the end of the summer I knew I wanted to be a composer ... If you'd asked me at the beginning of my junior year what I wanted to study in college, I don't

\footnotetext{
${ }^{3}$ Stacy Garrop, interview by Kathryn Feetham, February 26, 2010. A full transcription of the interview can be found in Appendix A.
} 
know what I would have said. Maybe I would have thought science, but once I discovered composing, that was it."

Knowing that she wanted to compose, she applied to colleges that had strong music programs. She ended up attending the University of Michigan in Ann Arbor where she studied with George Balch Wilson, Michael Daugherty and Leslie Bassett, and earned her Bachelor of Music degree. At the University of Chicago, where she earned her Master of Arts degree, Shulamit Ran and John Eaton provided further training, as well as Andrew Imbrie, a visiting professor. Finally, she earned her Doctor of Music degree at Indiana University, where she studied with Eugene O’Brien, Frederick Fox and Claude Baker.

Garrop currently teaches composition at the Chicago College of Performing Arts at Roosevelt University in Chicago. In addition, she is a composer-in-residence with the Albany Symphony Orchestra for their 2009-2010 season.

Though she had written many orchestral and solo voice pieces during high school and college, she did not write her first choral piece until she entered a competition called Choral Ventures. "The thing that is striking about it is that I can't believe I got through three universities without writing a single choir piece," she observed. "I find it really scary that this is such a neglected field in the academic realm." 5 Though she did not win the commission, Choral Ventures provided a starting point for Garrop's choral works; she wrote a piece setting Edna St. Vincent Millay’s sonnet that begins "What lips my lips have kissed, and where, and why."

\footnotetext{
${ }^{4}$ Garrop, interview.

${ }^{5}$ Garrop, interview.
} 
After the competition, Garrop was interested in reading more of Millay's sonnets, and she found new inspiration in them. "I literally have pages and pages of configurations of sonnets about how I could put them together into different sets," she noted. However, since the beginning of the project, her schedule has gotten tighter between teaching, commissions, and her time as a composer-in-residence for various organizations. Six of the eight planned sets are complete, and she is still thinking ahead to the final two, but they have been put aside for now.

Since she has already stepped away from Millay, Garrop does not have any specific plans for her time after they are complete. Still, the effect of the project is evident when she speaks about it:

I'm also going to miss having the opportunity or reason to read over Millay's sonnets the way I have been. It was very useful to read enough of her sonnets, to read a couple of different biographies at the same time, and really try to get into her head, about what her thought process was when she was working on these. That part's been fun. She had such a remarkable life. ${ }^{6}$

\footnotetext{
${ }^{6}$ Garrop, interview.
} 


\section{THREE}

\section{EDNA ST. VINCENT MILLAY}

I think people like my poetry because it is mostly about things that anybody has experienced. ... If you write about people who are in love, and about death, and nature, and the sea, thousands . . understand . . my poetry because it's about emotions, about experiences common to everybody.

Edna St. Vincent Millay, from an interview conducted by Elizabeth Breuer, $1931^{7}$

It can be considered a flaw in human nature that we are disturbingly fascinated with tragedies and scandals in the lives of famous people. The life of Edna St. Vincent Millay was wrought with both. Parts of her life would not be out of place in a soap opera or melodrama, but the hardships she faced laid the foundation for her poetry. Her passionate nature and her love of words helped to create lyrics that would be set by many composers during her life and long after her death.

\section{A brief biography}

Edna St. Vincent Millay was born on February 22, 1892. She was the eldest of Cora Millay's three daughters; she and her sisters, Norma and Kathleen, had roughly two years between each of their birth dates. In her youth, she preferred to be called "Vincent" rather than Edna, and she would continue to use the name with her familiars in adulthood. Vincent's father, Henry, was mostly absent during her childhood and was hardly able to support his family as he had trouble keeping a job. When she was seven, her mother had had enough and sent him away. A divorce would soon follow.

\footnotetext{
${ }^{7}$ Nancy Milford, Savage Beauty: The Life of Edna St. Vincent Millay (New York: Random House Trade Paperbacks, 2001), 335. Used with permission.
} 
The Millay household, then, was full of women. Cora's love of literature led to a thorough education for her daughters in the literary arts. At the young age of five, Cora taught Vincent to read by giving her poetry. Vincent would later remember her first time reading poetry:

I know that it knocked the wind clear out of me, and left me giddy and almost actively sick... when, on opening at random my mother's gargantuan copy of Shakespeare, I read the passage from Romeo and Juliet about the "dateless bargain" and Death keeping Juliet as beautiful as she was in life, to be his 'paramour' . . . truly terrifying. . . . It grew and grew in both my mind and my body until I became so giddy that I must surely have fallen had I not at the time been lying flat on my stomach on the attic floor. ${ }^{8}$

It is obvious that she was a highly passionate person, a stereotypical redhead.

One of her teachers from the Elm Street grammar school would remember her appearance as it was influenced by her disposition: "She was small and frail for a twelveyear-old.... Her mane of red hair and enormous gray-green eyes added to the impression of frailty, and her stubborn mouth and chin made her seem austere, almost to the point of grimness."9 Indeed, she would take certain aspects of her life very seriously, including the writing of her poetry and dramatic works, but her famously bohemian lifestyle would begin to make an appearance in university.

Vincent's first experience with publishing was successful - in a way. Her poem "Renascence" was submitted to the poetry contest sponsored by The Lyric Year in 1912. It did not place, but it did receive accolades by the media. Her biographer, Nancy Milford, wrote, "For her loss of the prize there was the balm of the publicity stated, clear

\footnotetext{
${ }^{8}$ Milford, 24.

${ }^{9}$ Ibid., 5 .
} 
injustice of the judges" inept decision." ${ }^{\text {10 }}$ Indeed, "Renascence" continues to be one of the most celebrated poems that she ever wrote.

Vincent began college at a later age than most of her peers. Vassar College, a women's college at the time, was very interested in her because of the talent she possessed in writing. Due to what Vassar deemed as inadequate education in primary and secondary school, they required that she spend some time at Barnard College to prepare herself for the rigors Vassar would present. When she arrived at Vassar, she met Elaine Ralli. A friend of Ralli would tell Nancy Milford much later that the girls had been lovers:

Elaine told me that they were ... she felt she had been loved by Vincent and surely she had loved her. Millay was a seductress. Oh, I should think so! You have only to look at those poems. ... Elaine felt there was a ruthlessness about Vincent. That her work came first. ... She always thought Vincent had an eye on herself, her future.... She felt it was her first love, and perhaps her only one: her poetry. ${ }^{11}$

This sentiment would be echoed by many of Vincent's other lovers from various periods in her life. She was constantly breaking hearts. Later, a man named Floyd Dell, with whom she would keep in touch until her death, had the misfortune of falling in love with her:

Dell wanted to know everything about her and pressed her relentlessly. When he said he wanted to marry her, she deflected him. She told him, playfully at first, that she was not the girl to cook his meals and iron his shirts. When his importuning became unbearable, she cautioned him, "Never ask a girl poet to marry you, Floyd." Finally, she

\footnotetext{
${ }^{10}$ Milford, 80.

${ }^{11}$ Ibid., 130.
} 
said point-blank, "I am not so hopelessly besotted with you as that!" Which didn't mean she was no longer interested in him sexually. 12

Was it misfortune for Dell? Their relationship was presumably fun, and Dell could say that he knew a famous poet. In fact, even had she not been famous, some might say the privilege of knowing someone such as her would enrich one's own life. Though this may be the case, the ease of falling in love with such a passionate girl was probably overwhelmed by the difficulty in keeping her love. Dell would learn this firsthand. He conceded, “. . . this girl poet would always be falling in love with someone else,"13 and he could not be satisfied with that.

Vincent was not entirely immune from heartbreak, however. Witter Bynner (or Hal, as he was commonly called) proposed to her in a letter which she never received. Instead, she heard of his intent from a mutual friend. She wrote to him immediately, but did not hear from him as quickly as she had responded, so she sent two more telegrams accepting his proposal. But by then he was torn, and ultimately would retract his proposal. Milford suggests that he was struggling with his homosexuality ${ }^{14}$, but even this would not have softened the blow to Vincent.

It is at this point in her biography that Milford mentions that Vincent had a second abortion. The first had been late in 1920, and had been botched; it was one of the first times she had become seriously ill. ${ }^{15}$ The second occurred in 1922 after a love affair in Paris with a man named Daubigny; Vincent had applied for a "Certificat de Coutume," a

\footnotetext{
${ }^{12}$ Milford, 158.

${ }^{13}$ Ibid., 165.

${ }^{14}$ Ibid., 223-226.

15 Ibid., 197.
} 
document allowing her to marry in France without the consent of her parents. It was never used. She and her mother travelled to England and she frequently wrote to various people that she was very ill. Cora researched herbal remedies in a seventeenth-century herbal guide and helped Vincent miscarry. Norma would say to Nancy Milford later, "Vincent drank a potion Mother had concocted and walked and walked and walked."16 And thus, she was successful in "losing" the baby.

Later, when Vincent was asked about children in an interview in 1931, she said, “I don't know. Doubtless if I had children I wouldn't be so free, but I would try to be intelligent about it and not give every moment to them. But I don't really know.... I am a very concentrated person as an artist. I can't take anything lightly." ${ }^{\prime 1}$ Yet she took the care of her body lightly, some might say. Vincent was troubled with ailing health throughout her life, and it is quite possible that her early abortions were one of the many things she did to herself that would affect her health later. Regardless, she would never birth a child, and her health would begin to suffer soon after her second abortion.

In the spring of 1923, she became the first woman to win the Pulitzer Prize for poetry for "the best volume of verse published during the year, based on 'The Ballad of the Harp-Weaver,' 'A Few Figs From Thistles,' and eight sonnets published in ‘American Poetry, 1922, a Miscellany.",18 Yet this terrific achievement is hardly mentioned in her biography, because at the time Vincent's mind and energy were

\footnotetext{
${ }^{16}$ Milford, 240.

${ }^{17}$ Ibid., 338.

${ }^{18}$ Ibid., 251.
} 
concentrated elsewhere. In April, she had met Eugen Boissevain at a party where she was a houseguest. Floyd Dell was present, and wrote:

Eugene (sic) and Edna had the part of two lovers in a delicious farcical invention, at once Rabelaisian and romantic. They acted their parts wonderfully-so remarkably, indeed, that it was apparent to us all that it wasn't just acting. We were having the unusual privilege of seeing a man and a girl fall in love with each other violently and in public, and telling each other so, and doing it very beautifully. ${ }^{19}$

By the beginning of May, she was using his address as a return address, which meant she was living with him. Within another month, she was writing home to tell her mother that she was going to marry him. Though her health was continuing to trouble her throughout this time, her love for Eugen could not be tempered.

In fact, it was her health that pushed them to marry so quickly. On July 17, Millay's doctor insisted on surgery the next day for appendicitis. Before she went to the hospital, she married Eugen so that he could join her there. ${ }^{20}$ The ceremony was hastily planned, and her veil was made of the mosquito netting from the porch. Her photographs from the wedding show her as sickly and delicate. His role in her life was to become both husband and nursemaid, and she was the primary earner.

Yet her attention could not be held by a single man for very long. In September of 1928, she met George Dillon, fourteen years her junior, on a reading tour when he introduced her to the audience. Her romantic affair with him would last at least six years, and even after its end, affection remained between them. She was attracted to his poetic

\footnotetext{
${ }^{19}$ Milford, 250.

${ }^{20}$ Ibid., 254.
} 
talent; she had no way of knowing that his greatest claim to fame would be his continued relationship with her, and not his poetry. In 1931, she wrote a short poem to Dillon, including the lines:

Let us be fools \& love forever,

There was a woman, if tales be true, Who shattered Troy for a shepherd boy Less beautiful than you. ${ }^{21}$

Eugen knew about it from the beginning. ${ }^{22}$ Poor Eugen, for though he would have his own affairs, Millay's continued feelings for Dillon would cause jealousy and feelings of neglect in her husband. He tried to be accommodating, but eventually this became difficult. During a trip to Paris in 1932, Dillon came to visit them, and Eugen graciously decided to leave them alone together. Millay did not come home, and he wrote to her on June 5:

I am not going to be the black shadow between you and George and make you think that you must snatch your happiness whenever the ogre is away.... Settle down quietly, Edna, take a place for a year or come back here with him, do what you like, but do not think of me as the plague of Egypt, or as a husband who with a cold hand any day can be expected to separate two young lovers . . . tell yourself, that you're going to be together for ever and ever, or as long as you wish to. As for me, I will not do anything drastic and will live off your money for a year, unless we make some definite decision before that time. But in a year, all three of us ought to know what we want. ${ }^{23}$

${ }^{21}$ Milford, 342.

${ }^{22}$ Ibid., 304-305.

${ }^{23}$ Ibid., 354. 
Many more letters fraught with tension and jealousy were exchanged, and on July $5^{\text {th }}$ they spoke on the telephone and she had decided to return home, though she would not until August. $^{24}$

Vincent's number of diary entries for the next several years decreased, though in letters she continued to refer to herself as ill. It was obvious to her friends that she was succumbing to alcoholism.

In April of 1937, she accepted an honorary doctorate from New York University, but it was in the wake of what Vincent considered a severe, sexist insult. A dinner was to be held by the chancellor's wife in her honor, but her fellow recipients, who were male, would be honored at a separate dinner at the Waldorf-Astoria. Vincent did not consider this appropriate and would have declined the degree entirely had she not already accepted. Of course, she wrote a scathing letter to the chancellor: "I beg of you, and of the eminent Council whose representative you are, that I may be the last woman so honoured, to be required to swallow from the very cup of this honour, the gall of this humiliation." 25 It was her fifth honorary degree; she had already accepted degrees from Tufts University, Russell Sage College, the University of Wisconsin, and Colby College.

She had not kept in touch with her youngest sister, Kathleen, but this changed when Kathleen wrote to her in 1939 requesting financial assistance. Her husband had left her, and she wanted money to obtain a divorce. Unfortunately, her own career in writing had been overshadowed by her more talented elder sister, and she was wholly unsuccessful. In addition, she was suffering from the same ailments as Vincent, namely

\footnotetext{
${ }^{24}$ Milford, 365-66.

${ }^{25}$ Ibid., 403.
} 
ill health and alcoholism. But Vincent was generous - at first. She allowed her husband to take care of the correspondence with Kathleen, and he became more and more frustrated with Kathleen's ever-increasing requests. Finally, he wrote to her to explain, somewhat harshly, that they would not be able to continue the gifts of money due to Vincent's own finances. They did not hear from her again. ${ }^{26}$ In fact, Vincent would continue to send her money and would go into debt with her publisher in order to do so. Worst of all, Kathleen was not even using the money to secure her divorce. It was the cause of much resentment in the family, certainly between the sisters but perhaps most of all with Eugen.

On September 21, 1943, Kathleen went to the hospital "weak and unable to eat,"27 but the doctors could not find out what was wrong with her. After several hours, she lost consciousness and died. Because the cause of death was unknown, an autopsy was performed, and it was found to be acute alcoholism. Her obituary was titled "Kathleen Millay, Sister of the Poet," a final slight. ${ }^{28}$ Though she was not directly in touch with Kathleen at the time and did not attend her services, Vincent did hear of the diagnosis and may have been affected by it; she and Eugen began to keep detailed records of their own medication, which by then were long and varied — and mixed with alcohol. In 1939, she had been prescribed morphine, estrogen, and Dilaudid, an opiate, for the head and back pain that her doctors associated with menopause. ${ }^{29}$ However, she eventually associated

\footnotetext{
${ }^{26}$ Milford, 424-27.

${ }^{27}$ Ibid., 474.

28 Ibid.

${ }^{29}$ Ibid., 438-41.
} 
the pain, probably correctly, with an accident that had occurred months before, when she had been thrown from a car during a turn due to a faulty latch on the door.

The last years of her life were mostly unproductive. She was in debt and very ill, and wrote very little. Eugen died on August 29, 1949 of a cerebral hemorrhage after an operation for lung cancer. Vincent retreated to their home alone against the suggestions of her friends, but her strong will was not dampened by the death of her spouse. She would survive him by only a year and three months; on October 19, 1950, she was found in her home at the bottom of the stairs with a broken neck. The draft of a poem was found next to her, and the last three lines were circled:

I will control myself, or go inside.

I will not flaw perfection with my grief.

Handsome, this day: no matter who has died. ${ }^{30}$

She was a poet to the very end.

\section{The sonnets in a personal context}

It is likely that much of Millay's poetry was written in response to events in her own life. Knowing the history behind her work can be as interesting as the work itself. This is certainly the case with the sonnet that begins "Pity me not because the light of day." According to Nancy Milford, the sonnet was first published in 1920, though it would not be included in a book until 1923. Its first publication occurred nine months after the end of Vincent's affair with Jim Lawyer, an engineer and a married man.

Their affair was documented in letters. Eighteen of those letters from him still survive, beginning with one dated November 27, 1919. Vincent was twenty-seven.

\footnotetext{
${ }^{30}$ Milford, 508.
} 
"From the beginning of this correspondence he was troubled by thoughts of his wife's response to his deception," Milford wrote. "By December 22, he referred to his wife no longer as Mrs. Lawyer but as Louise, and by January 2 Louise knew 'that I love you more than anyone else and that we intend to live together." ${ }^{31}$ At first, his wife was only aloof to Jim, hiding her feelings beneath contempt and jokes. She even made light of the situation to others. But during the holidays, she attempted suicide. The event encouraged Jim to break off his relationship with Vincent. He returned all of her things and destroyed the letters she had sent him. Because he was distraught, and he could no longer confide in either Louise or Vincent, he secretly turned to Vincent's sister, Kathleen, and they began to date.

Years later, as Nancy Milford was researching Vincent's past, she found a draft of "Pity me not because the light of day" among Jim's letters to Vincent, as well as a small snapshot of Jim. Millay’s sister Norma begrudgingly told her,

Jim was a beautiful boy, you must understand that. He was tall and slim and blond. Godlike, really, a lovely man. And yes, he was married ... and yes, Vincent loved him. Well, you know, it can happen that you can feel quite a lot for someone who is not in any way your equal. ${ }^{32}$

The history behind "Thou famished grave, I will not fill thee yet" is not as certain. It was first published in 1939, though it had long been completed. She wished it to be published with Wine from These Grapes as a set in 1934, but her publishers did not follow her wishes. ${ }^{33}$ Within it, an entire section is devoted to her friend Elinor Wylie

\footnotetext{
${ }^{31}$ Milford, 178-179.

${ }^{32}$ Ibid., 179.

${ }^{33}$ Ibid., 380.
} 
after her death in December, 1928, and it is possible that the sonnet was written in response to the death of her friend. However, it is not contained in the set for Elinor. Instead, it appears later among other sonnets. Cora Millay, Vincent's mother, passed away in February of 1931, so her death may also have prompted the sonnet.

Most likely, however, is that the sonnet was inspired by both deaths and Vincent's own illness, which had begun again in earnest in 1932. The poet rails against death, insisting that she will fight against it until the very end. Indeed, she would persist in life for almost twenty more years. 
FOUR

ANALYSIS OF THE TEXT

"The sonnet is Donne's original 'well wrought urne'-compact, shapely, highly finished, and able to contain, in concentrated form, almost all that is human.",34

Michael R. G. Spiller

A thorough analysis of Garrop's setting of Millay's texts requires an

understanding of the text itself: its form, meaning, and artistry. The two poems that Garrop has set are extremely different. They are both sonnets, though the forms are not the same. One uses a significant amount of imagery, while the other relies more on a wavering between emotions. But there are similarities as well, such as Millay's colorful language, and there are reasons that Garrop intends the two works to be performed as a set.

The Italian form for the sonnet was initially quite strict, though liberties have been taken by brazen poets throughout its existence. The original form consists of fourteen lines broken into two parts: an octave, the first eight lines, and a sestet, the second six lines. Each line is most commonly written in iambic pentameter, ten syllables organized into five sets of stressed and unstressed syllables. The octave and sestet are organized by the rhyming of the last words. Traditionally, rhyming in the octave followed an ABBA ABBA style (alternately $\mathrm{ABAB} A B A B)$, and the sestets were usually $\mathrm{CDE} C \mathrm{CDE}$, though there were several alternate forms for the sestet.

Millay wrote a significant portion of her poetry in sonnet form. When trying to write a preface to her Collected Sonnets in 1931, she noted:

\footnotetext{
${ }^{34}$ Michael R. G. Spiller, The Development of the Sonnet: An Introduction (London: Routledge, 1992$), 1$.
} 
I did not know then what a sonnet was. I thought, as many people think, and not at all unreasonably, that a sonnet was any kind of short lyric, the word sounds like a diminutive, and informal. What greatness of spirit, what nobility of mood, what austerity, what solemn and serene behaviour, what formal grace and method of procedure as of a ritual most precise and perfect of high ecstasy restrained - what a sonnet could be, what it was meant to be, and what it sometimes even was, I was to learn. ${ }^{35}$

"Thou famished grave, I will not fill thee yet" follows the more traditional Italian sonnet structure, whereas "Pity me not because the light of day" is written in the English form. The sestet in "Thou famished grave, I will not fill thee yet" is written as CDCDCD, commonly denoted as Type 2 in the variances of the Italian sonnet. ${ }^{36}$ The structure is easily seen when considering the last words of each line and their relation to each other (see Figure 1).

1 Thou famished grave, I will not fill thee yet, A

2 Roar though thou dost, I am too happy here; B

3 Gnaw thine own sides, fast on; I have no fear B

4 Of thy dark project, but my heart is set A

5 On living - I have heroes to beget A

6 Before I die; I will not come anear B

7 Thy dismal jaws for many a splendid year; B

8 Till I be old, I aim not to be eat. A

9 I cannot starve thee out; I am thy prey C

10 And thou shalt have me; but I dare defend D

11 That I can stave thee off; and I dare say, C

12 What with the life I lead, the force I spend, D

13 I'll be but bones and jewels on that day, C

14 And leave thee hungry even in the end. ${ }^{37}$ D

Figure 1: Italian sonnet structure is shown in "Thou famished grave, I will not fill thee yet."

\footnotetext{
${ }^{35}$ Milford, 459.

${ }^{36}$ Charles Tomlinson, The Sonnet: Its Origin, Structure, and Place in Poetry (Folcroft, PA: The Folcroft Press, Inc., 1970), 4. The various "types" of the sonnet sestet reflect the differences in rhyme scheme from one type to the next.

37 “Thou famished grave, I will not fill thee yet" Copyright (C) 1939, 1967 by Edna St. Vincent Millay and Norma Millay Ellis. Reprinted by permission of Elizabeth Barnett, Literary Executor, The Millay Society.
} 
Millay's use of punctuation is of particular interest when reading "Thou famished grave, I will not fill thee yet." As might be expected, the octave and sestet are parted by a period (after "eat"). However, other phrases are often split over two lines. For instance, "I have no fear/Of thy dark project" begins in the middle of the third line and ends in the middle of the fourth. Because the technique is used constantly, the poem takes on momentum and, depending on the reader, may seem alternately impassioned or anxious. The text itself also bears discussion. Many of the words Millay chooses to use for the sonnet have bleak or gritty connotations: gnaw, dark, dismal, starve, prey, bones. Such words are not unexpected in a sonnet about death. Because Millay's defining emotion is not depression or despair but rather courage, she balances those words with others that have more positive implications: happy, heart, heroes, jewels.

The structure of "Pity me not because the light of day" follows a popular English form of the sonnet that emphasizes the two-line turn at the end of the poem. The turn is made of two rhyming lines, or a couplet, that do not match any others in the text. Since the last two lines of the sonnet are set apart, the first twelve lines are treated differently than in the Italian sonnet. The twelve lines are broken up into sets of four. Often, the rhymes stand alone in each set of four (ABAB, CDCD, EFEF), but some poets prefer to use a "couplet link" 38 between each set (ABAB, BCBC, CDCD). Also, "the greater flexibility in rhyming is not the main difference between the English and Italian form. More important is the difference of effect in the proportions eight to six and twelve to two, particularly in the ending of the sonnet, where the couplet makes the English sonnet

\footnotetext{
${ }^{38}$ John Fuller, The Critical Idiom, ed. John D. Jump, vol. 26, The Sonnet (London: Methuen \& Co. Ltd., 1972), 21.
} 
seem particularly summary or epigrammatic. ${ }^{39}$ English poets have often used the final two lines to add a "twist" to the end of the poem.

The English sonnet form has been subject to heavy criticism. John Fuller states,

Just as it is hard in the Italian sonnet to use the second quatrain for constructive organic development, the three isolated quatrains of the English sonnet are similarly prone to simple variation or repetition. Ideally there should be even greater tension in the proposition of the English sonnet, three turns of the screw so to speak, before the point is driven home in the couplet. In practice this is not often so... ${ }^{40}$

When looking at "Pity me not because the light of day," are Fuller's concerns applicable? Millay chooses not to use couplet links between the three sets of four lines (see

Figure 2).

$\begin{array}{lll}1 & \text { Pity me not because the light of day } & \text { A } \\ 2 & \text { At close of day no longer walks the sky; } & \text { B } \\ 3 & \text { Pity me not for beauties passed away } & \text { A } \\ 4 & \text { From field and thicket as the year goes by; } & \text { B } \\ 5 & \text { Pity me not the waning of the moon, } & \text { C } \\ 6 & \text { Nor that the ebbing tide goes out to sea, } & \text { D } \\ 7 & \text { Nor that a man's desire is hushed so soon, } & \text { C } \\ 8 & \text { And you no longer look with love on } m e . & \text { D } \\ 9 & \text { This have I known always: Love is no more } & \text { E } \\ 10 & \text { Than the wide blossom which the wind assails, } & \text { F } \\ 11 & \text { Than the great tide that treads the shifting shore, } & \text { E } \\ 12 & \text { Strewing fresh wreckage gathered in the gales: } & \text { F } \\ 13 & \text { Pity me that the heart is slow to learn } & \text { G } \\ 14 & \text { What the swift mind beholds at every turn. }{ }^{41} & \text { G }\end{array}$

Figure 2: English sonnet structure is shown in "Pity me not because the light of day."

\footnotetext{
${ }^{39}$ Fuller, 15.

${ }^{40}$ Ibid., 16-17.

41 "Pity me not because the light of day" Copyright (C) 1923, 1951 by Edna St. Vincent Millay and Norma Millay Ellis. Reprinted by permission of Elizabeth Barnett, Literary Executor, The Millay Society.
} 
Millay does introduce a theme in the beginning of the sonnet that Fuller may dislike for its repetition, but she does not hold on to it for long. The first eight lines support the entrances of "pity me not," but the repetition ends with the beginning of the ninth line and a new structure takes its place. In a way, the sonnet is reminiscent of the older Italian form because it respects the relationship between the octave and the sestet, even though it directly follows the English model including emphasis on the couplet and its dramatic twist.

It is worth exploring the traditional pentameter that Millay uses in her sonnets since it does not occur perfectly in "Pity me not because the light of day." Using the common scantion pattern of " $\mathrm{x}$ " for an unstressed syllable and "/" for a stressed syllable, the traditional iambic pentameter is written as $\mathrm{x} / \mathrm{x} / \mathrm{x} / \mathrm{x} / \mathrm{x} /$. When applied to the sonnet, it is immediately obvious that the word "pity" creates a problem:

$$
\text { / } \mathrm{x} \times \text { / } \mathrm{x} / \mathrm{x} / \mathrm{x} /
$$

Pity me not because the light of day

Since "pity" occurs so frequently at the beginning of a phrase, the rhythm of the sonnet is disjointed. The final line also contains a similar problem:

$$
\begin{aligned}
& \text { / } \mathrm{x} / / \mathrm{x} / \mathrm{x} / \mathrm{x} / \\
& \text { What the swift mind beholds at every turn. }
\end{aligned}
$$

To begin the line on a stressed syllable creates an issue of where and how to return to the normal cadence. However, the practice is not wholly reprehensible. Peter L. Groves makes the case that "the prosaic patterns of language are inevitably more complicated than the simple alternations and recurrences of metrical form. To write in English in an undeviating succession of naturally-occurring iambics would be impossible without 
laying Draconian and quite impractical restrictions upon one's choice of language . . "42 If Groves' realistic approach to the issue is taken, Millay's imperfect iambic pentameter is appropriate because it respects the rules of the language over the rules of sonnet construction.

Just as in "Thou famished grave, I will not fill thee yet," punctuation also plays a large role in understanding "Pity me not because the light of day." Technically, the sonnet contains only two sentences, though the sentences are further broken into multiple phrases. The first finishes at the end of the eighth line, underscoring the octave-sestet relationship. Millay often uses punctuation for the end of a sentence in this place in her poetry, so it is possible that she recognizes the elegance of the Italian form even when she is not strictly following it. The first sentence is broken into three main parts: lines 1-2, 34, and 5-8. The first phrase does not pause until the end of the second line, where Millay uses a semicolon. The second two lines follow the same pattern. Lines 5-8 are broken into four parts by the use of commas at the end of each line until the end of the sentence, which is given the sonnet's first period. If the text were transcribed into prose, the comma in the seventh line is not necessary since lines 7-8 encompass one thought, but Millay has chosen to split the phrase to continue the stanzaic feel.

The second sentence is quickly differentiated from the first with the appearance of a colon in the middle of the first line. The next phrase is a line and a half, returning the rhythm to its line-by-line motion. Did Millay intend any special significance for the colon? It will become apparent later that Stacy Garrop does consider the colon an

\footnotetext{
${ }^{42}$ Peter L. Groves, ELS Monograph Series, ed. Robert M. Schuler, vol. 74, Strange Music: The Metre of the English Heroic Line (Victoria, B.C.: English Literary Studies, 1998), 19.
} 
important piece of punctuation since she treats the beginning of the line very specifically, setting the phrase apart and emphasizing its importance. The sentence continues with pauses at the end of each line until reaching the couplet, which is set apart by another colon. In the last two lines, Millay is providing the twist and ultimately the message of the sonnet, so she has deemed it appropriate to indicate the importance with another colon. Though the grammar would not be appropriate in prose, it is not inappropriate for Millay to take artistic liberties in her poetry.

When examining the words Millay chooses to use, it becomes clear that "Pity me not because the light of day" is rife with nature imagery. Of the fourteen lines, nine are dominated by text about the outdoors. Though nature does not encompass the theme of the poem, it is certainly the metaphor that Millay chooses. Furthermore, the imagery is always about death, destruction, or the end of something: the fading of seasonal flowers, or the devastating effect of the sea on ships and coastlines. Millay's choice of text certainly sets a somber mood. The last two lines of both the octave and the sestet are used to express the poet's poignant emotions, and the ninth line begins a declarative statement.

Stacy Garrop has noted in an interview that the meter of the text and the structure of the sonnet each play a large role in her compositions. Before writing a single note, she takes a great amount of time analyzing the poem:

When I write the piece, what I do first is look at the text and figure out the rhythm of the text. I have all these sheets in this Millay book where it's just the text with the rhythm and note heads written out. From that, I figure out what the meter is. So before it even gets set to music, those stages are done. I also look at that and figure out what is the 
formal structure that the words are suggesting. With Millay and these fourteen line sonnets, sometimes it's a 4-4-4-2 pattern in the way she breaks down her lines; sometimes it's 6-4-4. I figure out what kind of form that suggests. So all that information is gathered; then I go to the piano and start figuring out what I actually want to do with the notes. $^{43}$

\section{Composing the pieces for women}

Garrop was already deeply involved in the composition of eight groups of sonnet settings for mixed chorus when Paul Carey and Vox Caelestis approached her in 2003 about a commission for the treble choir. Though it would not fit into the sets she was already composing, she decided to use Millay's "Pity me not because the light of day" for the group. When asked why she chose not to set a poem from a different poet, she replied, "I think because it was such a new project for me, and I got so excited about taking on this big, multi-set project that the thought of leaving Millay's world for a while was not something I wanted to do yet."44 She had worked hard to try and group many of Millay's sonnets together into sets that made sense, and "Pity me not because the light of day" (and later, "Thou famished grave, I will not fill thee yet") were not finding proper places among the others. She was still interested in setting them, so she waited until the right opportunity appeared.

The poem is clearly written from a woman's point of view, so any low-pitched male voices in a chorus would sound out-of-place, especially if given text from the original poem. Instead, Garrop chose to include piano, a departure from the a cappella SATB pieces she had been composing. The piano adds depth and range, as well as a new

\footnotetext{
${ }^{43}$ Garrop, interview.

${ }^{4}$ Ibid.
} 
timbre, without the burden of text. It should not be considered a replacement for male voices, but rather an entirely new character. This character is not in contention with the female singers as males might be, but instead acts as a supporting force.

When a second opportunity to compose a piece for treble chorus came along in 2006, she decided to set "Thou famished grave, I will not fill thee yet" as a companion piece to Pity Me Not. Though the text does not specifically suggest a female voice, Garrop had complex melodies and harmonies in mind. She needed the piano to feel comfortable with giving the singers such difficult music. She explained, “ . . when I write for a chamber ensemble and soloist, the soloist can be fed pitches by the instruments, and my language can go out a lot further. When it comes to choral writing, even with the piano I try to be a lot more careful and a lot more tonal so that the choir will have an easier time."

Traditional harmony in Thou Famished Grave can only be applied loosely, since the key shifts constantly throughout the piece. Even so, the vocal melodies are beautifully linear in contrast to the piano's brusque bass lines and clustered chords. In addition, when Garrop speaks about the piece, she identifies the speaker of the poem as a woman. She explained, “This woman is saying, 'I know you're going to get me some day, but you're not going to get me now, and I'm going to enjoy life every moment I can until you get me.",45 Perhaps it is Millay herself whom Garrop hears behind the poem.

\footnotetext{
${ }^{45}$ Garrop, interview.
} 
When Paul Carey and his chorus Vox Caelestis commissioned a piece from Stacy Garrop in 2003, she had already completed three sets of choral works setting sonnets by Edna St. Vincent Millay and was planning five more. However, her sets were for mixed chorus, and Vox Caelestis was a women's chorus. Though she could have chosen to compose a piece completely unrelated to her work in progress, she opted instead to set a sonnet by Edna St. Vincent Millay that would not be included in the larger work. The sonnet she chose begins "Pity me not because the light of day" and she shortened its title to Pity Me Not.

The sonnet is suitable for a women's chorus because of its subject-matter. Millay, writing from a woman's perspective, speaks about the fleeting nature of a man's romantic passion. Within the music's three minutes and thirty seconds, Garrop's setting effectively conveys the emotion that Millay felt while writing the poem. It is written for treble chorus and piano, an important departure from her other a cappella works. The piano helps to extend the range of the vocalists that is even further limited by the lack of male voices. Garrop rarely chooses to stretch the singers beyond their normal vocal ranges ${ }^{46}$ while still managing to convey the intense emotion involved in the sonnet text.

\footnotetext{
${ }^{46}$ Richard Wigmore cites a soprano's range as $B_{3}$ to $C_{6}$, and an alto's range as $\mathrm{G}_{3}$ to $\mathrm{G}_{5}$. His entries on range can be found in the following sources:

Richard Wigmore, "Contralto," in The Oxford Companion to Music, edited by Alison Latham, Oxford Music Online, http://www.oxfordmusiconline.com.libaccess.sjlibrary.org/subscriber/article/opr/t114/e1596 (accessed February 20, 2010).

Richard Wigmore, "Soprano," in The Oxford Companion to Music, edited by Alison Latham, Oxford Music Online, http://www.oxfordmusiconline.com.libaccess.sjlibrary.org/subscriber/article/opr/t114/e6341 (accessed February 20, 2010).

Specific pitches will be referred to based on the system where $\mathrm{C}_{4}$ is equal to Middle $\mathrm{C}$.
} 
Garrop chooses to change the meter frequently in Pity Me Not. Though mostly in $3 / 4$, she often uses $2 / 4$ or $4 / 4$ meter to accurately depict where the strong beats fall instead of bending the movement of the line to a single meter or relying on tenuto or accent articulations to delineate strong beats.

The tonal center also shifts frequently, though it may not be as noticeable. The piece begins in a tenuous $\mathrm{F}$ minor, suggested mostly by the pedal $\mathrm{F}$ in the right and left hands of the piano instead of a reliance on traditional harmonic progression. By m. 19, Garrop has begun a shift into $\mathrm{B} b$ minor and will stay in that tonal region until the final section. The smooth transitions are nearly seamless to the listener.

\section{Form}

The form of Pity Me Not is carefully structured. While not used in this example of Millay's sonnets, the traditional Italian sonnet form begins with an ABBA rhyme scheme for the first and second sets of four lines, or octave $\mathrm{e}^{47}$. Garrop mimics sonnet form with a loose ABBA structure. Brief introductory material given by the piano is followed by the entrance of the vocalists with the text. The texture is sparse; each vocal part sings a single line of text in succession, and the piano provides only small bits of harmonic material in accompaniment. The rhythm of the vocal lines is guided by the meter of text itself instead of relating only to a melodic line. Words meriting emphasis are given longer durations and often fall on strong beats, such as "day" in m. 9 (see Example 1) and "moon" in m. 18 (see Example 2).

\footnotetext{
${ }^{47}$ Fuller, 2.
} 


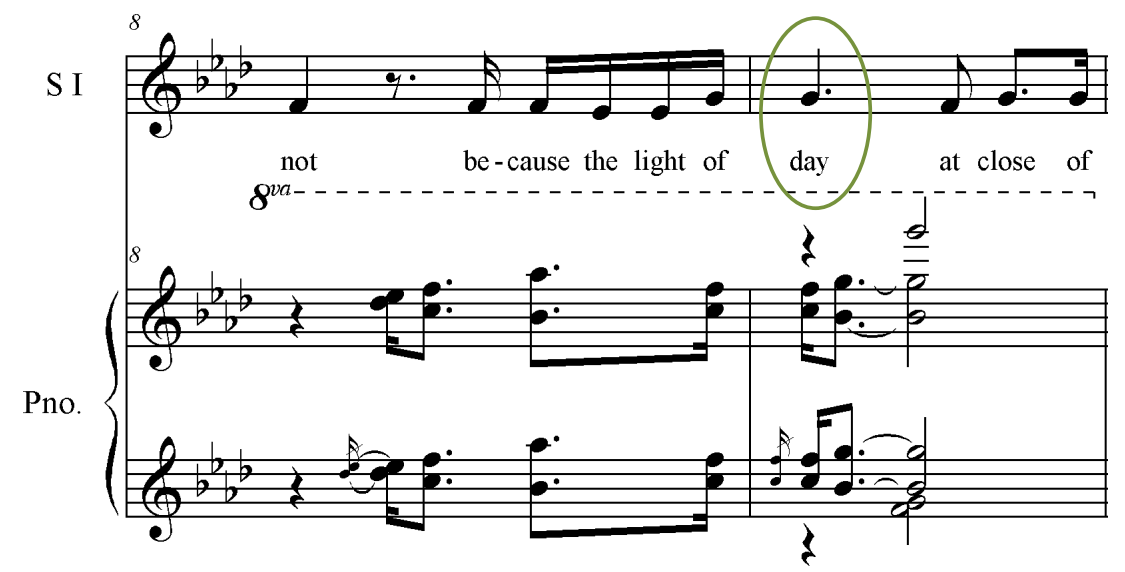

Example 1: Pity Me Not mm. 8-9.

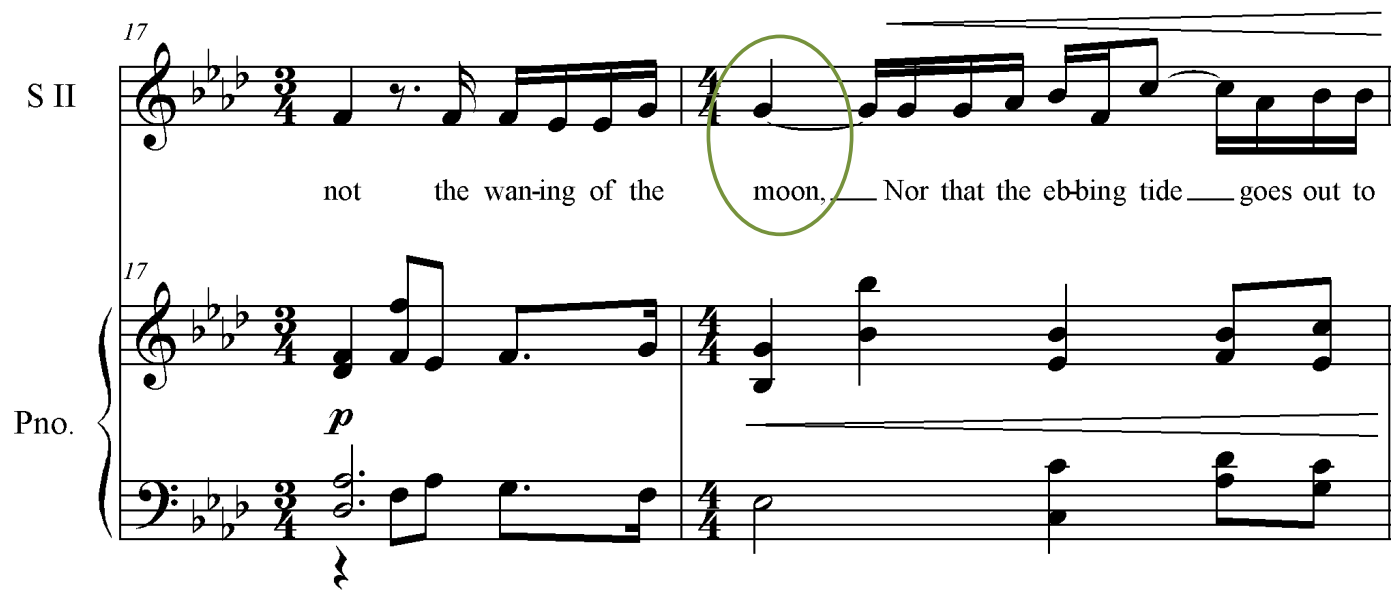

Example 2: Pity Me Not mm. 17-18.

No portion of the text is repeated here. After the first six lines of the poem, all three vocal parts sing together at the end of the A section.

The accelerando beginning in m. 23 marks the beginning of the B section. Here, the text adheres to the melodic rhythm that Garrop has chosen. The vocal texture thickens into three separate lines, and though the first sopranos have the main melody, the other two parts also sing melodies that fit into a larger harmony. The piano part drops in 
register, the right hand mixing with the vocalists in the same range, $B_{3}$ to $G_{5}{ }^{48}$ Though the minor melody and haunting lines suggest pain and despair, each of these elements are mild compared the dramatic shift into a $\mathrm{B}^{1}$ section, beginning in $\mathrm{m} .33$. Garrop reorganizes the chorus into four parts rather than three, with the melody and countermelody doubled in the soprano and alto parts. The piano, too, is given a more dramatic role. The left hand jumps in register continually, and the right hand soars over the top of the vocal lines. More dotted rhythms occur, adding to the striking tension. During the loudest and most dense point in the piece, the $\mathrm{B}^{1}$ section climaxes into a return of the piano material from the introduction but heavier and lower this time.

Finally, Garrop ends with a Coda that, while not exactly like the original A section, is quite reminiscent of the beginning of the piece. The pianist returns to the higher registers, and the focus is given to a soprano soloist who sings the lines that provide the poem's dramatic twist. An alto soloist joins her for the end. The rest of the chorus whispers "Pity me" beneath the melodic lines, adding an eerie quality.

Text

Of all of the musical elements that may be used to suggest specific emotions in a piece of music, text painting is perhaps the most obvious to the listener. Text or wordpainting can be described as "the use of musical gesture(s) in a work with an actual or implied text to reflect, often pictorially, the literal or figurative meaning of a word or

\footnotetext{
${ }^{48}$ Specific pitches will be referred to based on the system where $\mathrm{C}_{4}$ is equal to Middle C.
} 
phrase."49 Garrop chooses to employ the compositional device frequently in Pity Me Not, though the technique is not as heavily used as in some art songs. Other facets of her composition also bring the text to life, such as rhythm, density, tempo, and specific emotional themes represented by melodic fragments that Deryck Cooke describes in The Language of Music. Though controversial, Cooke's research provides another interesting facet of analysis that can be applied to Garrop's works.

Garrop chooses to begin the piece with brief introductory material set in the piano. The expression marks for the first section read "Stark; stilted." The high, crashing chords of the percussive piano achieve it, and Garrop introduces a rhythmic gesture that will be a signature of the piano throughout the work: A.)., a sixteenth note followed quickly by a dotted eighth note. Even with the slow tempo at $\bullet=48$, the use of the sixteenth note as the first division of a beat creates rhythmic tension that is not assuaged by the following dotted eighth note. If the sixteenth note was an anacrusis to a beat, it may not have the same effect. The remainder of the A section that follows is made up of the first eight lines of text, and she presents them rather quickly with no repetition of text. The rhythm of the vocal lines is mostly true to the natural cadence of the text. The choir is split into three sections, and each section takes two of the first six lines without overlapping, so the timbral texture is somewhat thin and exposed and the richness that can be achieved in choral music is stifled. Since the images that Millay describes are not

\footnotetext{
49 Tim Carter, "Word-painting," in Grove Music Online, Oxford Music Online, http://www.oxfordmusiconline.com.libaccess.sjlibrary.org/subscriber/article/grove/music/30568 (accessed February 20, 2010).
} 
yet personal, the sparse texture could be Garrop's way of keeping the listener at a distance.

The first melodic material given to the singers is on scale degrees $\hat{3}, \hat{2}$, and $\hat{1}$ in mm. 7-8. This downward scalar movement in the minor key is what Cooke calls "an incoming feeling of pain ... fierce despair ... or a powerful feeling of subjection to fate." ${ }^{50}$ It is a perfect beginning for the theme of the piece, which will be discovered as the audience listens to the text and to the music that Garrop has set to it. It is unlike the ascending minor scale, which Cooke insists has more sense of protest ${ }^{51}$ instead, the poet is expressing her sadness at her inability to learn from past, painful mistakes.

In mm. 10-11, another gesture is sung, the minor $\hat{5}-\hat{6}-\hat{5}$. Cooke states: "The chief and almost only expressive function of the minor sixth is to act as an appoggiatura on to the dominant, giving the effect of a burst of anguish." 52 But in this case, the $\hat{6}$ belongs to the chord below it, a minor iv and subdominant chord. It is, perhaps, one of the few exceptions to Cooke's rather hyperbolic statement. The effect may still be valid; the $\hat{\sigma}$ is the highest point in the arc of the melodic fragment and prepares the plagal cadence. Though the cadence is obscured by non-chord tones in the piano accompaniment during the second half of the measure, it still touches the audience with its plaintive quality.

The vocal dynamic in the A section reaches mezzo-piano at the loudest. However, there are elements that build as the poetry turns to a personal subject. When Garrop approaches the phrase "Nor that a man's desire is hushed so soon," she

\footnotetext{
${ }^{50}$ Deryck Cooke, The Language of Music (Oxford: Oxford University Press, 1959): 106.

${ }^{51}$ Ibid.

${ }^{52}$ Ibid., 146.
} 
acknowledges that this phrase is Millay's first departure from abstract imagery. She treats it accordingly by including all three vocal parts, a rise in dynamics, and the first instance of an extended vertical density. Previously hovering around five notes per beat, "-sire" at the beginning of m. 20 spikes at nine (see Figure 3).

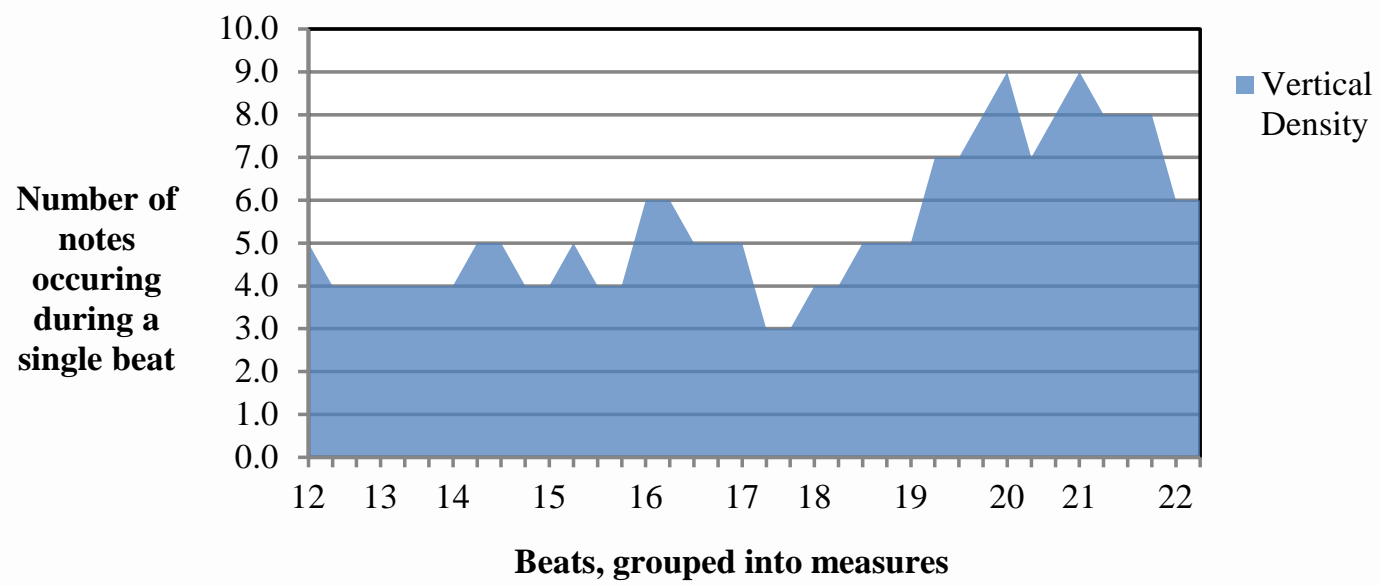

Figure 3: Vertical density in Pity Me Not mm. 12-22.

The distance between the piano's highest and lowest notes also reaches a maximum, adding depth. The piano crashes with its lowest notes yet, within an octave of the keyboard's lowest notes (see

Figure 4). 


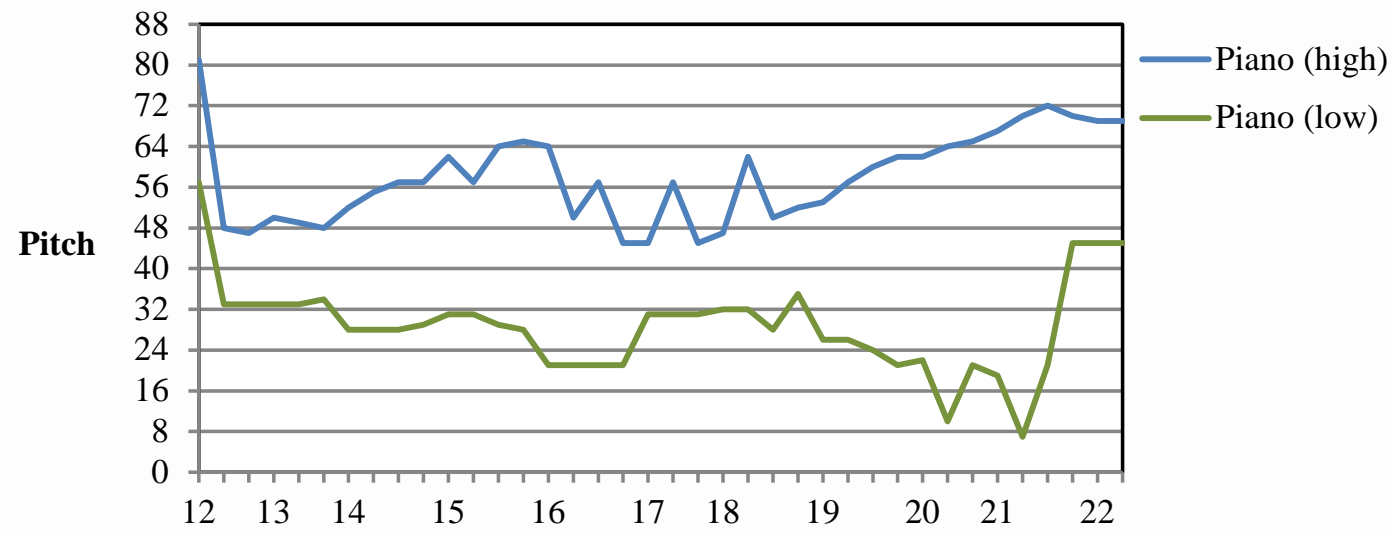

Beats, grouped into measures

Figure 4: Pitch in Pity Me Not mm. 12-22. Pitch: 1 represents $A_{0}, 88$ represents $C_{8}$.

"Hushed" is followed with a quick sixteenth rest that is particularly effective when combined with the "-sh-" in the word. The second sopranos accusingly sing "And you..." without finishing the thought, while the first sopranos and altos sing the rest of the line quickly in sixteenth notes (see Example 3). 

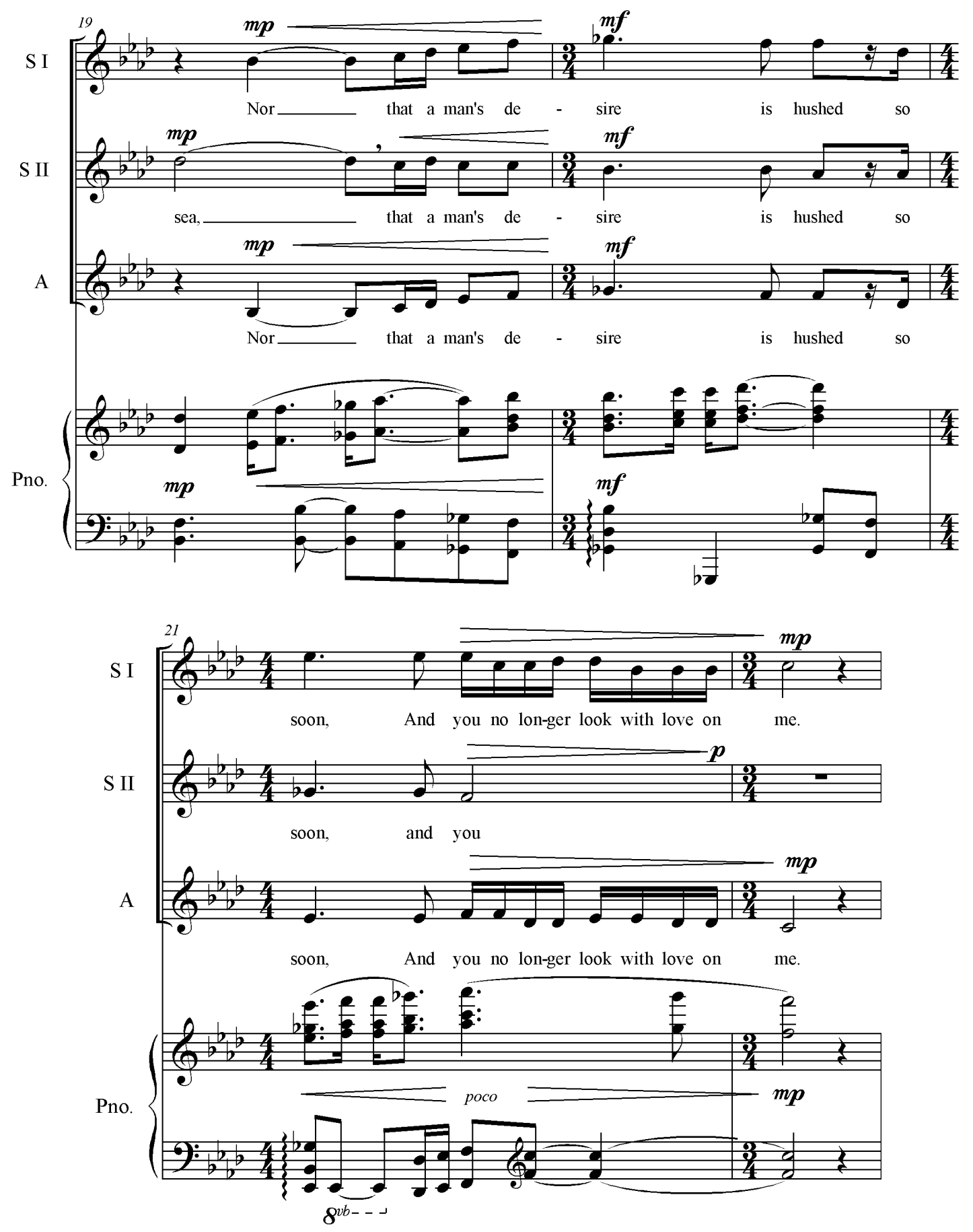

Example 3: Pity Me Not mm. 19-22.

Is this agonizing thought being forced out, as though speed will deaden or shorten the pain? Garrop admits that the reason behind the sixteenth notes is more mundane. She 
was matching some of the earlier groups of sixteenth notes: “ . . there's something about the rapid-fire way of delivery of all these sixteenth notes that I thought it would be nice to bring that back before I moved on to the next section." ${ }^{53}$ Garrop concludes the section with a rest, the first of two moments of complete silence in the entire piece.

Though it can be considered the beginning of the B section, Garrop's setting of "This have I known always" is almost an interlude, as it is set apart and completely different than any other part of the work. The piano is silent for these two measures. "This" is rearticulated in each voice, after which they move in sync with each other, making the text easy to decipher for the audience. A second rest occurs after "always" before the piece continues with the remainder of the verse (see Example 4). The line is literally surrounded by silence.

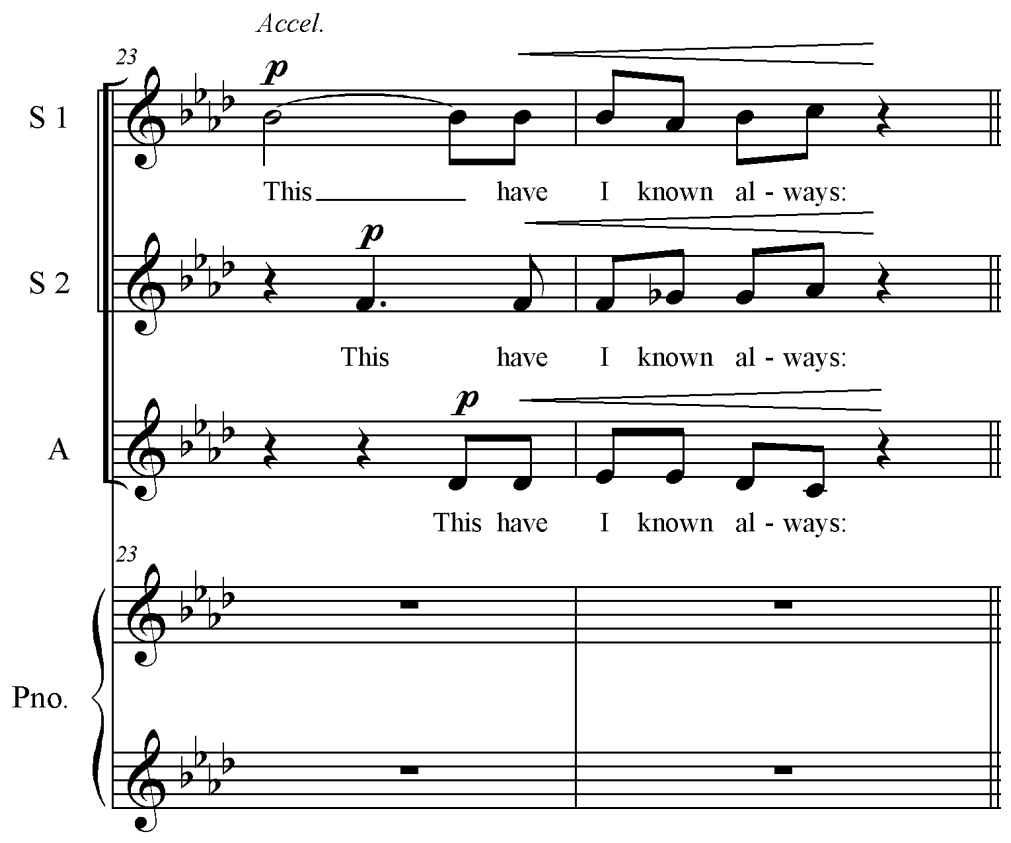

Example 4: Pity Me Not $\mathrm{mm}$. 23-24.

\footnotetext{
${ }^{53}$ Garrop, interview.
} 
Garrop is making a statement; each of these elements encourages the audience to listen closely, for what is being said is important.

Mm. 23 and 24 are marked with an accel. that leads into the quicker B section. The musical rhythm is no longer as dominated by the textual rhythm, and the vocal texture richens with the use of three separate lines moving at different times. Garrop uses a clear tonal center, $\mathrm{B} b$ minor. Now the emotions of the text have changed. Each vocal line begins with a rising minor scale; the first sopranos and the altos $\operatorname{sing} \hat{1}-\hat{2}-\hat{3}-\hat{4}-\hat{5}$ separately, expressing "an assertion of sorrow, a complaint, a protest against misfortune." ${ }^{54}$ Indeed, Millay writes more declaratively in this portion of the text and another layer is added to her pain and frustration, all shown with the rising minor scale. During "Than the great tide that treads the shifting shore," Garrop moves out of the tonal center with a sudden influx of sharps (see Example 5). The chords themselves, $\mathrm{G} \sharp$ minor, $\mathrm{E}$ major, and $\mathrm{C} \sharp$ minor, do not suggest a temporary retreat into a different key, but rather a drastic departure from traditional harmony, illustrating the shifting shore of Millay's text. The melodic line moves up, crests, and falls back down, much like a wave or the tide. Underneath "Strewing fresh wreckage," the piano plays a conflicting, triplet rhythm that adds to the sense of "strewing." Rhythmically, the piano is at its least dramatic here, and the right hand has dropped out of the higher register to mingle with the vocal lines (see Figure 5) while the left hand plays mostly supporting roots of chords (see Example 5).

\footnotetext{
${ }^{54}$ Cooke, 122.
} 


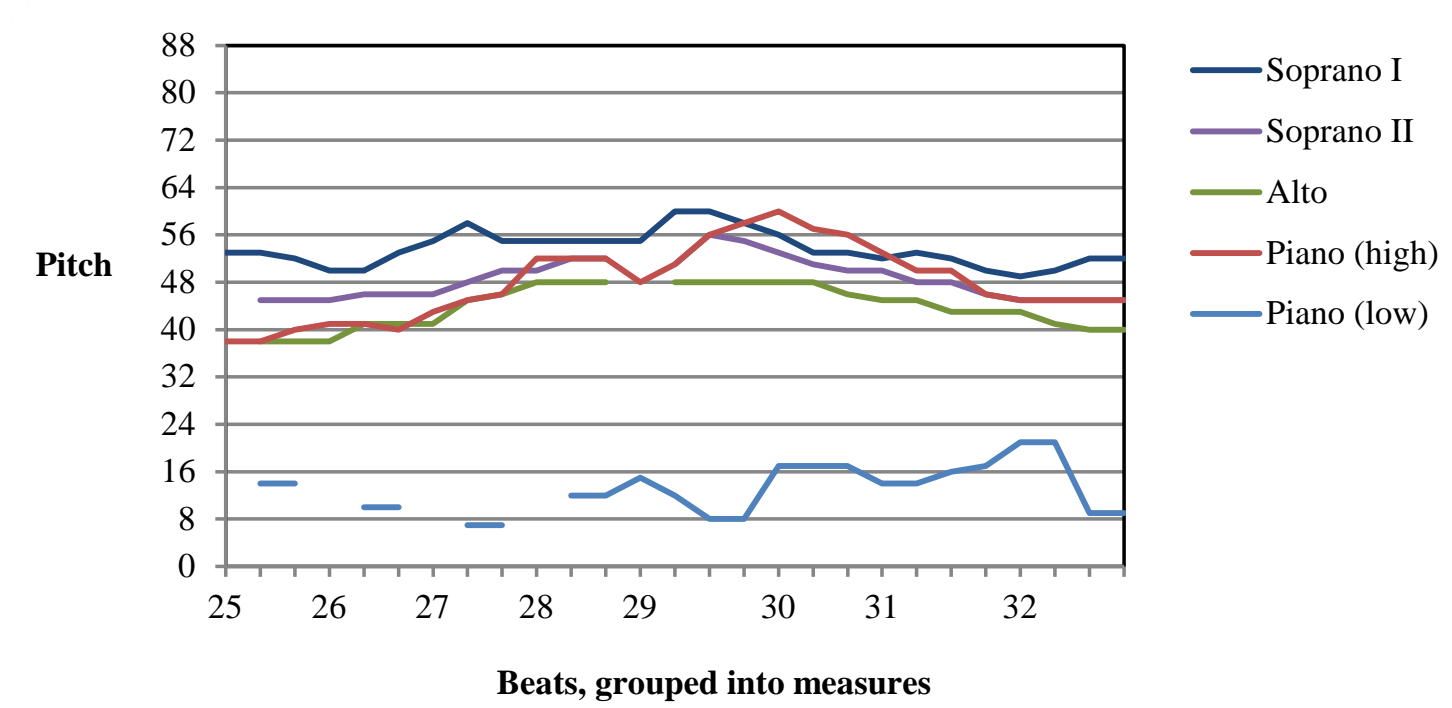

Figure 5: Pity Me Not mm. 25-32. Pitch: 1 represents $A_{0}, 88$ represents $C_{8}$. 

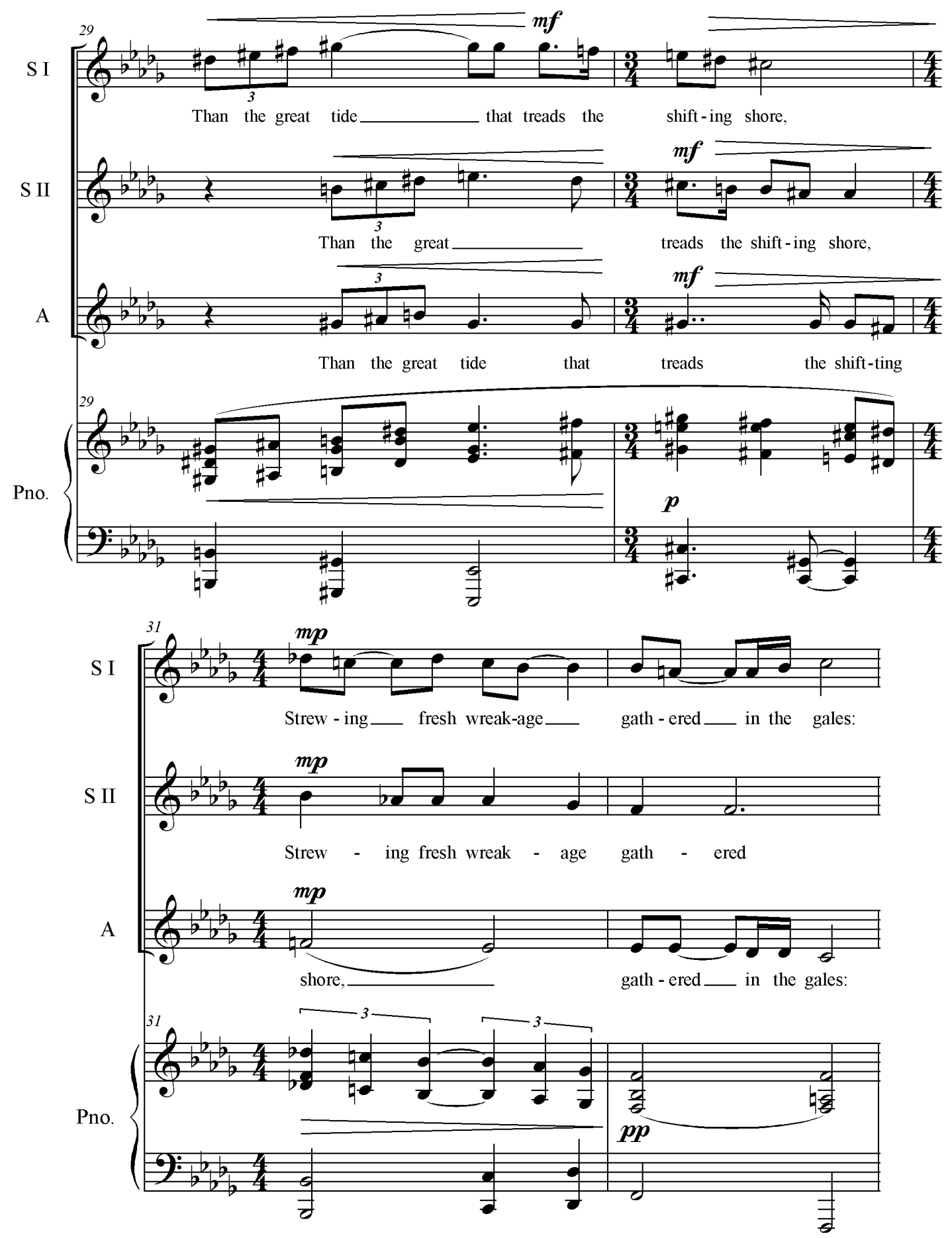

Example 5: Pity Me Not mm. 29-32. 
At the end of the section, mm. 31-32, the melodic lines are moving downward which signifies that the pain and suffering have become more passive once again. The second sopranos begin their descent on the tonic, $\hat{1}-\hat{7}-\hat{6}-\hat{5}$. Cooke states:

To fall from the tonic to the dominant, taking in the "mournful" minor seventh and "anguished" minor sixth, is clearly to express an incoming painful emotion, an acceptance of, or yielding to grief; passive suffering; and the despair connected with death. As with the major form, it is a near-synonym of 5-4-3-2-1, and often merges with it; but again, when it is used on its own, it has an open, continuing feeling (never-ending despair) whereas 5-4-3-21 suggests finality (death itself). ${ }^{55}$

Though both the sopranos and altos seem to be moving toward $\hat{1}\left(\mathrm{~B} b_{4}\right.$ for the sopranos, $\mathrm{B}_{b_{3}}$ for the altos; see Example 5), at the end of the phrase they both end on $\hat{2}$ to support the half cadence that occurs. The piece is not over; Millay and Garrop still have more to say. The listener is not given any sense of resolution and no indication that one will occur even by the end.

Instead of moving forward in the text, Garrop chooses to repeat the same four lines with a $\mathrm{B}^{1}$ section. Though similar to the previous section, there are several key differences. Since it is a repeat of text already heard, Garrop has more opportunity to obscure the words, and while they are still relatively easy to understand, she adds new elements for interest. She reiterates "This have I known always" and repeats it. The second instance is shaped by a slightly more complex rhythm, a poco accelerando, and a crescendo, leading again into the next portion of the text. The rising minor scale returns in protest. The piano is not silent here as it was the first time, and plays in a high register

${ }^{55}$ Cooke, 162-163. 
until a sudden drop for "Love." Here, Garrop adds a countermelody to accompany an already higher melodic line. She splits the choir into four parts for the first time but keeps the texture simple with octave doublings:

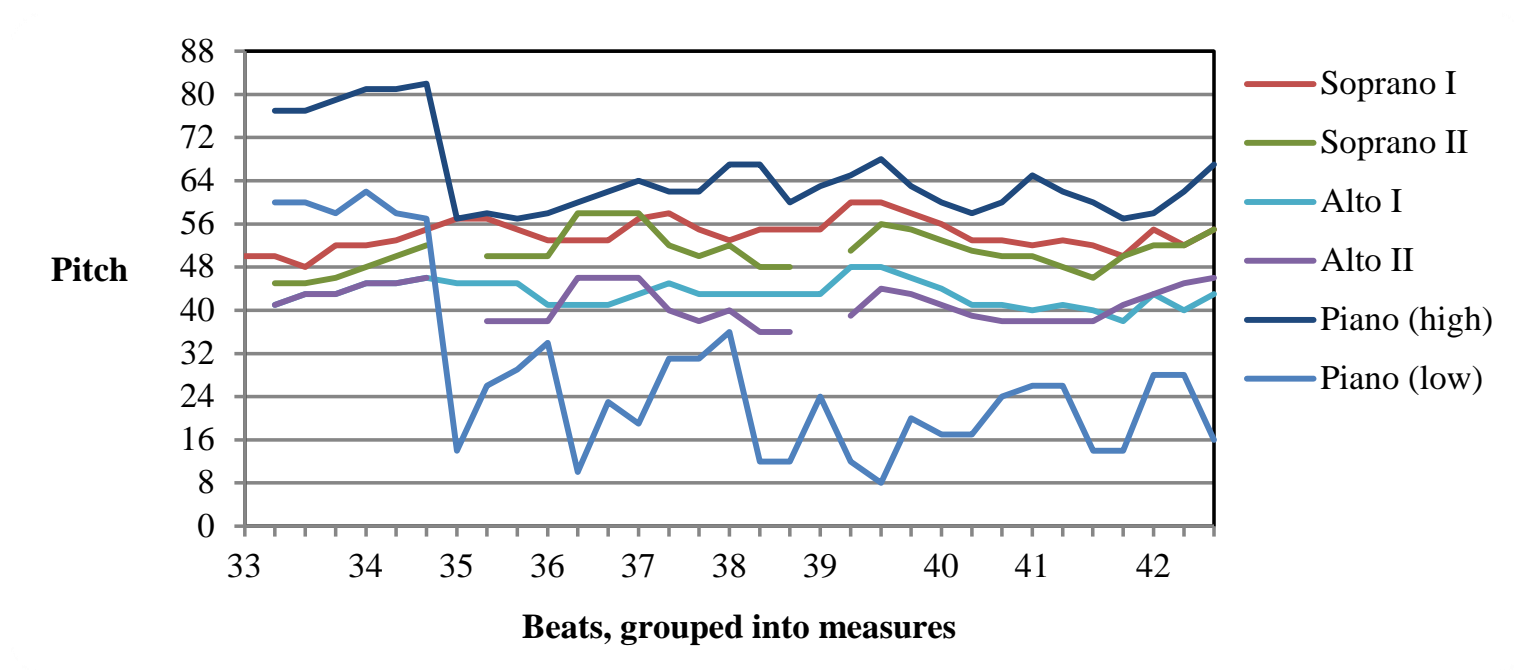

Figure 6: Pitch in Pity Me Not mm. 33-42. Pitch: 1 represents $\mathrm{A}_{0}, 88$ represents $\mathrm{C}_{8}$.

However, she does not entirely complete the phrase before moving into the climax of the work. She reaches "Strewing fresh wreckage" in much the same way as in the original B section, but repeats only those words without finishing the thought. Another accelerando and a crescendo lead into a fortissimo climax at a quicker tempo (see Example 6). 


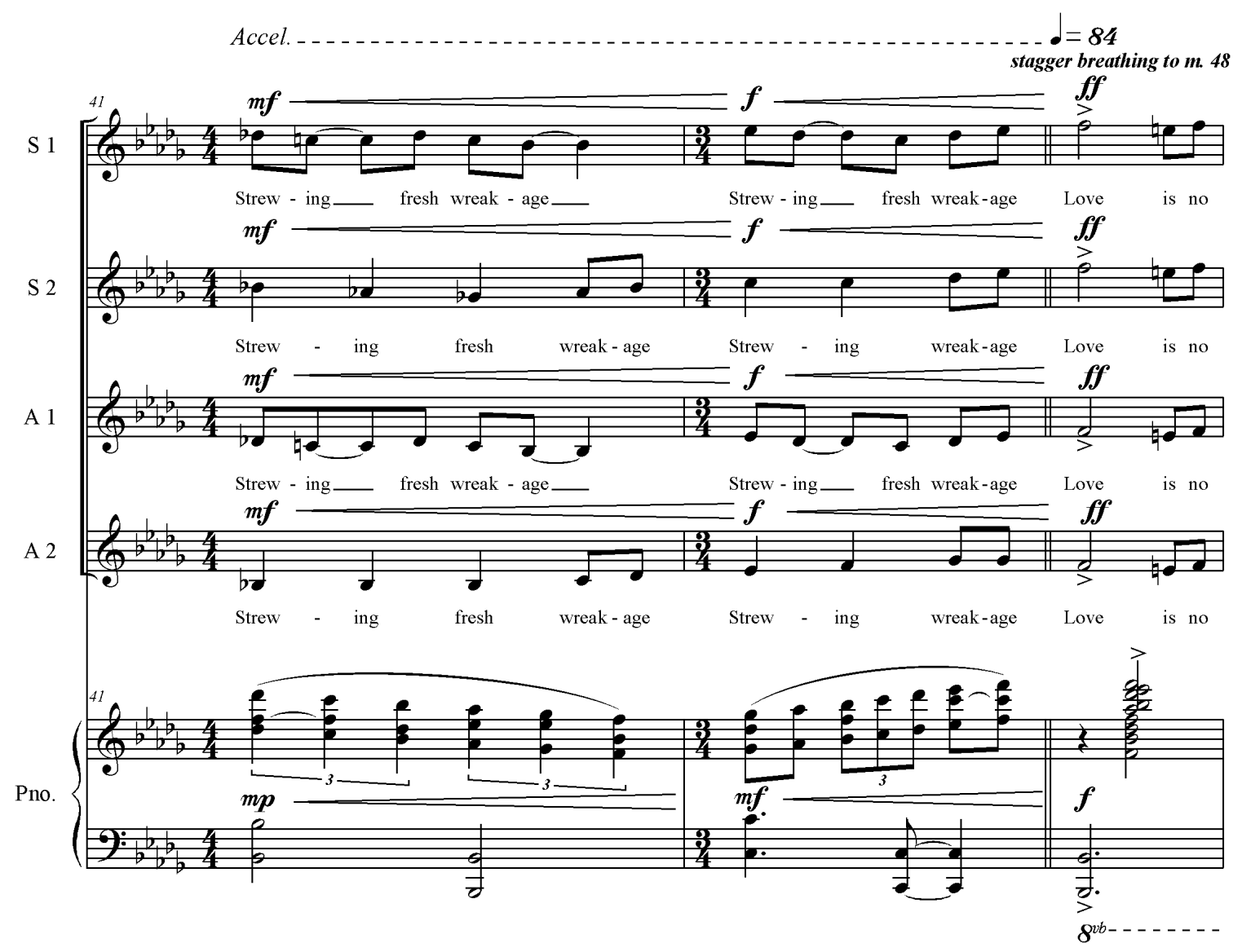

Example 6: Pity Me Not mm. 41-43.

For the climax, Garrop chooses to repeat text once again: "Love is no more."

Massive clustered chords crash in the piano in the extremes of the high and low registers.

The final "no" is shaped by a ritardando and a fermata before resolving into the slower, original tempo. The vocalists end their final word, "more," with a crescendo to fff and a sudden cutoff (see Example 7). 


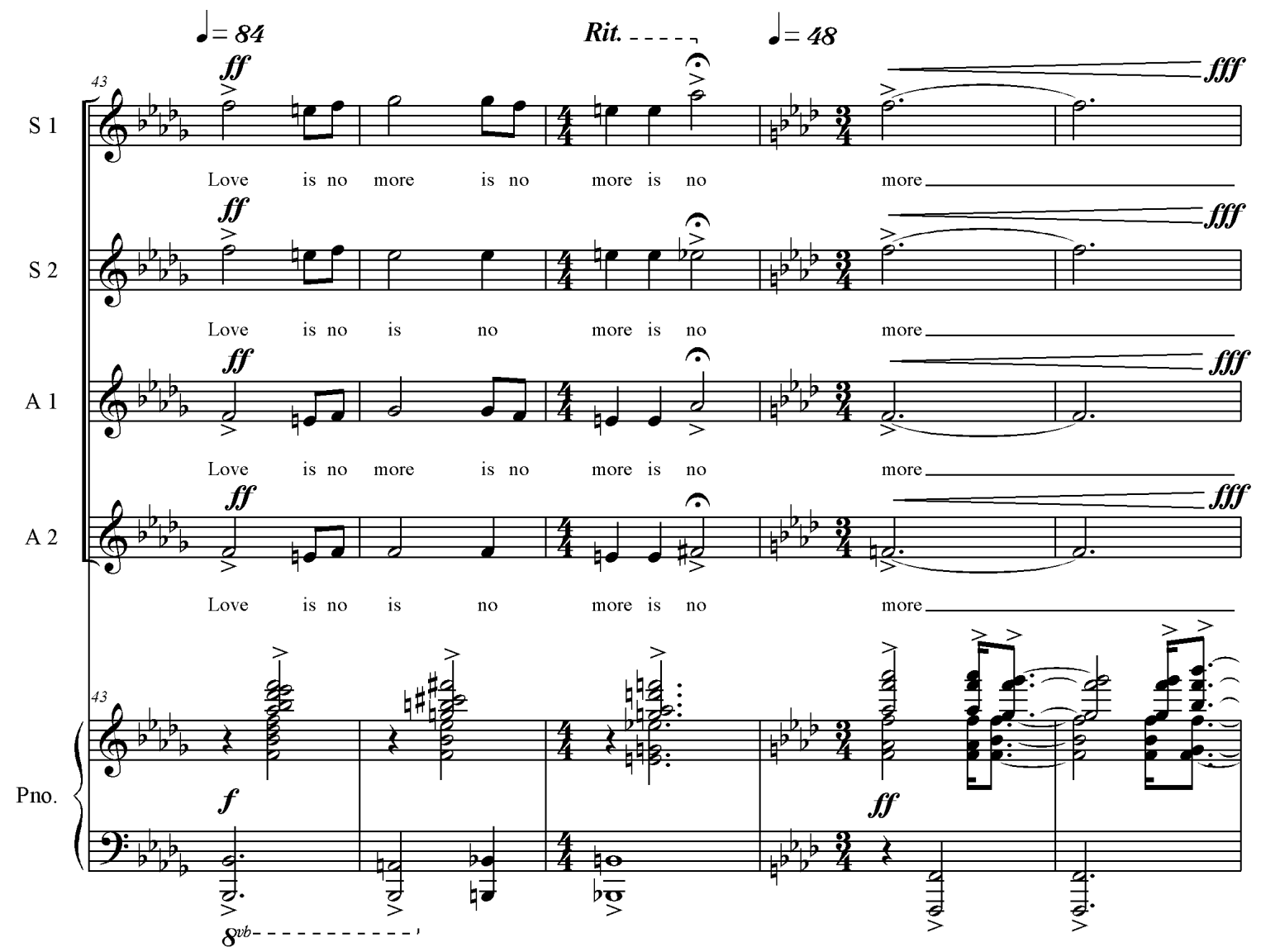

Example 7: Pity Me Not mm. 43-47

This could signify an anguished cry and a sharp turning away, as though the singers are unable to face the painful reality that they have presented. Here, the piano presents a more dramatic echo of its opening introductory material. While the harmony remains the same, more notes and a wider range add to the depth. Though Garrop pauses with a fermata on the bar line between $\mathrm{m} .49$ and $\mathrm{m} .50$ before beginning a coda reminiscent of the A section, she instructs the pianist to sustain the clustered chord with the damper pedal through the end of the fermata. She does not want silence here; instead, the ringing chord is dissonant with minor seconds and tritones, and she delays the resolution to illustrate pain (see Example 8). 


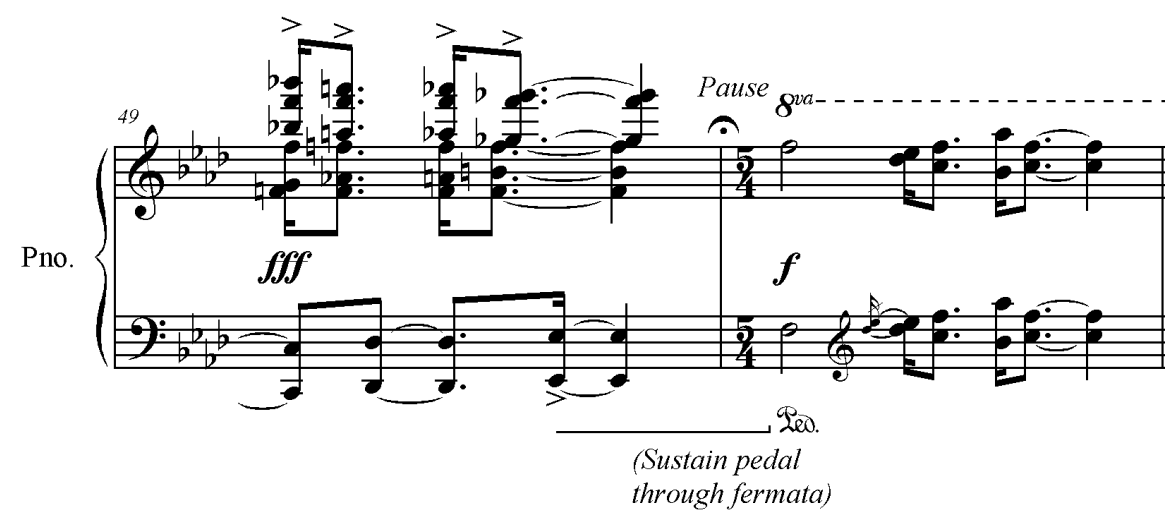

Example 8: Pity Me Not mm. 49-50.

When the resolution finally comes, it is with a repeat of pianistic material from the A section. This coda contains the twist in the sonnet, and Garrop opts for soloists to present it. By using soloists, she is suggesting again that the audience should pay attention here. The rest of the choir whispers "Pity me" underneath the soloists' lines, echoing the essence of the sonnet. The word "swift" is painted with five quick notes. As the piece draws to a close, the harmonic structure simplifies, ending on a single note, $\mathrm{B} b$, in three octaves (see Example 9). 


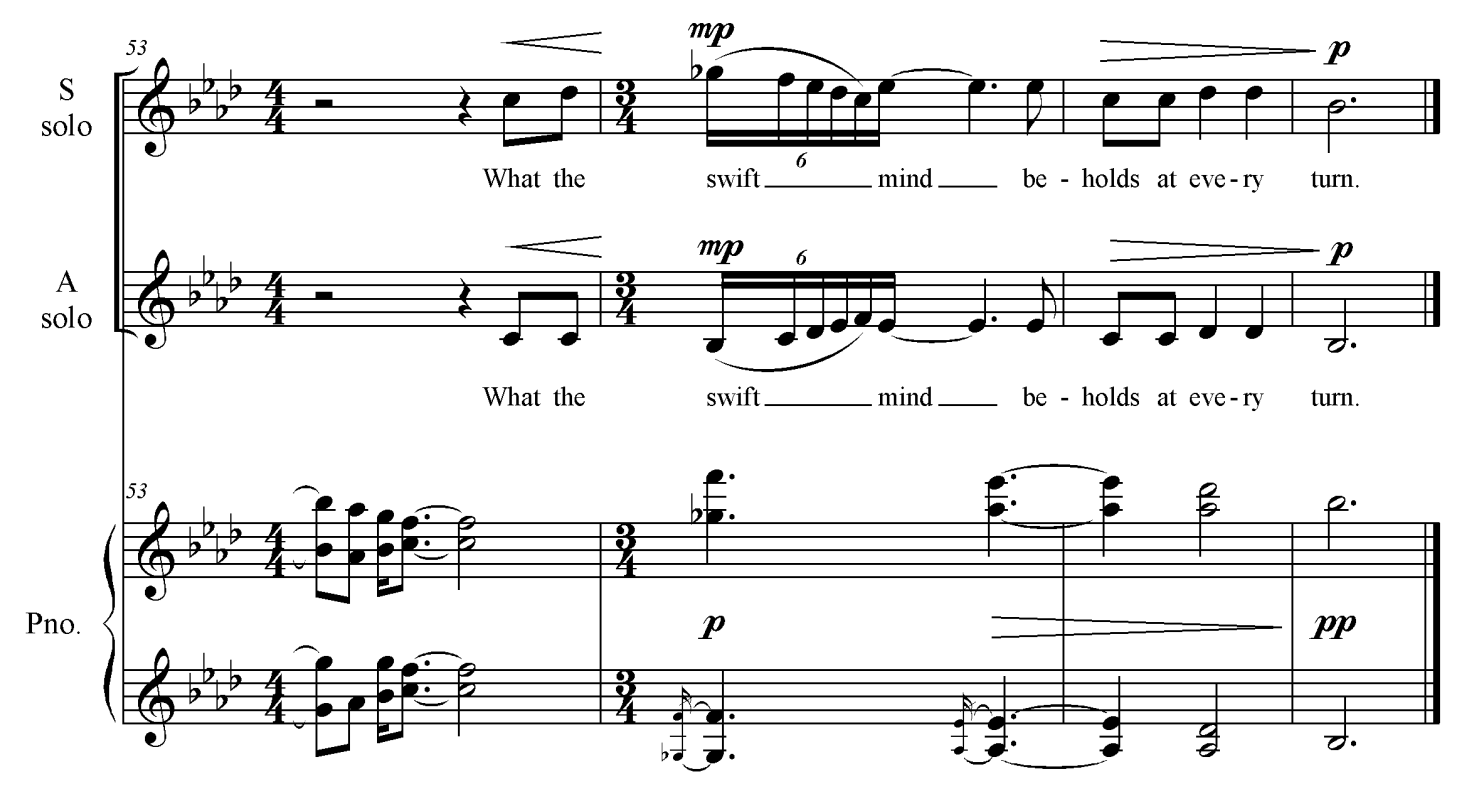

Example 9: Pity Me Not mm. 53-56.

The volume has dropped to $\boldsymbol{p}$ in the voices and $\boldsymbol{p} \boldsymbol{p}$ in the piano, and the vertical density is sparse. It seems as though the chorus has spent all of their energy on the emotional climax, and the end is almost an afterthought. Yet, because of its quietness and simplicity after such a dramatic burst, the audience is inclined to notice the change and listen closely. This is exactly what Garrop is intending.

\section{Harmonic analysis}

The definition of tonality is complicated and somewhat controversial. As Brian Hyer notes in Grove Music Online, "One of the main conceptual categories in Western musical thought, the term most often refers to the orientation of melodies and harmonies towards a referential (or tonic) pitch class." ${ }^{56}$ Garrop's music rarely lends itself to the standard Roman numeral analysis and its implied procedures, from chord quality to

\footnotetext{
${ }^{56}$ Brian Hyer, "Tonality," in Grove Music Online, Oxford Music Online, http://www.oxfordmusiconline.com.libaccess.sjlibrary.org/subscriber/article/grove/music/28102 (accessed October 20, 2009).
} 
resolution. Pity Me Not adheres more closely to standard harmonic progression than some of the composer's other works, and it struggles between two different tonal centers.

The audience's first impression of a tonal center occurs immediately. A brilliant minor third built on $\mathrm{F}$ a suggests $\mathrm{F}$ minor, and the pedal $\mathrm{F}_{4}$ in the pianist's left hand during the introductory material strengthens the impression. If $\mathrm{F} \sharp$ is $\hat{1}$, then the other notes in the first two measures, such as $\mathrm{A}$, and $\mathrm{G}$, fit easily into an F minor scale. In m. 3, the clarity of the tonal center wavers when the pedal tone shifts to $\mathrm{F} \#$, first in the right hand while the left hand holds the $\mathrm{F} \sharp$, and then the reverse. Other tones not present in $\mathrm{F}$ minor appear. The raised $\hat{4}$ and raised $\hat{7}$ do not resolve as they would in standard harmony: $\mathrm{E}$ q moves down to $\mathrm{D} \sharp$ in the left hand, and $\mathrm{B}$ q moves up to $\mathrm{C}$ in the right. The lack of traditional resolution creates even stronger tension in the already dissonant chords. When both hands return to $\mathrm{F} \sharp$ in $\mathrm{m}$. 4 , the $\mathrm{A} b_{4}$ in one hand fights the $\mathrm{A} \xi_{5}$ in the other, and the minor tonality wavers. Garrop returns to this technique frequently during the piece. When the $\downarrow \hat{2}$ in $\mathrm{m} .5$ resolves down firmly to $\mathrm{F} \sharp$ in $\mathrm{m} .6$, the tonal center is reestablished and will remain for most of the A section.

From the beginning to $\mathrm{m} .18$, the piano and all voices exist entirely in F natural minor. Garrop does not use the leading tone for tension and resolution, though a $\hat{6}$ in $\mathrm{m}$. 11 on the word "longer" does resolve down to $\hat{5}$. In $\mathrm{m} .13$, the two hands of the piano fight a second time for a major or minor tonality on beat 2 . Regardless, F is still clearly the tonal center-but not for long. 
In $\mathrm{m} .19, \mathrm{a} \mathrm{G} b$ appears in the piano and is repeated in $\mathrm{m} .20$ by the singers. What would have been a iv chord at the start of $\mathrm{m} .19$ functions as a pivot chord and becomes $\mathbf{i}$ in $\mathrm{B}$, minor. What follows is a standard harmonic progression in a minor key, the key of $\mathrm{B}$ b minor, most importantly ending on a somewhat hollow $\mathbf{V}$ that is missing the leading tone in m. 22 (see Example 10). 

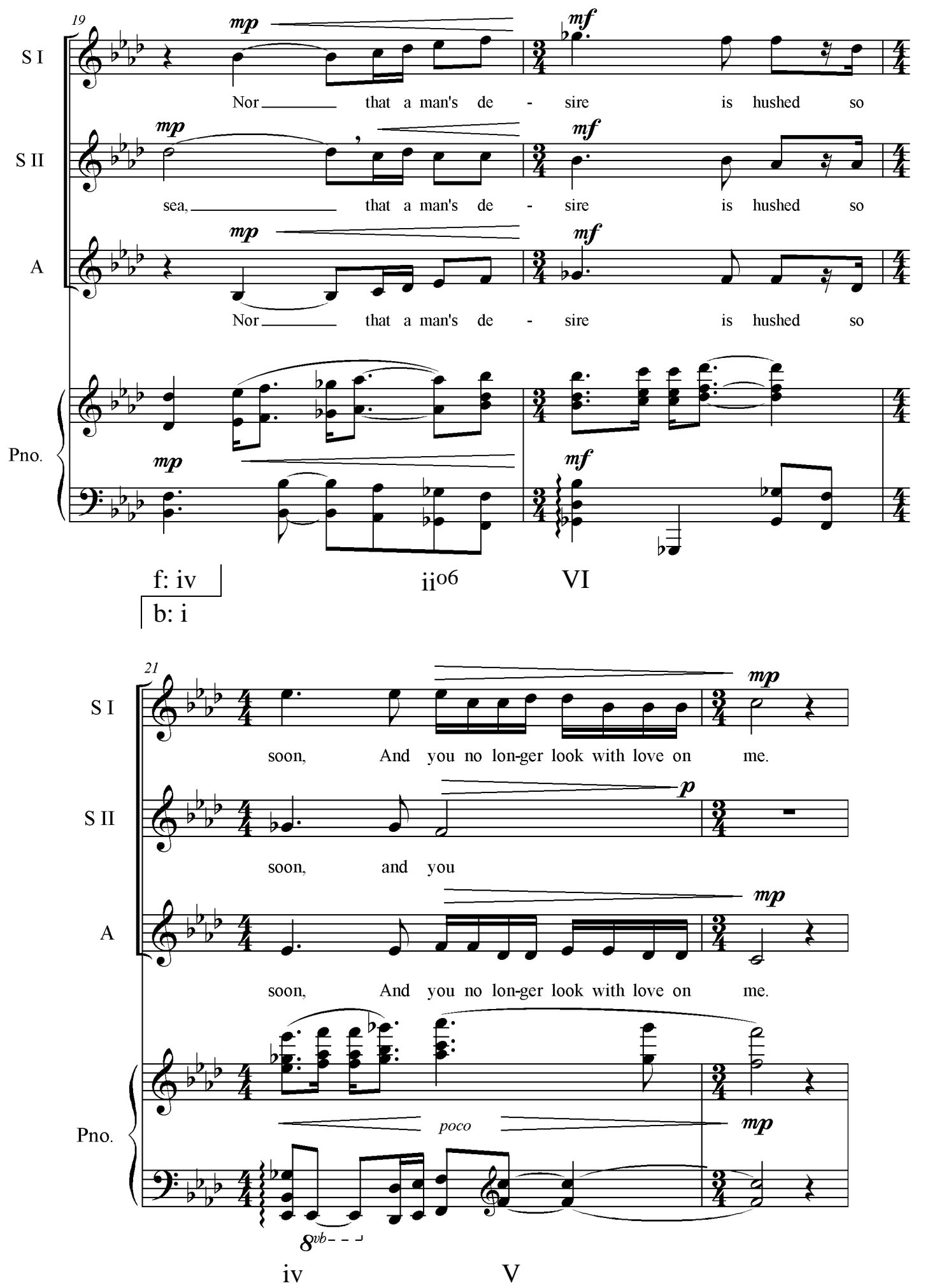

Example 10: Pity Me Not mm. 19-22 with Roman numeral analysis. 
The $\mathbf{V}$ chord, even though it lacks a major or minor third, is still important for establishing the new key of $\mathrm{B} b$ minor. Despite the flurry of $\mathrm{G} b \mathrm{~s}$, the listener may not yet be convinced that the key has changed. The firm resolution of $C(\hat{2})$ and $F(\hat{5})$ to $B$ b $(\hat{1})$ confirms it by suggesting the most powerful pull in Western music: the authentic cadence. Further evidence for the musicians is the change of key signature in $\mathrm{m} .24$ to five flats.

In mm. 29-30, all chords are suddenly non-diatonic (see Example 11).

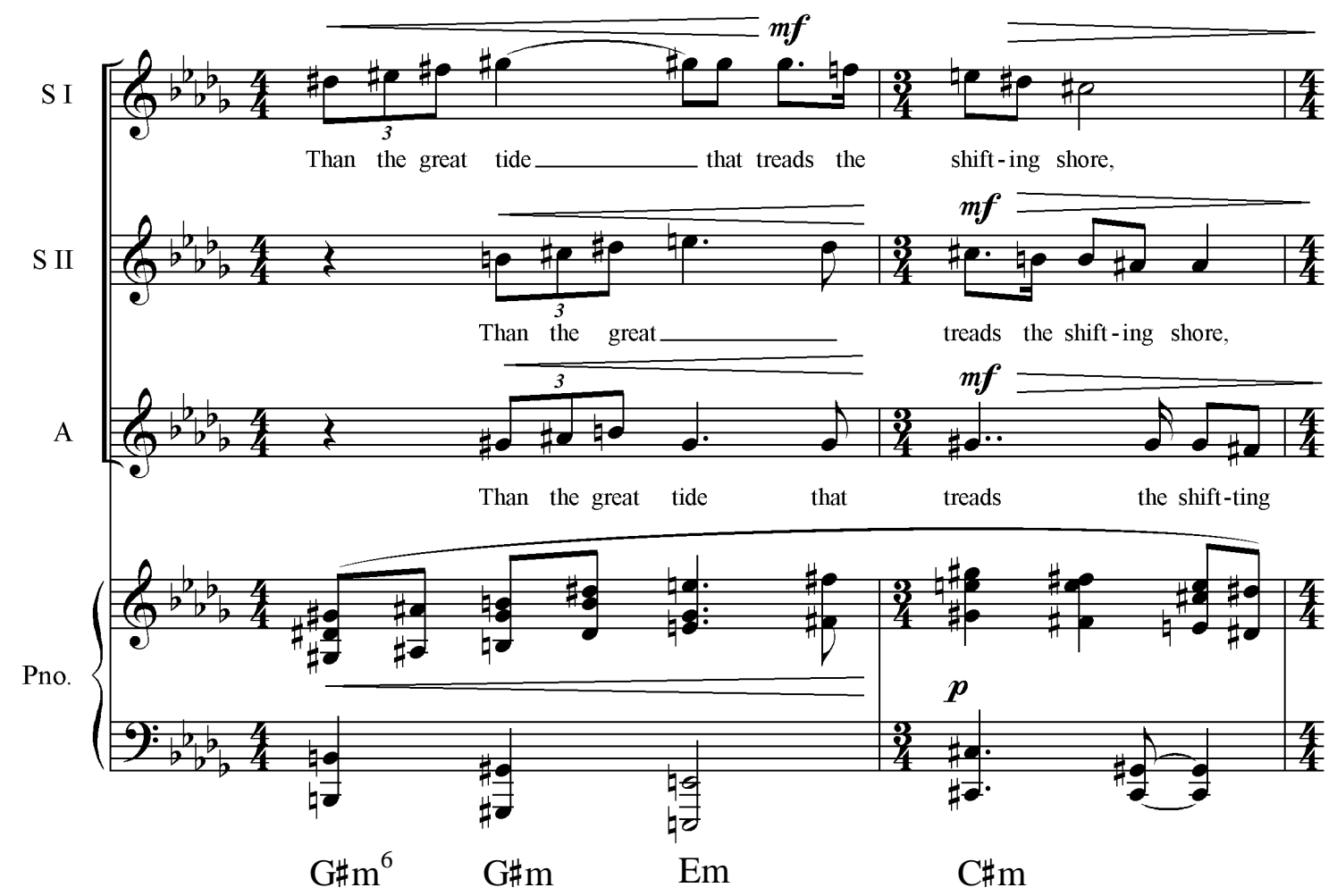

Example 11: Pity Me Not $\mathrm{mm}$. 29-30 with chord root analysis.

Not only does Garrop choose to use sharps here instead of flats, but even the enharmonically equivalent chords are not normally found in the key of $\mathrm{B} b$ minor. The chord on the third beat of m. 29 is built on $\mathrm{E}$, the tritone of B b. In addition, each chord in 
the two measures is minor, following no discernable pattern based on traditional harmonic progression. Garrop's intention here is a strongly audible shift to match the text: "Than the great tide that treads the shifting shore."

When $\mathrm{B} b$ minor returns in $\mathrm{m} .31$, it is to set up an extremely strong half cadence in the next measure. Finally, the listener is given a true leading tone: $A \sharp$. A standard $\mathbf{V}$ chord appears on beat three of m. 32 without non-chord tones that might confuse the listener. The $\mathrm{B}^{1}$ section follows, matching the $\mathrm{B}$ section harmonically. In the final portion of $\mathrm{B}^{1}$, Garrop employs thick clustered chords in the piano to enhance the climactic tension. In $\mathrm{m} .43$, the first clustered chord is made up of entirely diatonic notes (beside the $\mathrm{E} \sharp$ in the voices): $\mathrm{B} b, \mathrm{D} b, \mathrm{E} b, \mathrm{~F}$, and $\mathrm{A} b$. The next cluster is more dense and includes notes foreign to $\mathrm{B}$ b minor: $\mathrm{B} b, \mathrm{C} \#(\mathrm{D} b), \mathrm{E} b, \mathrm{~F}, \mathrm{~F} \#, \mathrm{G}$, and $\mathrm{A}$. $\mathrm{B}$ औ is added in beat three. Garrop chooses to use the $\mathrm{C} \#$ spelling to reduce confusion for the pianist. Finally, the last cluster is the thickest and most dissonant, as well as being held the longest for the most effect. It includes $\mathrm{B} b, \mathrm{~B} \sharp, \mathrm{D}, \mathrm{E} b, \mathrm{E} \sharp, \mathrm{F}, \mathrm{G}$, and $\mathrm{A} b$, as well as $\mathrm{F} \#$ in the second alto part on beat three. When the cluster is released and changes to a standard minor third, the audience is not even given a chance to breathe a sigh of relief, since the dynamic continues to increase from $\boldsymbol{f f}$ to $\boldsymbol{f f f}$, and the pianist echoes the tensionladen chords from the beginning of the A section.

The key signature has returned to F minor, and the first notes of $\mathrm{m} .50$ are an open octave on F. After the climax of the previous few measures, this forte passage might seem quiet in comparison because of its simplicity. Fs in the piano reinforce the key, 
though the vocal lines could be used in either $\mathrm{F}$ or $\mathrm{B}$, minor. A sudden inclusion of $\mathrm{G} b$ in m. 54 suggests a return to $\mathrm{B}$, minor yet again, and the piece ends on $\mathrm{B}$, (see Example 12). The change is seamless, and the listener may not hear a return to $\mathrm{B} b$ minor at all.

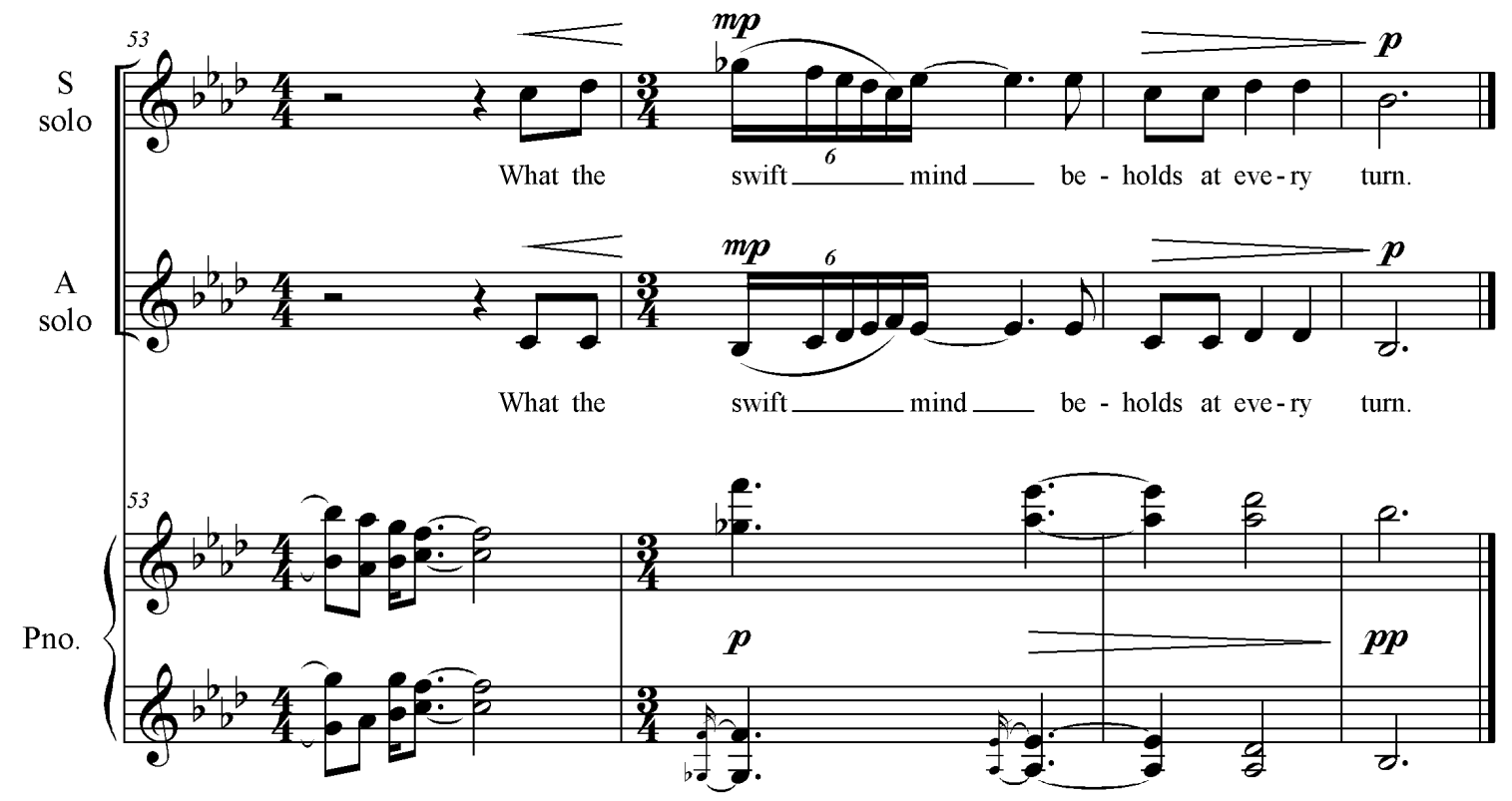

Example 12: Pity Me Not $\mathrm{mm}$. 53-56.

Rhythm, tempo, and meter

During an interview, Garrop admonished that she does not "write the easiest music, ${ }^{, 57}$ but she was referring to a singer's ability to keep track of their notes when a work does not have a clear tonal center. However, many of her works are complex for additional reasons, and Pity Me Not is no different, especially when considering its complex rhythms. The pianist and singers are often at odds rhythmically, so the conductor must be impeccably clear to avoid confusion. Small rhythmic motives are evident from the beginning, and larger patterns emerge as the piece continues.

${ }^{57}$ Garrop, interview. 
Constructed as a typical arch, the middle sections are the most complex, whereas the beginning and end are simpler and less intense by comparison. The tempo is also arched. It begins slowly, emphasizing the high, thin chords in the piano at " $\bullet=48$, Stark; stilted, ${ }^{, 58}$ builds to $\bullet=84$ for the climax, and returns to the original tempo for the coda.

Within the first measure, the ...) rhythmic motive is introduced by the pianist. This motive and its inversion, $\triangle A$, are heard numerous times in both the piano and vocal parts. The motive occurs most frequently in the piano, and its stringent rhythmic quality adds dramatic tension to the relatively slow-moving piece. The introductory material from the piano is particularly strident (see Example 13).

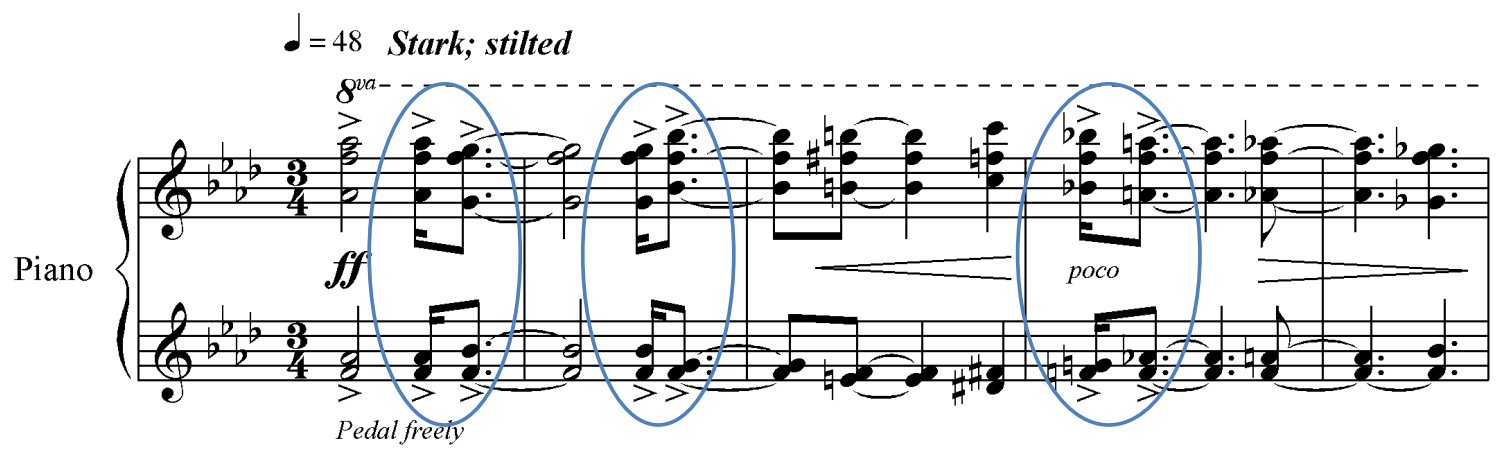

Example 13: Pity Me Not mm. 1-5 with rhythmic motive circled.

This motive emphasizes the percussive nature of the piano, especially when played very high on the keyboard where the striking of the keys is more apparent due to the thinner timbre of the strings.

The rhythm of the vocal lines in the A section generally follows natural speech inflections. More important words are longer and tend to fall on downbeats of measures. Therefore, the first note of each measure is at least a quarter note in length, and the

\footnotetext{
${ }^{58}$ Stacy Garrop, Pity Me Not (Chicago: Stacy Garrop, 2002): 1. Used with permission.
} 
vocalists linger there in the slow tempo. Though the dotted motive appears in the singers' parts, it is always rhythmically inverted (see Example 14).

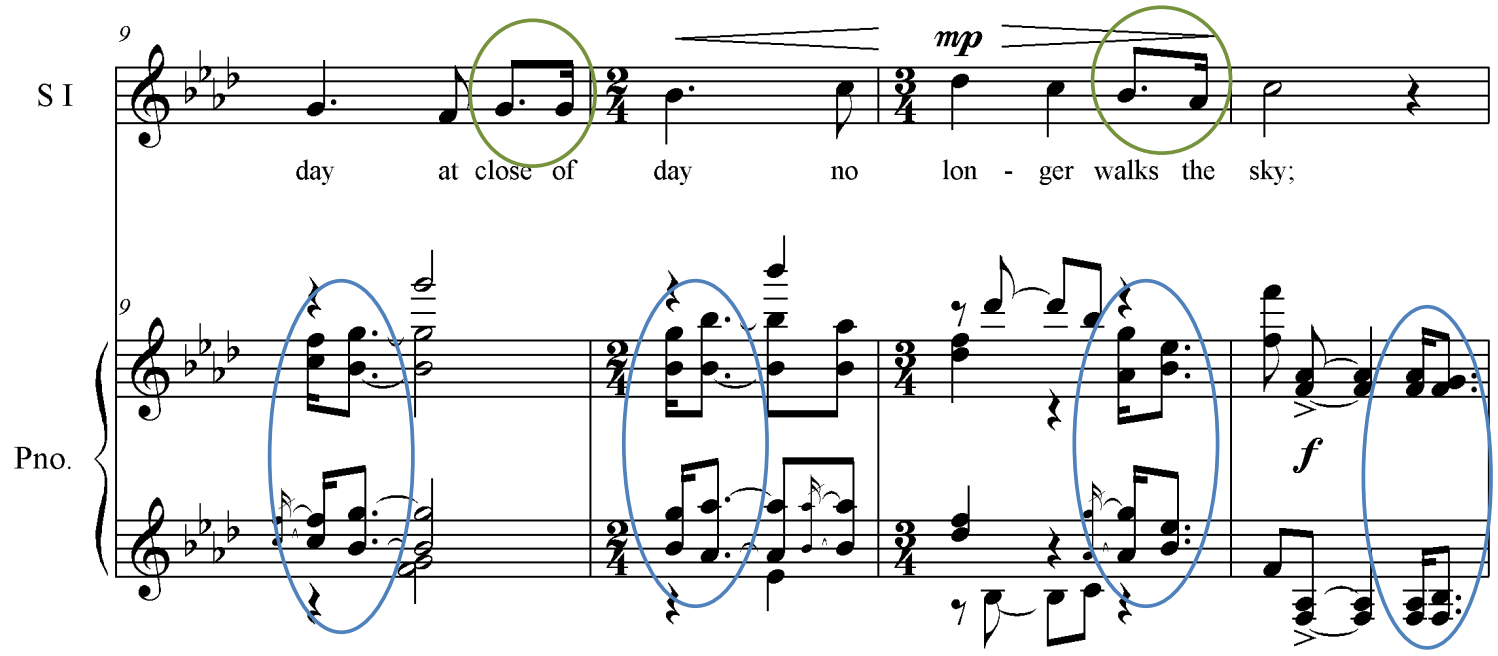

Example 14: Pity Me Not mm. 9-12 with rhythmic motives circled.

The same is true throughout the piece. In contrast, the piano plays.${ }^{\circ}$. with rare exception. Garrop had a specific use in mind for the sixteenth notes: "In general, whenever you have those dotted-eighth-sixteenth or the sixteenth-dotted-eighths, that's the angular motion playing into the stark character of the piece, the angry character of the piece." $" 59$

At first glance, the rhythms of the B section appear simple when compared to the A section, but the appearance of the notes on the page is misleading. Though the piano part and the vocal parts are simpler by themselves, they create polyrhythmic textures. In addition, the second sopranos and altos enter a beat later than the firsts, and their melody

\footnotetext{
${ }^{59}$ Garrop, interview.
} 
is offset for the remainder of the phrase. The tension increases further in the $\mathrm{B}^{1}$ section due to the acceleration and the return of dotted motive.

Surprisingly, the climax that begins on m. 43 is fast but simple. Rhythmically, they are the simplest three measures in the work. The smallest note division is an eighth note, and the only dotted notes make up a long chord in the piano. But given the standard set by the previous sections, the climax makes an impact because of its simplicity. Not only is it loud, high, and thick with pitches, but the change in the rhythmic texture also stands out to the listener.

The Coda adheres to the rhythmic standards set by the introductory material and returns to the original tempo. Until the last two measures, sixteenth notes, dotted rhythms, and even grace notes abound. In m. 54, a sextuplet helps to illustrate the word "swift." But the piece is not meant to end too excitedly; instead, the mood is somber, resigned. At the close, the final two measures simplify in rhythm and the number of pitches is reduced, though the notes between the soprano and the alto soloists are doubled, as are the notes in each of the pianist's hands. A choral director will slow the tempo when approaching the final notes, and the dynamics are reduced. Despite the recent rhythmic interest, there is no doubt that the end has come.

Piano

Unlike Garrop's sets for SATB, both Pity Me Not and Thou Famished Grave include the use of piano. There are two primary reasons for choosing to include this compositional element. Vocalists offer a limited range, especially in a piece written for 
women only. An alto's range is $\mathrm{G}_{3}$ to $\mathrm{G}_{5},{ }^{60}$ while a soprano can typically sing from $\mathrm{B}_{3}$ to $\mathrm{C}_{6}{ }^{61}$ Singing at the edges of those ranges requires more skill than the middle of the range, and composers often limit the time that singers need to spend in the higher register. The inclusion of a piano stretches the range dramatically and provides greater breadth. Richer harmonics can be achieved with the use of the piano's lower registers. In Pity $\mathrm{Me} \mathrm{Not}$, the piano also provides a contrasting character. It acts in opposition rhythmically to the vocalists at many points in the piece. Thus, the question may be raised: can the piano represent the jilted poet's lover?

Garrop's descriptors at the beginning are "Stark; stilted." ${ }^{26}$ She achieves this with her use of the piano in the introduction, before the vocalists enter. The dynamic marking here is $f f$, and the jolting character is enhanced with the piano's extremely high register. The ..? rhythm that is featured prominently throughout the piece has its debut. The fall of the hammer on the piano's notes is felt more than heard because of these elements.

Though the first few chords strongly suggest F minor, Garrop thrusts chromaticism on her listener within a few measures. The sense of a tonal center is maintained with a pedal tone on $\mathrm{F}$ in both hands. It is distorted slightly in $\mathrm{m} .3$ when the $\mathrm{F}$ q shifts to $\mathrm{F} \sharp$, but each hand maintains an $\mathrm{F}$ q when the other shifts. The immediate return to $\mathrm{F}$ a in $\mathrm{m} .4$ suggests $\mathrm{F}$ minor again, though it may feel a little less steady now (see Example 15).

\footnotetext{
${ }^{60}$ Wigmore, "Contralto."

${ }^{61}$ Wigmore, "Soprano."

${ }^{62}$ Garrop, Pity Me Not, 1.
} 


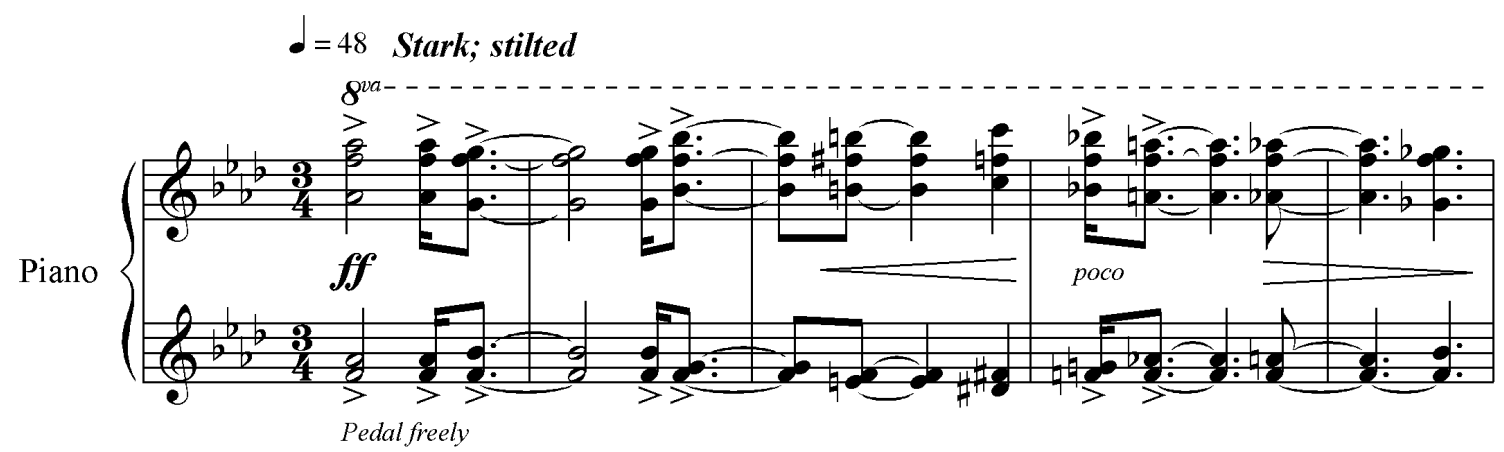

Example 15: Pity Me Not mm. 1-5.

By $m$. 6 , the protesting dynamic has diminished to $\boldsymbol{m p}$, and the volume continues

to fall for the singers' entrance in $\mathrm{m}$. 7. The $\boldsymbol{p}$ vocal line would otherwise be lost in the midst of louder dynamics in the accompaniment. In $\mathrm{m} .8$, a single quarter rest in the piano occurs on the word "not," ensuring that the attention of the audience is appropriately focused on the text. At the end of the first phrase, or two lines of sonnet text, the piano drops suddenly in register as a prelude to the next phrase (see Example 16).

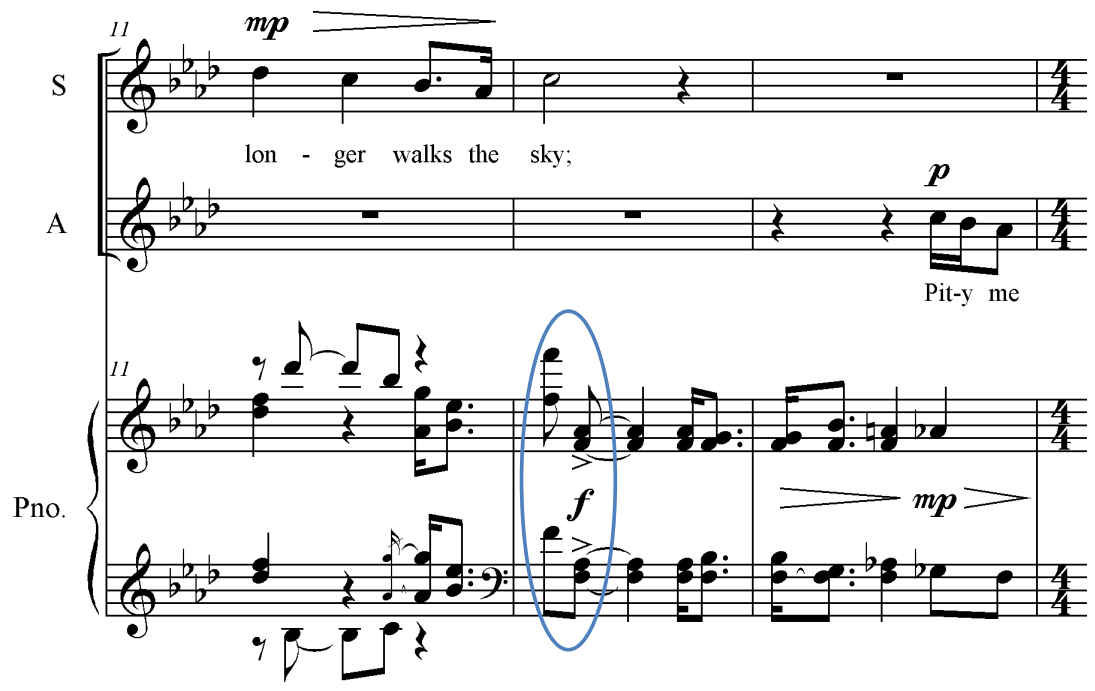

Example 16: Pity Me Not mm. 11-13. 
The same technique occurs at the end of the second phrase when the left hand moves down by an octave, and the right hand fills in the empty register with notes below its higher, melodic material. Slowly, the texture thickens. By m. 20, all singers are professing their despair and the piano chords ring high and low around them. This is the first instance of thickened vertical density, enhanced by the breadth in register (as seen previously in Figure 3 and 4).

For the first two measures of the B section, the piano disappears entirely, allowing the text to sound clearly without competition. When the piano reenters, the left hand plays low octaves while the right hand intermingles with the vocalists. The piano also maintains a primarily simple rhythm with notes on each beat, eschewing the previously pervasive. .) motive. At times, it opposes the vocal lines. In mm. 26 and 29, the right hand plays a duplet against the first sopranos' triplet; the opposite occurs in mm. 27 and 31. The constant shifting between duplets and triplets between the vocal lines and the piano suggests a struggle, though no clear winner is declared.

The return of the. .? motive in the $\mathrm{B}^{1}$ section beginning in $\mathrm{m} .33$ creates more tension behind the restatement of the text and melody. Instead of "with gaining emotion," "63 Garrop stipulates that this portion of the piece should be "passionate."64 The piano accompanies the phrase "This have I known always", but both hands play high above the vocalists. The emphasis is still on the text here, and the high piano chords decay quickly as the singers build in volume and intensity. As soon as the word "love" is sung, the left hand returns to its low register with chord roots and frequently shifting

\footnotetext{
${ }^{63}$ Garrop, Pity Me Not, 3.
}

${ }^{64}$ Ibid., 5. 
melodic fragments providing additional texture. Though at first the notes in the right hand are intermingled with the vocal parts, soon the top notes of each chord are soaring above the singers, creating a broad range of heard pitches and a more "passionate" effect. Compare the beginning of the B section (see Example 17) to the corresponding portion of the $\mathrm{B}_{1}$ section (see Example 18).

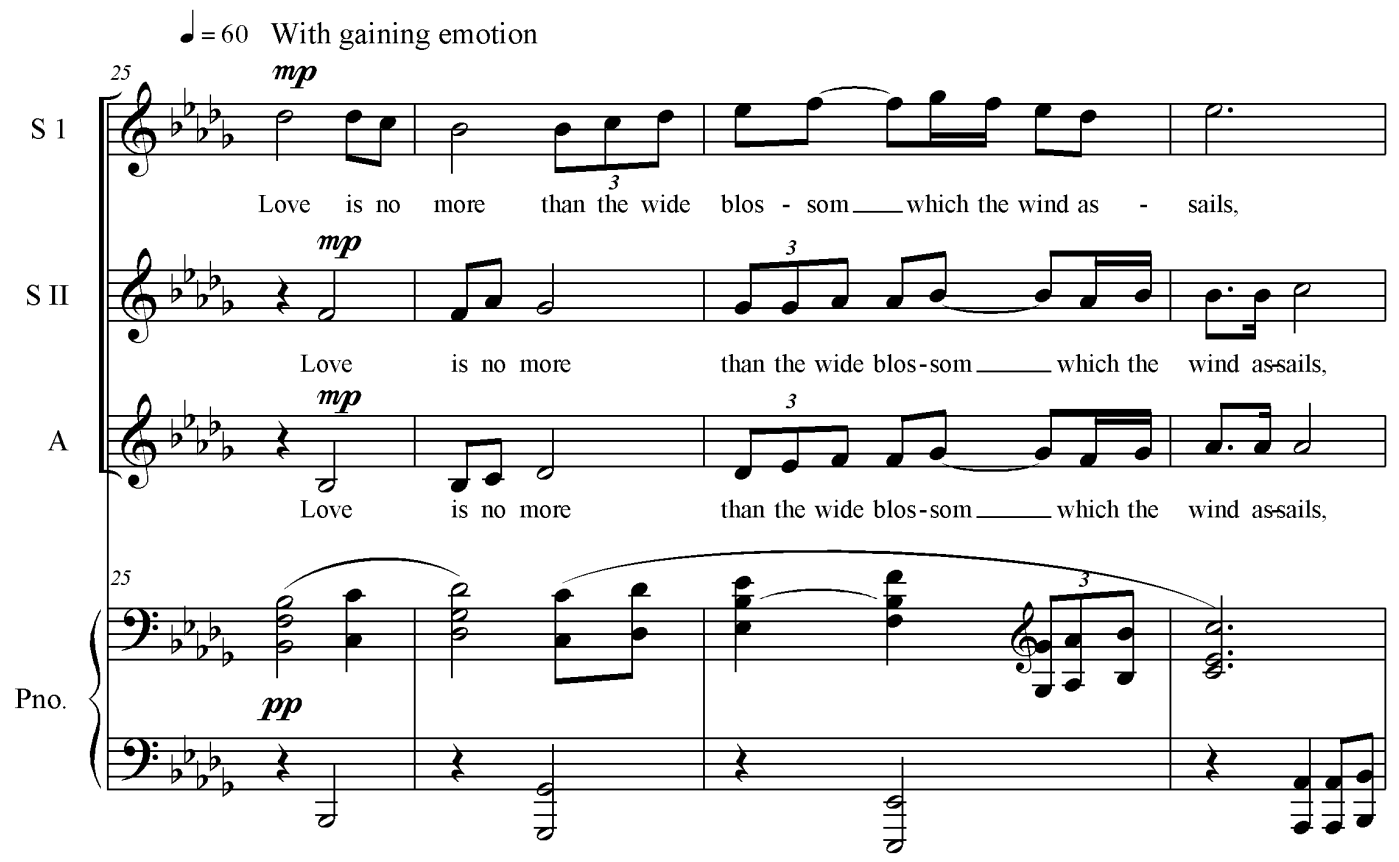

Example 17: Pity Me Not mm. 25-28. 


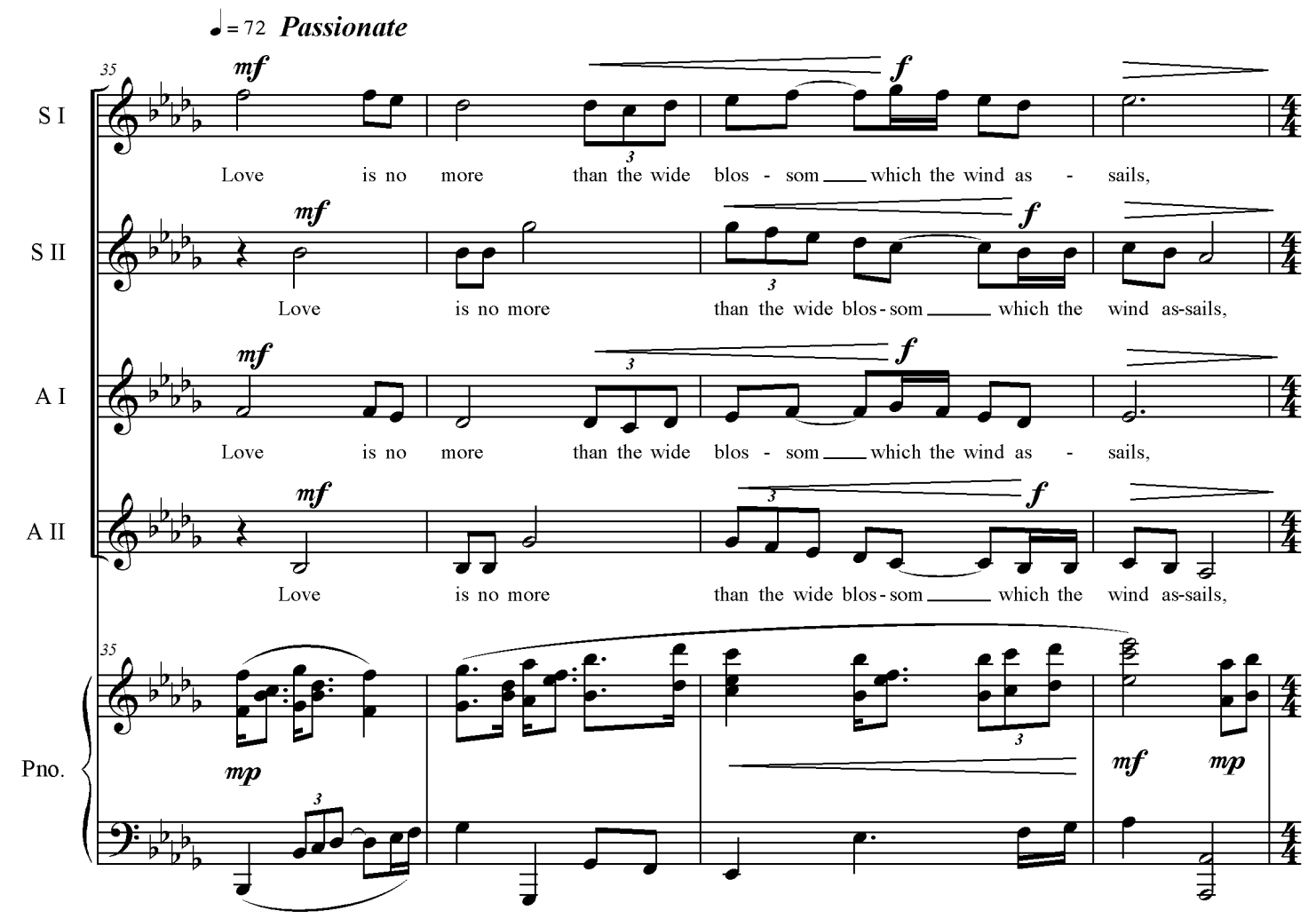

Example 18: Pity Me Not mm. 35-38.

The accelerando prepares the climactic blocked chords in the piano beginning in m. 43. The rhythmic texture slows considerably, allowing the thick, clustered chords to ring for a couple of beats before moving onto the next. In $\mathrm{m} .46$, the piano returns to the introductory material from section A, doubled at the octave in several places and with low, octave pedal tones for a more dramatic effect. The dynamic is also extremely loud at fff. Garrop purposely placed a fermata above the bar line into $\mathrm{m}$. 50, with the additional instruction to "pause." 65 The pianist is further instructed to "Sustain pedal through fermata," indicating that the clustered chords should be allowed to ring and then

${ }^{65}$ Garrop, Pity Me Not, 7. 
decay. The dissonant notes blend together, creating an aural mush that is given no rest before the following notes (see Example 8).

The remainder of the piano's part is very stark. The first beat of m. 50 is an open octave, more hollow than the fifth in the comparable m. 6. Both hands move higher in register. As the chorus pauses and soloists take its place, the left hand plays where the chorus would have sung. The warmth of the human voice is replaced with the percussion of the piano, and the resulting texture is bleak. In the final three measures, the rhythm slows dramatically, and all parts end on $\mathrm{B}$, in three octaves. This sudden shift from the climax of the previous section indicates the poet's submission of defeat.

Though the rhythms in the piano sometimes conflict with the rhythms of the singers, the piano mostly provides supporting material to the vocal lines and the text. The concept of the piano acting as a juxtapositional character to the poet is interesting, but it is not what Garrop intended. Instead, the piano part augments the tension and despair that the singers express, creating a more unified listening experience for the listener. Ultimately, the poet's pain is the element Garrop wished to emphasize, not the struggle between two lovers. 


\section{SIX \\ THOU FAMISHED GRAVE}

By the time another commission request for women's chorus came in 2006,

Garrop already had "Thou famished grave, I will not fill thee yet" in mind as follow-up to Pity Me Not. When Martín Benvenuto, the Artistic Director of the Peninsula Women's

Chorus, contacted her and suggested an Emily Dickinson poem for the celebration of the $40^{\text {th }}$ anniversary of the chorus, she responded,

Although I liked the Dickinson poem that you picked out, I've got a sonnet by Edna St. Vincent Millay that I've really wanted to set for a few years now, but have never had the chance (ironically, for women's chorus and piano it is meant to be a companion movement for Pity Me Not, another Millay sonnet I've already set for the same ensemble). Please read it through - this might work very well with your anniversary theme, not about hard work, but about living life to the fullest and enjoying every moment of it ...66

Benvenuto agreed, and Garrop began to compose the work with the Peninsula Women's Chorus in mind. When it was completed, the chorus devoured it in excitement.

Benvenuto wrote, "Your music is elegantly defiant as the text, very compelling. The sonorities you've envisioned really suit our choir well, and our pianist is thrilled to have an important role." ${ }^{67}$ The chorus premiered Thou Famished Grave in their anniversary concert the following March.

Thou Famished Grave for treble chorus and piano is performed in two minutes and forty-five seconds. Garrop took the opportunity to use a larger range for the singers, as the altos sing $\mathrm{G}_{3}$ a few times and the sopranos reach a $\mathrm{B}_{66}$ during the climax. As in

\footnotetext{
${ }^{66}$ Stacy Garrop, e-mail message to Martín Benvenuto, July 7, 2006.

${ }^{67}$ Martín Benvenuto, e-mail message to Stacy Garrop, October 27, 2006.
} 
Pity Me Not, the meter shifts frequently. However, the differences between the two pieces are more obvious than the similarities. The harmonic structure of Thou Famished Grave is not as strict as her previous sonnet setting for women, and the form is an interesting mix of sections unlike one another.

Form

The form of Thou Famished Grave is not as simple and elegant as that of Pity Me Not, but the same can be said of the poem. Compared to the quiet dignity of Millay's speech in Pity Me Not, her poem about defying death is more restless. She breaks phrases of text over multiple lines, making the text feel rushed. Garrop mimics the feeling by repeating a theme only once, and that theme is low and dour.

Thou Famished Grave begins with an Introduction, a thin, stark emergence of the vocal parts. The piano is absent entirely for these first sixteen measures. Other than an occasional clashing overlap of intervallic seconds, the vocal parts follow a single melodic line in octaves. Though the movement is primarily conjunct, the listener probably cannot discern a key, or may find that his or her initial impression does not match what follows in the next section. Garrop keeps the texture sparse until the first chord, a haunting diminished triad spanning an octave and a half, capped by a fermata and followed by a rest. The rest is significant since it is the only simultaneous rest for all parts in the piece. The pause reflects the semi-colon at the end of the second line of the sonnet, and in a performance space with good acoustics, it allows the strident chord to linger before the piece moves into somewhat more familiar territory. 
For some audiences, "familiar" may be too kind a word. The piano explodes in m. 17 with loud, high chords in 5/4 time, mixing $\mathrm{G}$ major and minor modes. It drops three octaves in as many measures and enters the low, brooding accompaniment that characterizes this, the A section. Sopranos and altos alternate, at first with longer phrases, then gradually singing nearer to each other until almost meshing in mm. 44-45 (see Example 19).

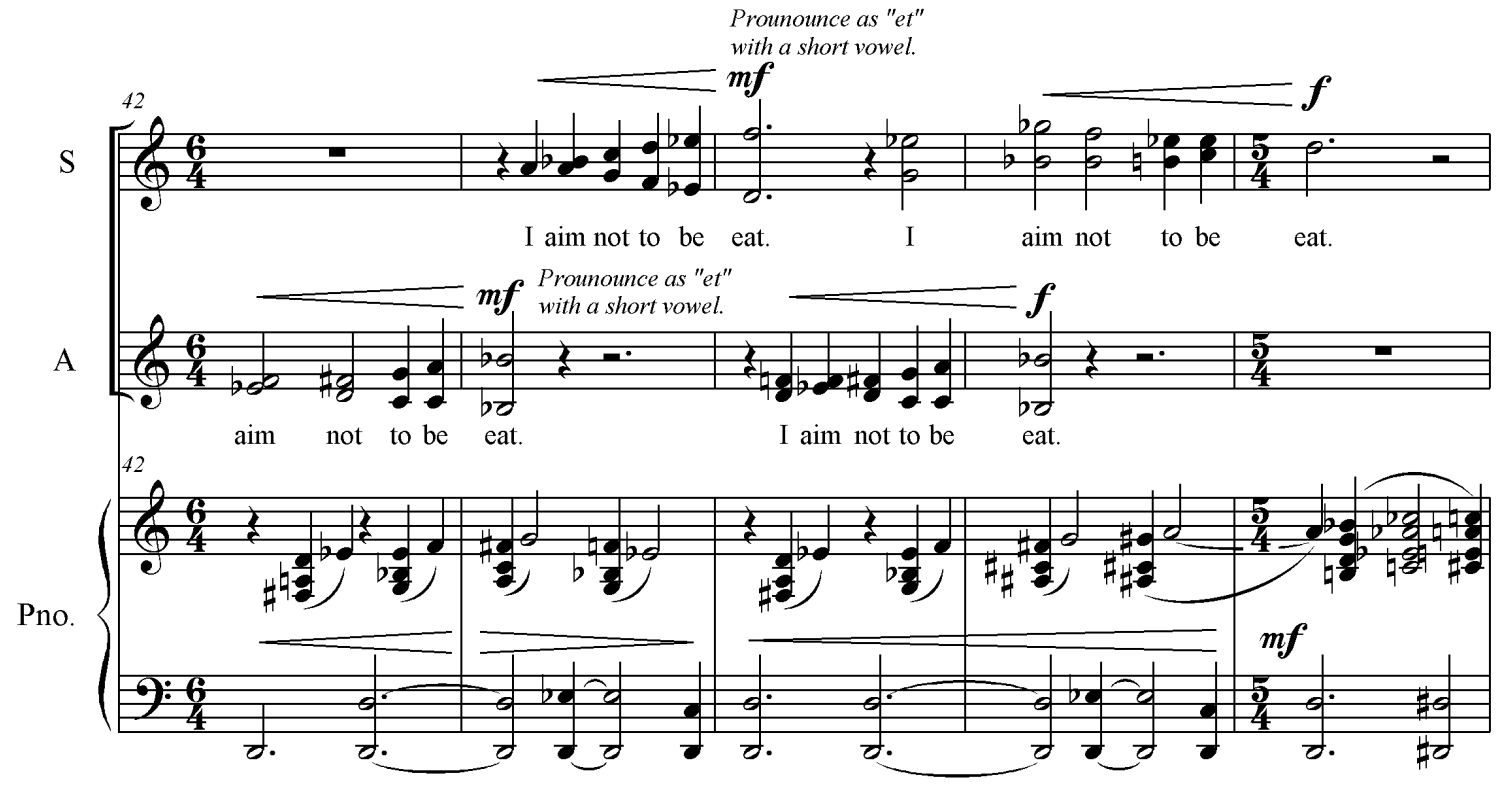

Example 19: Thou Famished Grave mm. 42-46.

Garrop chooses to use a $\mathrm{G}$ tonality for the basis of the first sections, but she moves away from it constantly. The bass line in the piano begins on a low $G_{1}$, then moves to $F \#$ in $m$. 25, and drops again to $\mathrm{F}$ in $\mathrm{m} .31$. After a short dalliance with $\mathrm{B}$, , she seems to settle for a few measures on D, only to move chromatically by step up to $\mathrm{G}$ and a suddenly bright, major chord. The abrupt departure from the brooding quality of the section marks the beginning of the next. 
The meter in this B section shifts to a rollicking $3 / 4$, and the chords are brilliantly major, though not based on traditional harmonic progression or a key. The pianist's left hand jumps octaves almost continually, and the right hand finally crests the register of the voices and floats above them. Yet almost as soon as it has begun, the section fades back to 5/4 meter and minor chords, and a slower $\mathrm{A}^{1}$ section emerges. This time, the downward, chromatic progression of the bass line starts on $\mathrm{D}_{1}$, already half an octave lower than before. The piano is richer and includes a new melodic line in the right hand. Despite the differences, the relationship of the $\mathrm{A}^{1}$ section (see Example 20) to the A section (see Example 21) is clear in the bass line and the melodic material in the vocal parts, as they are each transpositions of the material in the A section.

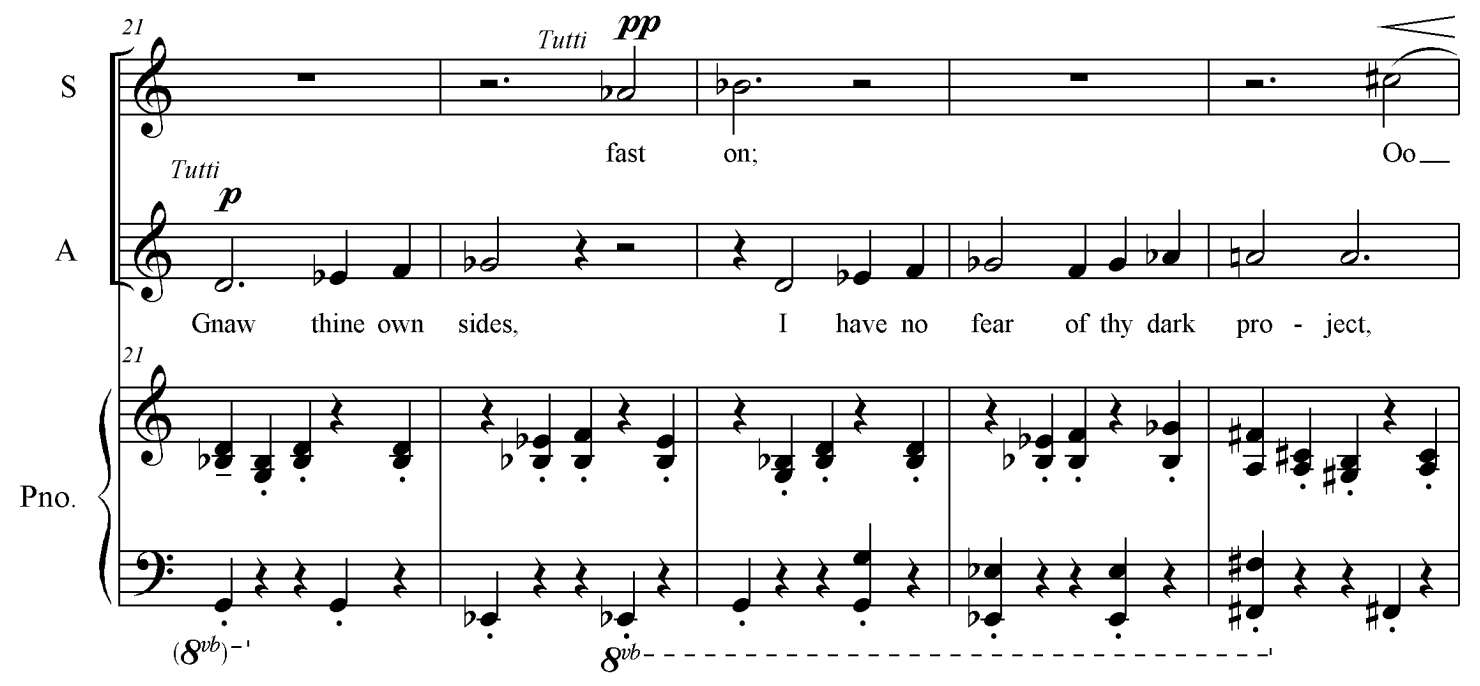

Example 20: Thou Famished Grave mm. 21-25. 


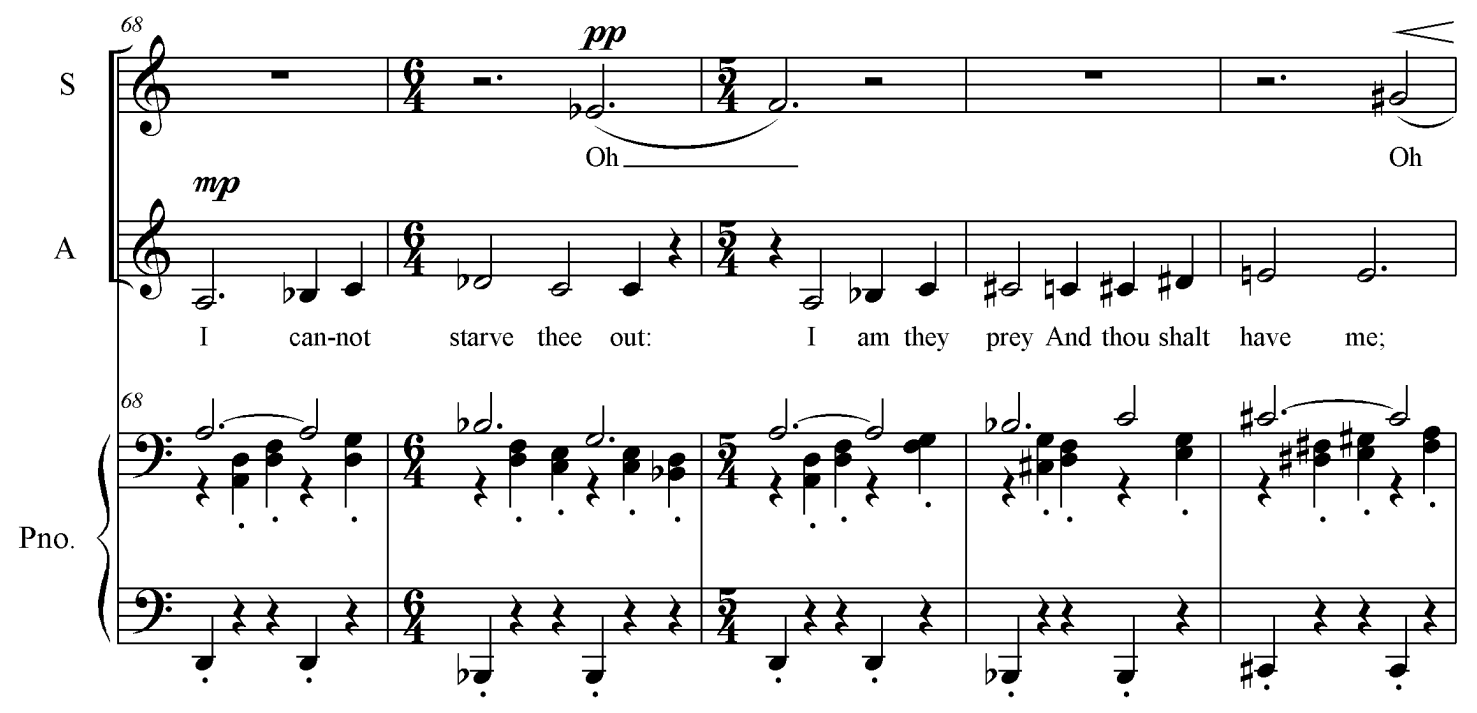

Example 21: Thou Famished Grave mm. 68-72.

Following this $\mathrm{A}^{1}$ section is another emergence of a major tonality, a loose $\mathrm{B}$ major, and again the chords in the right hand of the piano soar over the vocal lines. But it is not similar enough to the $\mathrm{B}$ section to call it $\mathrm{B}^{1}$; in fact, it is completely different. Traditionally, it could only be called $\mathrm{C}$ since it does not hearken back to any melodic or harmonic material already heard. Again, Garrop spends little time in a sunny major key, leaving the rich tonal density suddenly for a single line that comprises the next portion of the piece.

The line primarily suggests a minor tonality, but the bit of chromaticism around $\mathrm{F}$ and $\mathrm{F} \#$ leaves the audience questioning. It could possibly be intended as a return to $\mathrm{G}$ minor. Raising the $\mathrm{F}$ to an $\mathrm{F} \#$ provides the leading tone in an ascending minor scale. To the piano is added a $\mathrm{C} \#$, the tritone, for further tension. This line is repeated in the piano and each voice, overlapping more and more thickly until a final clustered chord in $\mathrm{m}$. 103. The elegance of this passage is portrayed on a graph in Figure 7. 


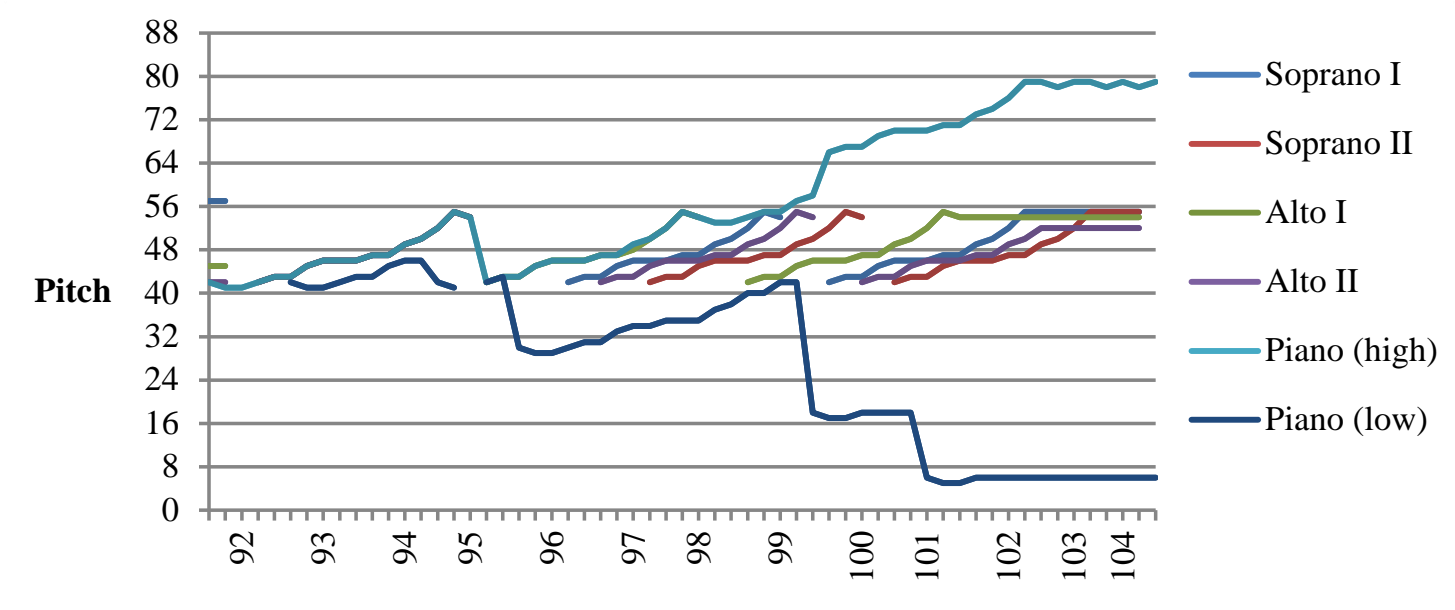

Beats, grouped into measures

Figure 7: Pitch in Thou Famished Grave mm. 92-104. Pitch: 1 represents $\mathrm{A}_{0}$, 88 represents $\mathrm{C}_{8}$.

The entire short section is made up of only that melodic line and a few supplementary notes in the piano. Again, it resembles nothing heard so far, but it is so completely unlike anything in the $\mathrm{C}$ section that it cannot be added to it casually. In this case, traditional guidelines dictate that this section be named "D." The listener may be expecting another A section, as in a rondo, but Garrop does not oblige.

The composer ends the piece with a Coda. The absence of the piano at first may resemble the Introduction, but the vocal parts do not. Again she employs mode mixing with a G major chord in $\mathrm{m} .105$ and a G minor chord in the next. The rhythmic intensity slows down momentarily, unlike the beginning. Finally, the piano enters, and after a frenzied, upward rush to the end, the final chord contains no modality at all, consisting of open fifths and octaves. Thus, the piece is finished, and the audience is left reeling.

When looking at the form in a traditional sense, it seems thrown together haphazardly: Introduction, A, B, A ${ }^{1}, \mathrm{C}, \mathrm{D}$, and a Coda. Describing the structure in these 
terms does suggest a connection to the rhyme scheme of the poem: ABBA, ABBA, CDCDCD. However, when viewed in a different way, it may make more sense. After the somewhat chromatic Introduction, Garrop moves the sections from major to minor in succession (see Figure 8).

\begin{tabular}{c|c|c|c|c|c|c} 
Intro & $\mathrm{A}$ & $\mathrm{B}$ & $\mathrm{A}^{1}$ & $\mathrm{C}$ & $\mathrm{D}$ & Coda \\
chromatic & minor & major & minor & major & minor & major...?
\end{tabular}

Figure 8. Form in Thou Famished Grave.

Perhaps this is a commentary on death and Millay's poem. The poet is obviously loathe to succumb to death. She alternates between lines of resignation and of perseverance, "I am thy prey/And you shall have me; but I dare defend/That I can stave thee off," just as Garrop alternates between modalities. At the end, she chooses neither, but ends on an open chord of fifths and octaves. So the question becomes: has the poet won, or has death? For each listener, the answer may be different for the moment, but one thing is sure: death will always win, eventually.

Text

Garrop does not employ nearly as much text-painting in Thou Famished Grave as in some of her other works, including Pity Me Not. Instead, it is her use of other musical elements that gives the piece its emotional sense. Even so, it is worth exploring the few instances where her compositional techniques bring the text to life, and where her choices regarding repetition of text change the expressive tone. There are also instances where 
short melodic passages resemble Deryck Cooke's "terms of musical vocabulary."68

Listeners will still be influenced by the innate emotional meaning in such passages, even if they may not consciously recognize the implied affect. Though Cooke bases his shapes on a single key, they need to be adapted for use in Garrop's constantly shifting tonalities by focusing on the key of the moment.

The audience is immediately thrust into dissonance and dark concepts. In m. 2 , Garrop uses a minor second, D and $\mathrm{E} b$, when the second sopranos and altos sing the word "grave." For increased effect, the notes are doubled at the octave by other vocal parts. The eerie word is given an eerie feel, augmented by the $f$ dynamic (see Example 22).

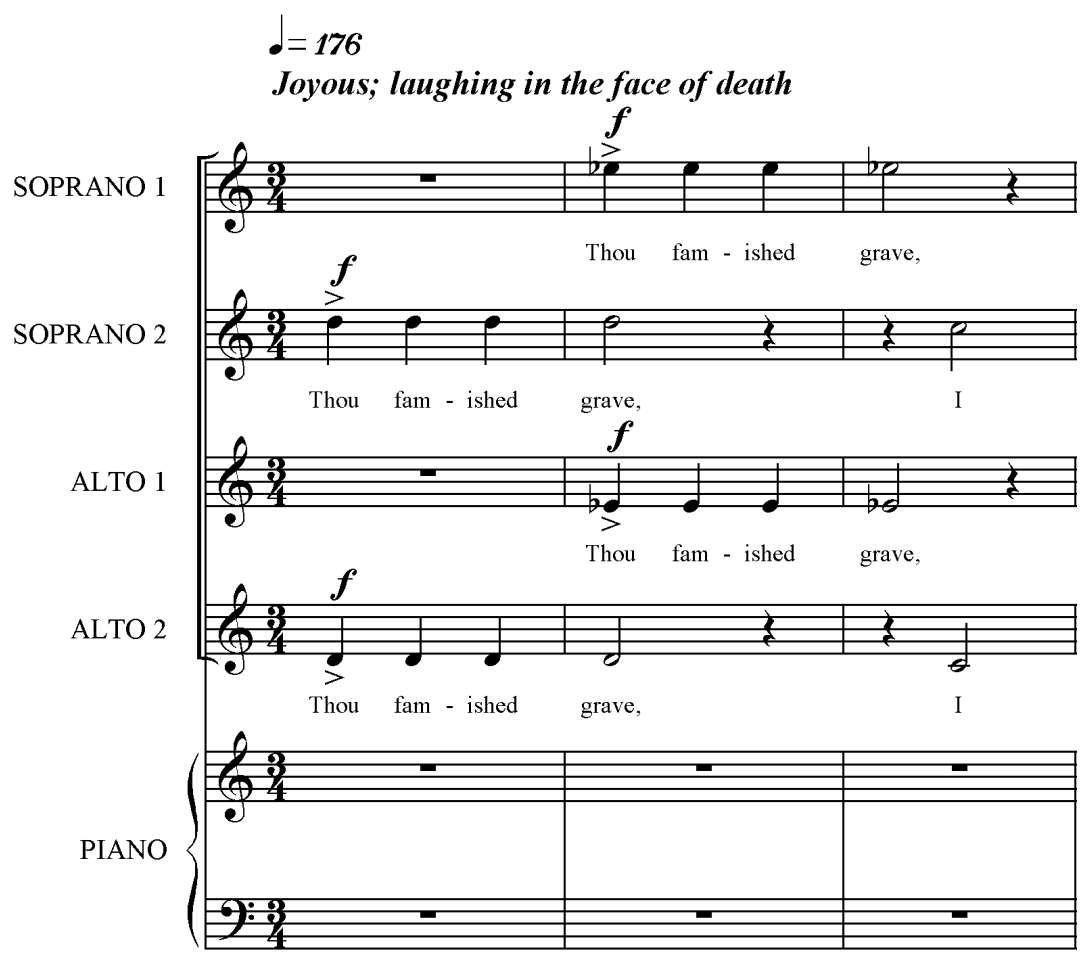

Example 22: Thou Famished Grave mm. 1-3.

${ }^{68}$ Cooke, 113. 
Soon after, the sopranos soar to high tessitura for the phrase "Roar though thou dost” in $\mathrm{mm} .8-10$, as though they are meant to roar. $A \mathrm{G}_{55}$ for the second sopranos and an $\mathrm{A}_{5}$ for the firsts on the word "dost" make roaring a directive for the entire phrase. Garrop also switches to sharps here, a technique that she will echo later. Though the audience does not see this change, it may have a psychological effect on the singers who might equate the sharps with higher pitches than the enharmonic equivalents with flats. According to Cooke, the rising minor scale, especially when fast and loud, represents "an excited, aggressive affirmation of, and/or protest against, a painful feeling." ${ }^{\circ 9}$ Garrop's use of a minor passage beginning on $\mathrm{F}_{5}$ in $\mathrm{mm}$. 8-10 exemplify this concept, as the poet is railing against death. Garrop's description of the introductory section is "Joyous; laughing in the face of death." ${ }^{, 70}$ The poet she envisions is defiantly happy, at least on the surface. But the poet shows her inner feelings right away: the next line, "I am too happy here," is written on a downward minor scale (see Example 23), suggesting "fierce despair" or "a powerful feeling of subjection to fate." "71 It is as if the poet knows that resistance against death is hopeless, but cannot bear to give up the fight.

\footnotetext{
${ }^{69}$ Cooke, 106.

${ }^{70}$ Stacy Garrop, Thou Famished Grave (Chicago: Inkjar Publishing Company, 2006): 1. Used with permission.

${ }^{71}$ Cooke, 106.
} 

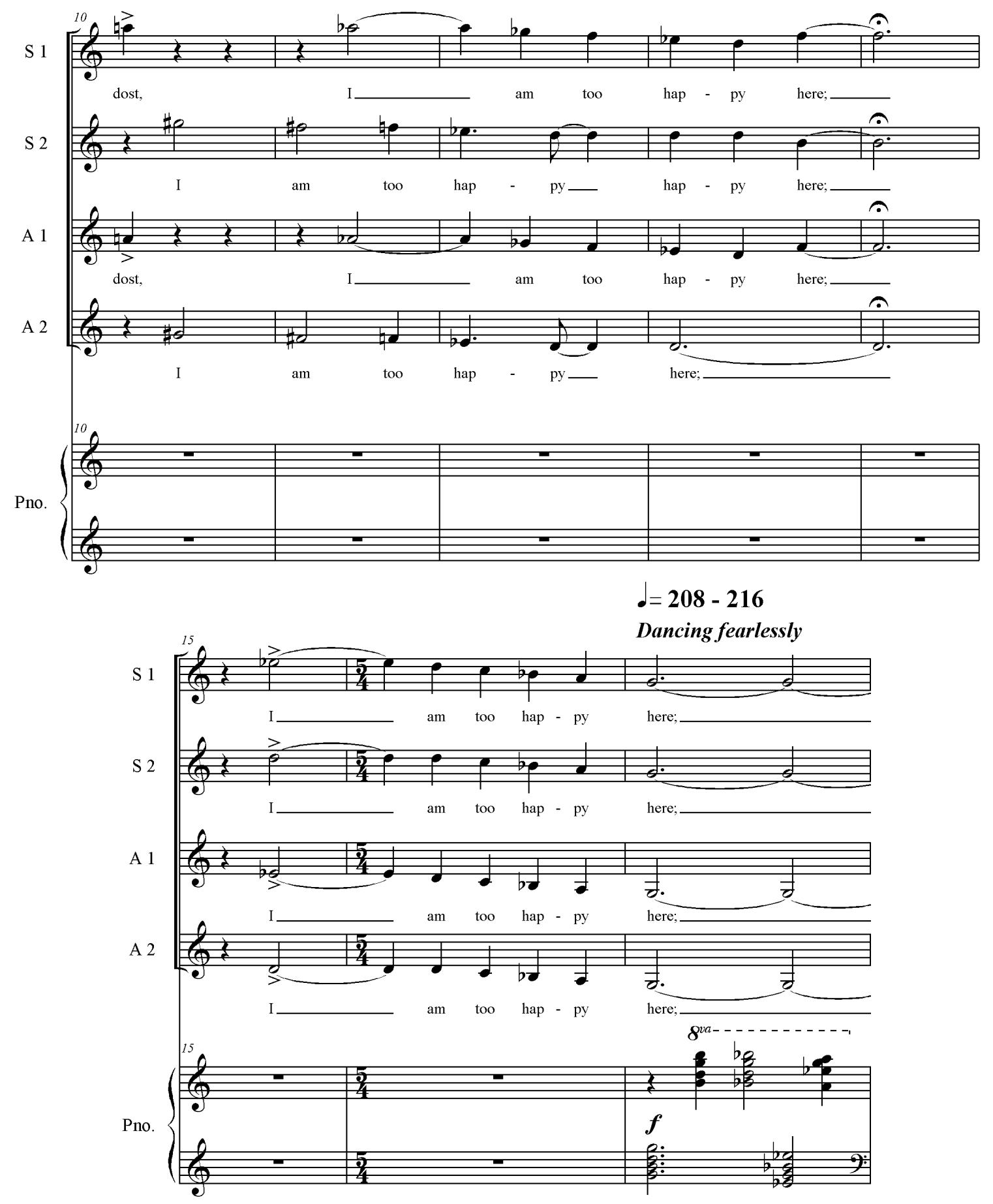

Example 23: Thou Famished Grave mm. 10-17.

In mm. 21-23, Garrop presents a distorted version of one of Cooke's musical shapes that moves from the altos to the sopranos. It resembles a minor $\hat{5}-\hat{1}-\hat{2}-\hat{3}$ with a bit 
of chromaticism incorporated. Instead of a $\mathrm{G}$ for $\hat{1}$, she uses a $\mathrm{G}$, so that the resulting chord built on $\mathrm{E} b$ is minor. The chromatic movement lends an otherworldly feel to the shape that "boldly acknowledges the existence of tragedy and springs onward (upward) into the thick of it,"

When the key shifts to $F \#$ minor, the sopranos sing a wordless $\hat{5}-\hat{6}-\hat{5}$ in minor, a "burst of anguish" that accents the altos' text. ${ }^{73}$

After a predominantly low and minor passage including words like "fear," "dark" and "dismal," the mood changes suddenly with a bright spot of major tonality. It falls on the line "for many a splendid year" (see Example 24).

${ }^{72}$ Cooke, 125 .

${ }^{73}$ Ibid., 146. 


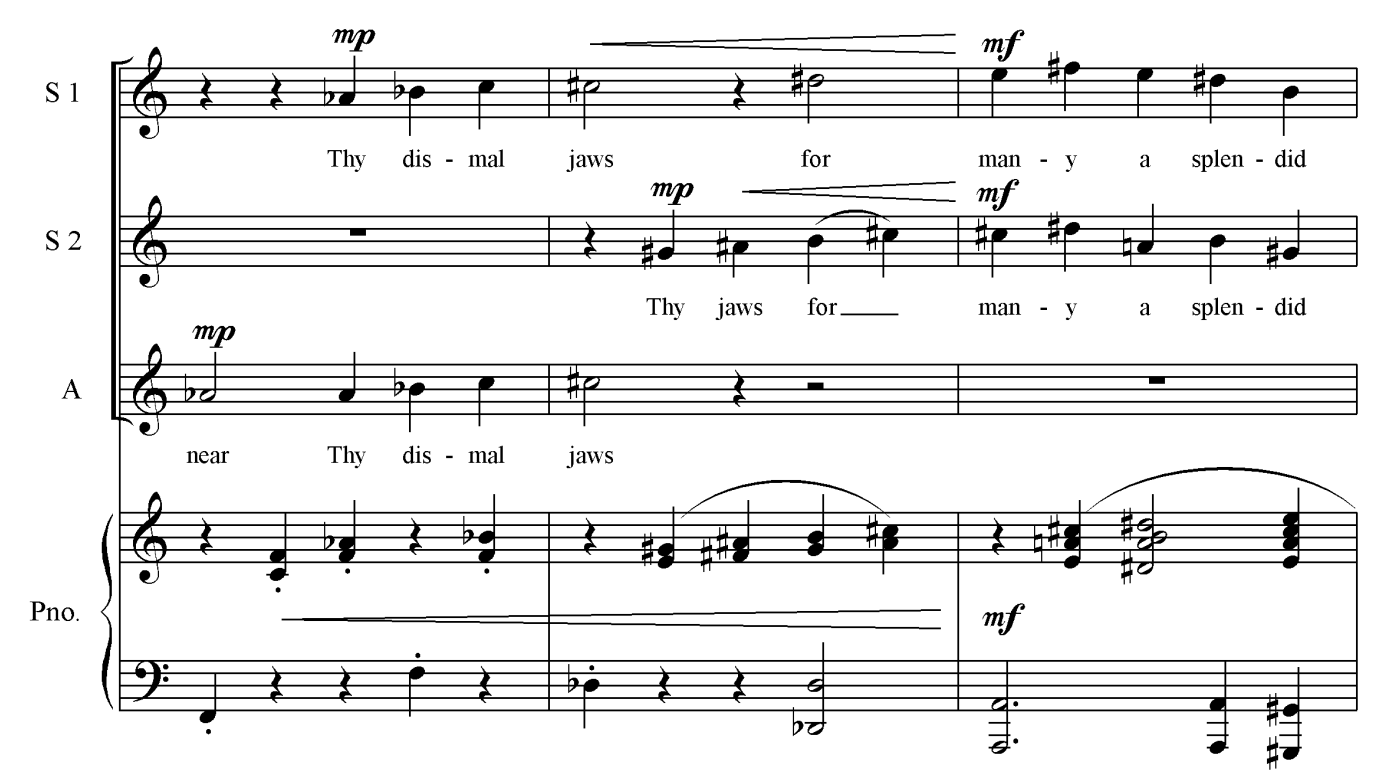

Fm $\mathrm{C} \# \mathrm{~m} \quad \mathrm{~A}$

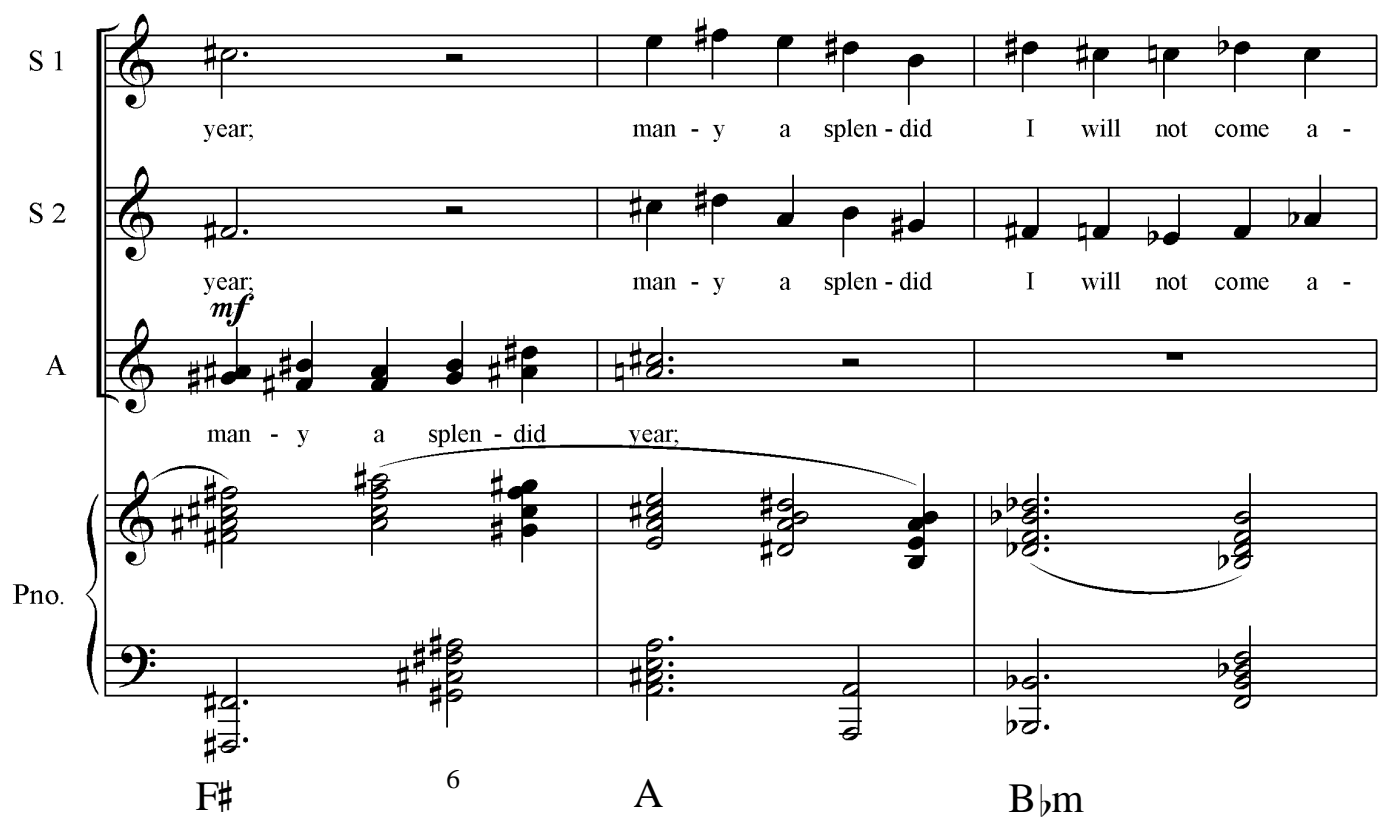

Example 24: Thou Famished Grave mm. 33-38 with chord root analysis.

The word "splendid" has probably influenced Garrop's composition for this passage, because of its particularly positive and uplifting quality. Until now, no text has been repeated beyond staggering; here, the phrase is introduced by the sopranos and repeated by all vocal parts. The chord provided by the piano is A major. In this new tonality, the 
first three notes sung by the sopranos in $\mathrm{m} .35$ are a familiar shape, $\hat{5}-\hat{6}-\hat{5}$, but now in major. Cooke calls this a "simple assertion of joy,"74 a dramatic contrast to previous material. Garrop also employs a sudden switch to sharps instead of flats, an emotional cue for the singers that she had previously used in $\mathrm{m} .8$, and both the melody and the right hand of the piano part peak. The left hand discontinues the staccato pattern and begins to play broader chords, enriching the sound (see Figure 9). After the previously sparse texture, these elements work together to provide a burst of pleasurable sound.

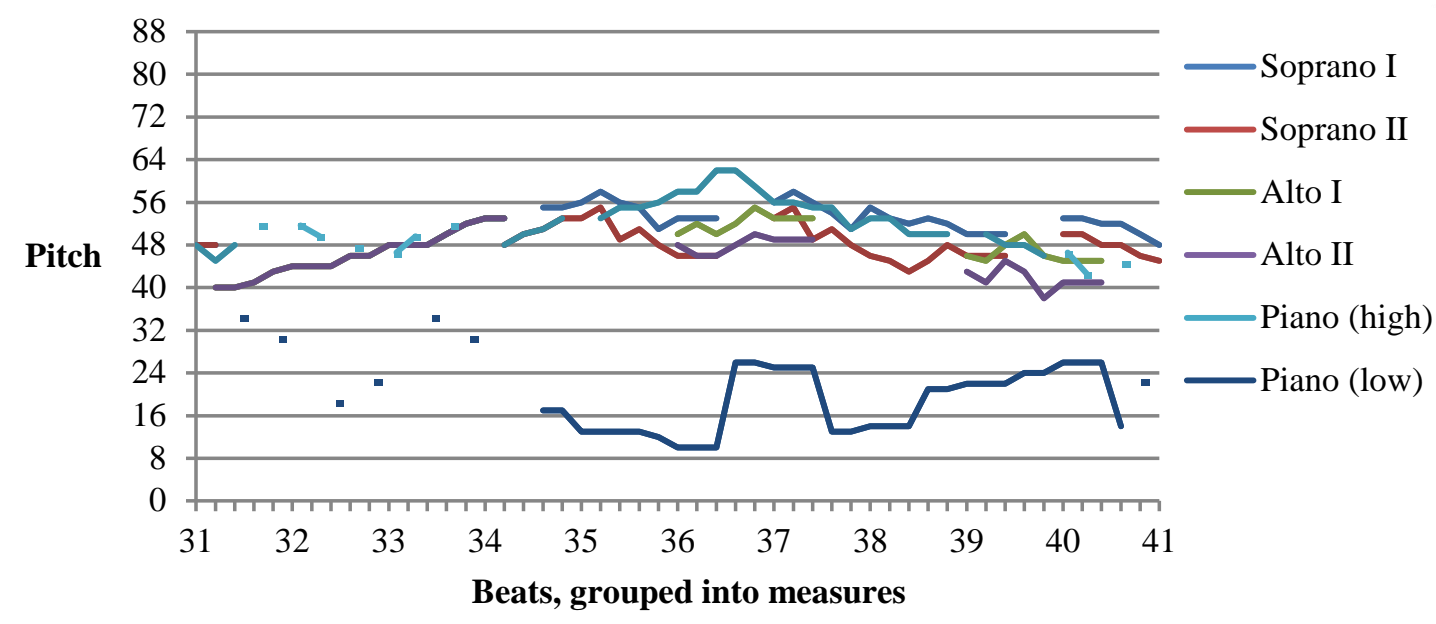

Figure 9: Pitch in Thou Famished Grave mm. 31-41. Pitch: 1 represents $\mathrm{A}_{0}, 88$ represents $\mathrm{C}_{8}$.

After a restless transition in the piano, the audience is suddenly thrust into $\mathrm{G}$ major chords and a rollicking 3/4 meter. Again, Garrop does not adhere to traditional harmonic progression; although the roots change, each chord is major. The first two lines of text, which were given such a chromatic, dissonant treatment in the beginning of the piece, are now bright and somewhat cheerful. The phrase "Roar though thou dost" crescendos into fortissimo, another suggestion of roaring. She switches to sharps again in

\footnotetext{
${ }^{74}$ Cooke, 143.
} 
m. 56 instead of using $\mathrm{C}$ b for the enharmonic equivalent of $\mathrm{B}$ major; though the change may be for purely technical reasons, the sharps here echo the similar switch in the Introduction and may again influence the singers. The return to flats appears in conjunction with the reappearance of 5/4 meter. The flats occur in the piano first and in the vocal parts a few beats later, with each line moving downward by roughly an octave by m. 64. Just as quickly as it arrived, this short B section has already wound down and moves into the $\mathrm{A}^{1}$ section, a return to dark, sparse melodies and rhythms.

When the piece shifts again into major, it is for the phrase, "I'll be but bones and jewels on that day." It is a short section, only eight measures, but it provides contrast before the next minor section, which is also brief. It is possible that Garrop chose to use a major tonality for this portion of the text because of its meaning. The poet suggests that she will have lived a long life before death is able to claim her, and by that time, nothing will be left of her except "bones and jewels." Later, beginning in m. 92, the second portion of a motive that will be repeated several times resembles another of Cooke's shapes. From $\mathrm{G}_{4}$ in $\mathrm{m} .93$ up to the $\mathrm{D}_{5}$ in $\mathrm{m} .95$ equals $\hat{1}-\hat{2}-\hat{3}-\hat{4}-\hat{6}-\hat{5}$ in the key of $\mathrm{G}$ minor (suggested by the leading tone, $\mathrm{F} \sharp$ ). According to Cooke, this particular shape "clearly expresses a powerful assertion of fundamental unhappiness - the 'protest' of 1-3-5 being extended into the 'anguish' of 5-6-5."75 Therefore, Garrop is suggesting that though the poet is triumphant in her thwarting of death until her old age, it is still a small consolation for the inevitable end of life.

\footnotetext{
${ }^{75}$ Cooke, 156.
} 
From this point in the score, Garrop repeats the first line of text once more, a last declaration of courage in the face of certain, if eventual, death. It is loud and high with no piano accompaniment until the last word. Like the Introduction, major and minor tonalities clash and fight. In mm. 109-111, the first soprano line beginning on $\mathrm{G}_{5}$ outlines $\hat{1}-\hat{2}-\hat{3}-\hat{2}-\hat{1}$ in minor. Cooke explains, "To base a theme on the tonic, only moving out as afar as the minor third, and returning immediately, is to 'look on the darker side of things' in a context of immobility, neither rising up to protest, nor falling back to accept."76 His rationalization sums up the entire piece and its source material eloquently. Though we may struggle against it, death will come for all of us eventually, and we know it.

Rhythm, meter, and tempo

Garrop's use of rhythm is perhaps one of the most interesting musical elements in Thou Famished Grave because it provides structure and interest simultaneously. She primarily chooses non-duple meters, a curiosity given the text. Sonnets as a form employ one of the strictest uses of meter in all of poetry, typically using iambic pentameter. Iambs are metric "feet" made up of two syllables, first an unstressed followed by a stressed syllable. In music, the downbeat of any measure would be best given to a stressed syllable, with the one before it serving as a pick-up. Pentameter means that a line is made up of five iambs for a total of ten syllables. Given the nature of the iambs, it would be surprising to use non-duple meters such as $5 / 4$ and $3 / 4$ for a piece based on sonnet text if the composer chose to use a simplified rhythm of one beat to every syllable.

\footnotetext{
${ }^{76}$ Cooke, 140.
} 
In Thou Famished Grave, the meters work well because Garrop has something entirely different in mind.

Of the 517 beats in the piece (not including the final five beats of rests), 490 separate notes are heard. Seven of the missing beats are in the Introduction, where held notes are scattered throughout the first sixteen measures. Nine are in the B section, with pauses featuring in mm. 56-58 helping to create dramatic tension for the line, "Roar though thou dost". Twelve of the missing beats can be found in mm. 105-111. The piano drops out and the vocalists provide a dramatic climax, aided by the sudden lack of continual pulsing, closed chords, and very high notes. Only a few measures contain more pulses than beats. Typically, the piano provides much of the continuous, rhythmic movement while the vocalists have more room to sing longer lines.

Without considering the last measure of silence, there is only a single rest in the entire piece shared by all musicians. The quarter rest occurs in $\mathrm{m} .15$, following a held diminished triad of four beats (six in the Alto II line) that is further lengthened by a fermata. It separates the repetition of a line of text: "I am too happy here." Since the piano is not playing, the rest could be a necessity so that the singers can take a breath, but until now the lines have been staggered so that there is no need. The sudden change is indicative of Garrop's purpose, letting the tension in the diminished chord linger before moving on into the quicker tempo of the A section, at $\bullet=208$-216. In addition, the rest clearly defines the separation between "I am too happy here" and its repetition. The repetition is sung by all singers simultaneously so that the listener will understand the text. 
The A section is not only quicker, but is also in 5/4 meter. Mostly, Garrop uses a $3+2$ subdivision of the meter, exemplified by the bass line in the piano and mostly supported by the vocalists. Even when the altos sing "fear of thy dark project" (mm. 2425, see Example 25) or the sopranos sing "before I die" (mm. 30-31, see Example 26) with notes falling on the third beats, Garrop's setting of the text makes the third beat an anacrusis to the next two.

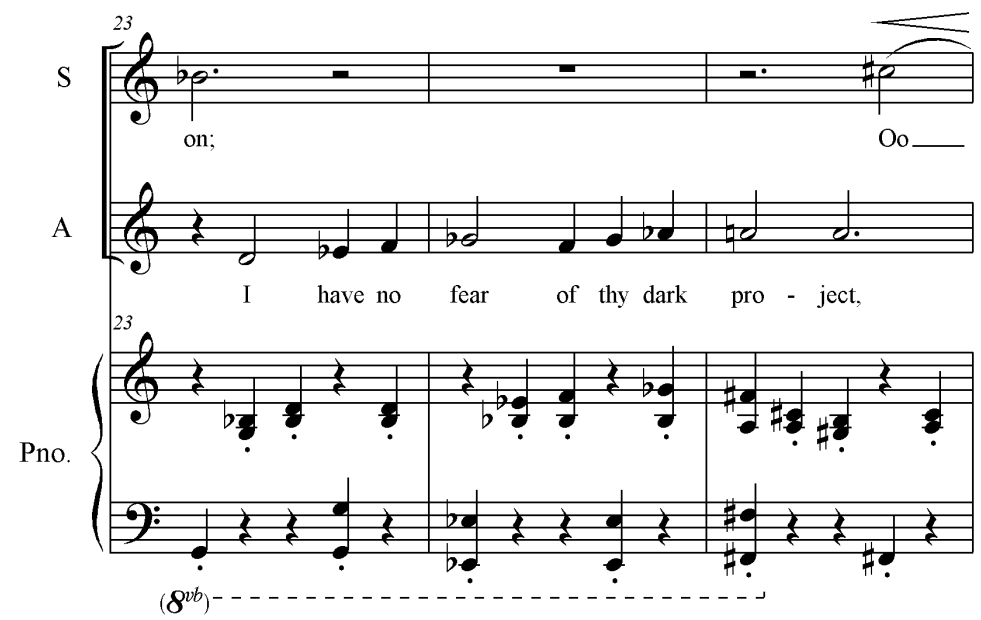

Example 25: Thou Famished Grave mm. 23-25.

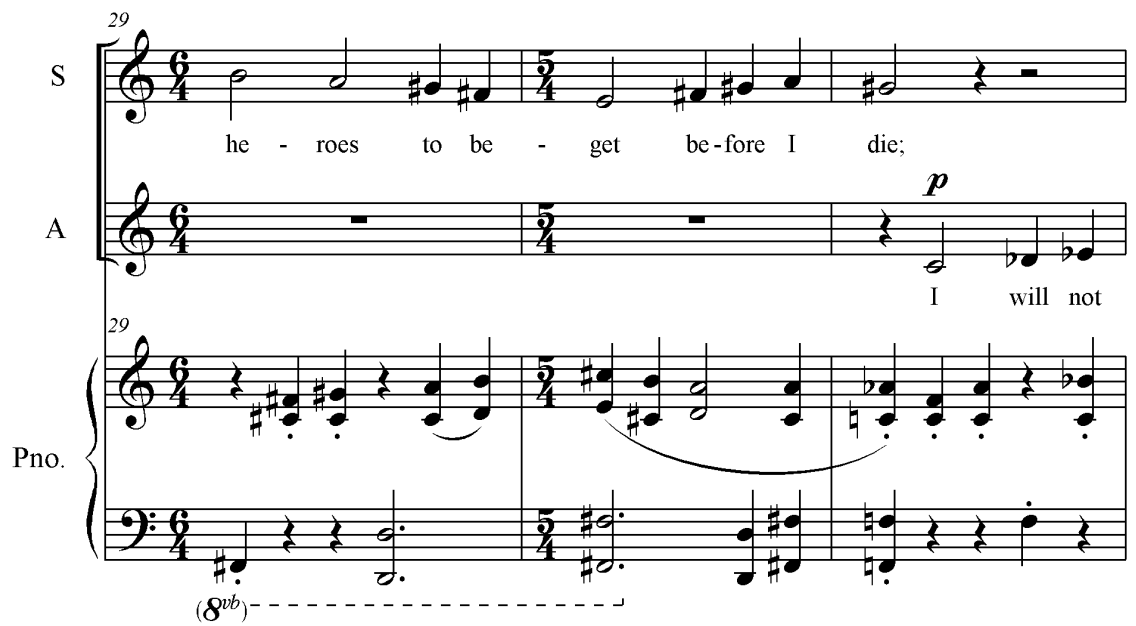

Example 26: Thou Famished Grave mm. 29-31. 
In m. 24, the word "of" on the weak beat leads into the stronger "thy" on the stronger beat. Similarly, "before" is broken over beats three and four of m. 30; the syllable with more emphasis falls on the stronger beat. Other comparable instances are found throughout the work, with rare exceptions. Occasionally, a change in meter is required to properly fit the text to the music. For instance, she did not want to rush the word "heroes" in m. 29, so she stretched the measure instead. The text always holds the priority when Garrop is composing.

In $\mathrm{m} .40$, the meter changes for a brief moment. The rhythm for "Till I be old" is different than what has come before. The pattern $d \cdot \cdot$ provides no pulse on the fourth beat, whereas a strong syllable was placed there in most previous measures. Could this be a brief switch to $2+3$ ? No; the pianist still plays the $3+2$ rhythm. Both are functioning in this measure. Garrop admitted that she did not want to emphasize the wrong word, but also that the different measure provides interest. "It's always nice to shake things up a little bit,"77 she said.

Garrop changes again to $6 / 4$ meter for $\mathrm{mm}$. 42-45. The phrase "I aim not to be eat" contains six syllables, and for mm. 43-44, each word receives one beat of time. In the other two measures, the rhythm is perhaps $2+2+2\left(d_{\bullet} \ldots\right)$. The half notes give heavier emphasis to the words "aim not" as the poet and singers declare their defiance against death. However, the pianist plays against the vocalists using a $3+3$ rhythm, the first beat shifting between the right and left hand, fighting against the singers and

\footnotetext{
${ }^{77}$ Garrop, interview.
} 
undermining what they have to say (as shown earlier in Example 19). For a short time, the meter returns to 5/4 meter and the pianist plays a swirling bridge to the next section.

The B section is reminiscent of the Introduction in both text and meter. The piece returns to $3 / 4$ meter, and the first lines of the poem are repeated. The soprano and alto sections alternate this time, instead of the first sopranos and altos against the seconds, but the result is similar. "Roar though thou dost" is sung together for great emphasis, adding to the crescendo. The piano fights the meter on occasion, splitting beats with dotted quarter notes. Almost immediately, the meter returns to $5 / 4$ for the text "I am too happy here," another similarity to the beginning. Garrop also inserts another line from the text here, "Till I be old". It is in the same rhythm as its first incarnation in mm. 40-41, and it leads into the $\mathrm{A}^{1}$ section.

Though similar to the first A section, the tempo is now slower at $\bullet=188$, and all pitches are lower by a fourth. The major outburst of the B section has spent all of the poet's and the musicians' energy: death is a powerful foe. It is clear here not only in the tempo and the register, but also in the text: "I cannot starve thee out: I am thy prey/And thou shalt have me". Two measures of $6 / 4$ meter slow the progress even further, but the fight is not yet through. The singers gain strength in the alternating text of mm. 79-83, and the pianist begins to play low, resonating chords held over several beats. An accelerando pushes the piece forward into $\bullet=208$, and another section featuring major tonality begins, this time staying in $5 / 4$ meter.

The $\mathrm{C}$ section and its $5 / 4$ time do not last for long, a mere eight measures. The $\mathrm{D}$ section is full of shifting meters; $4 / 4$ and 5/4 are constantly switching to accommodate the 
text. Garrop explained, "That was to accommodate the 'even in the' text. I wanted 'end' to happen on a strong beat, so it couldn't be on beat five, and nothing in the 'even in the' felt like it was more important than anything else, so those needed to be even quarter notes. And once again it shakes up the pattern., ${ }^{, 78}$ Just before the end of the section, Garrop moves to 3/4 meter in anticipation of the Coda, but after the overlapping parts and the frequent meter changes, the audience is unlikely to hear anything other than confusion. That makes the beginning of the Coda even more unanticipated; the tempo slows significantly, 3/4 time rings clear, and there are no longer notes to every beat. When the piano reenters on the last syllable of the text, it is for a few measures of the now-familiar 5/4 meter with its $3+2$ feel with notes on each beat, and the tempo has returned to $\bullet=208$. Though she ends in $6 / 4$ time, the audience is unlikely to notice the brief switch in the last two measures.

Piano

The role of the piano in Thou Famished Grave is similar in many ways to its use in Pity Me Not. By including it, Garrop is able to extend the range of pitches available to her, and the timbral quality of the piece is richened with the piano's percussive sound. The rhythm, too, is quite distinct. Garrop sets up a basic pattern for the rhythm and maintains it throughout most of the piece. Its consistency is the driving force that pushes the music forward, and the piano carries most of it.

The piece begins unaccompanied. Even so, the rhythmic intensity of the piece is introduced immediately by the singers with straight quarter notes in the first two

\footnotetext{
${ }^{78}$ Garrop, interview.
} 
measures. When the piano enters in $\mathrm{m} .17$ at the beginning of the A section, it follows the example previously set by the singers by keeping a simple quarter-note rhythm. The pitch drops by an octave each measure until m. 19, when the rhythm becomes staccato. The texture is sparse and disjointed; the meter creates an asymmetrical feel of $3+2$ beats per measure. For most of the A section, the piano part maintains the consistent quarternote rhythm by itself, leaving the more melodic lines to the singers. During the short B section that begins on $\mathrm{m} .49$, the piano's rhythm is not as consistent. The melodies in the vocalists' lines become more lyrical and less hurried, employing many longer notes, and the piano part changes to reflect the different emotion. Since the text is being repeated and clarity is not as important, Garrop allows the texture to thicken and gives the pianist broader chords. Also, the tempo has not changed, but because the 3/4 meter gives greater emphasis to the downbeat than the previous $3+2$ measures, the B section feels much more relaxed. Thus, the slowing of the following $\mathrm{A}^{1}$ section does not feel sudden.

In addition to the slower, more "introspective" tempo, the piano's pitch has also dropped, and in m. 68 a sustained line appears in the right hand above the staccato notes. The line hovers around $\mathrm{C}_{4}$, where the altos are also singing. The addition of this line makes the texture richer and adds an expressive quality to the otherwise staccato piano part. As the piece moves toward the $\mathrm{C}$ section, each of the piano's lines become more legato and the left hand moves into holding pedal notes.

The pedal tones continue in the next section, low and resonant. They are often tied over measures, and since the voices are singing against one another, the meter is obscured. The right hand plays broad chords higher, mingling with the soprano voices. 
The distance between the two hands is striking; the left hand plays significantly lower than any other pitch heard at the moment (see Figure 10).

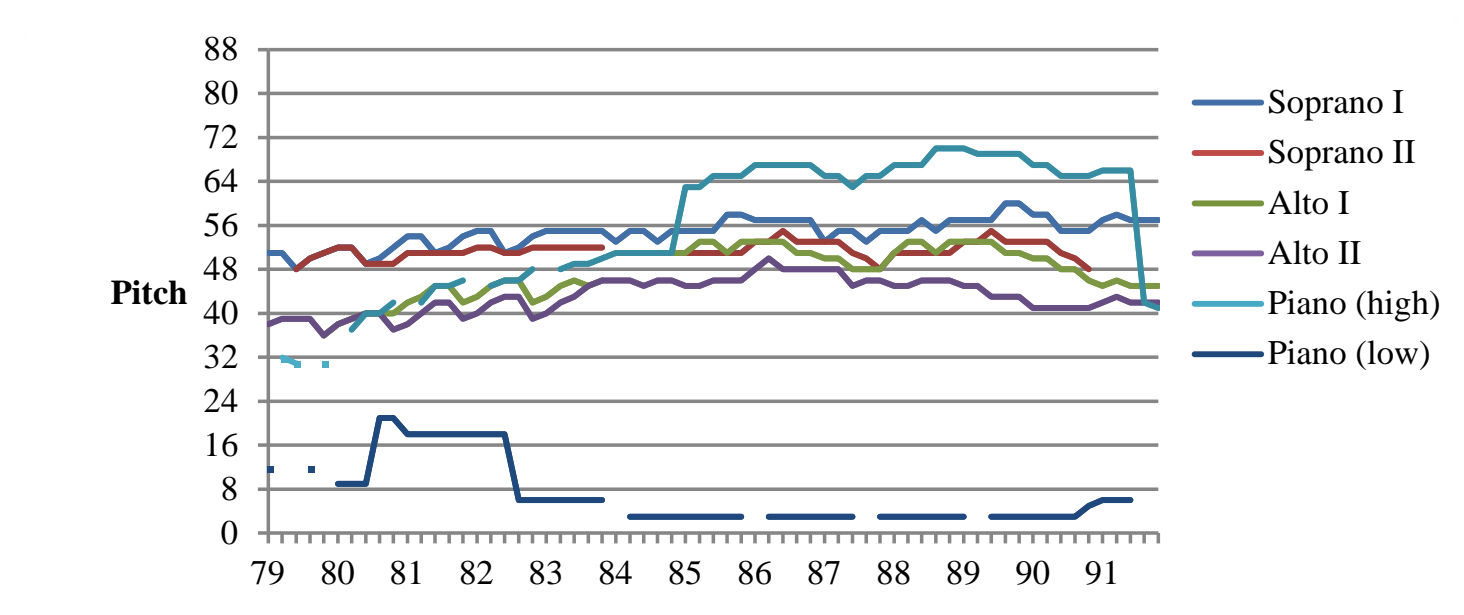

Beats, grouped into measures

Figure 10: Pitch in Thou Famished Grave mm. 79-91. Pitch: 1 represents $\mathrm{A}_{0}, 88$ represents $\mathrm{C}_{8}$.

The singers have picked up the constant quarter-note rhythm that the piano has dropped, so the piece still moves along quickly. Because of the chords, the pace feels less anxious and more like dancing, as Garrop intends for this section.

In the "defiant" D section, the piano becomes part of the fugal texture. The emphasis is no longer on the rhythm. Both hands participate in playing the motive that begins in the sopranos and the pianist's right hand (shown earlier in Figure 7). The left hand moves down an octave at a time while the right rises with the momentum of the melody. The pianist stretches; by m. 102, the hands are the widest apart they will be during the piece. Garrop emphasizes it with a significant ritardando; in a mere three measures, the piece slows from the previous section's $\bullet=208$ to $\bullet=120$. 
Without warning the piano breaks off, leaving the vocalists to their closed, blocked chords that herald the imminent end. When it reenters in $\mathrm{m} .112$, the tempo returns to $\bullet=208$ while the singers belt their final chord, approaching $f f f$. The pianist's left hand remains in its lower register for hardly an instant before beginning its rapid rise upward to meet the second altos on their note. The right hand begins intermixed with the singers' chord and moves higher to crest it. The open fifth is played or sung by all parts and the pianist cushions the singers' notes on the outer edges (see Example 27). 


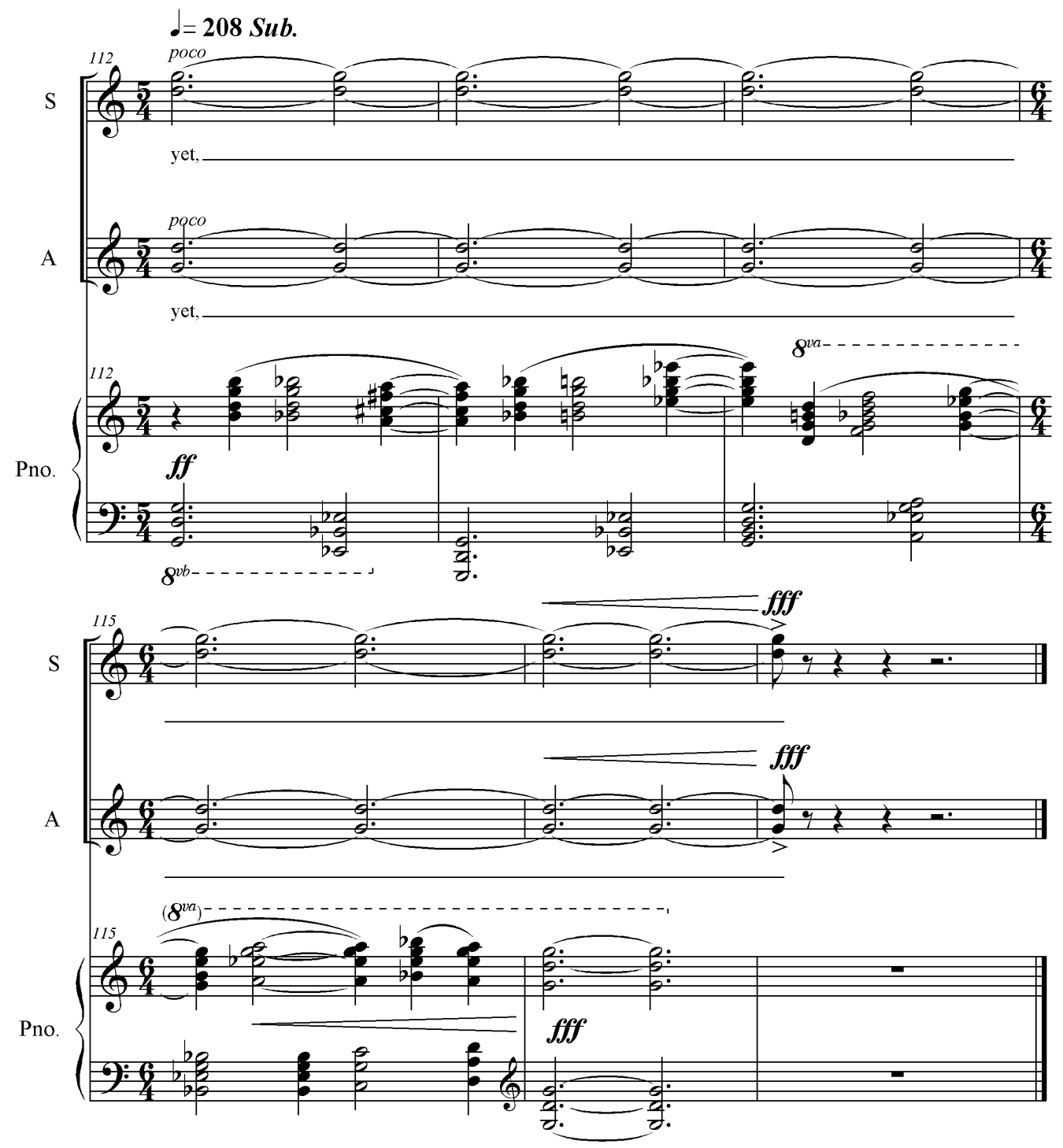

Example 27: Thou Famished Grave mm. 112-117.

Obviously, this is not a simple piano part. It can hardly be called an

accompaniment; even though one of its reasons for inclusion is to support the singers, the part also provides dramatic interest and a percussive element that are crucial to the character of the piece. Without the piano, the singers' lines are generally melodic. The listener may not feel the intensity or anxiety of the piece without the spectacular piano part. 


\section{SEVEN \\ COMPARISONS}

When looking at Pity Me Not and Thou Famished Grave in comparison to one another, several differences are easily recognizable. Pity Me Not is slow where Thou Famished Grave is quick. Pity Me Not moves through the text of the sonnet in a mostly linear fashion, whereas Thou Famished Grave repeats segments of text and returns to the first line frequently. The role of the piano is different for each; in Thou Famished Grave, it feels like more of an accompaniment than in Pity Me Not, where the piano takes on a separate character.

However, the similarities are much more interesting, especially since they appear in many of Garrop's other choral works for unaccompanied mixed chorus. Obviously, her other works stand apart from the two pieces for women because of their specific groupings into sets and the type of choir for which they are written (SATB, a cappella). Though the works for SATB were written with different goals, many of the same elements appear in several of the pieces.

For instance, a signature of Garrop's is that her tempo markings include emotional descriptions. In Pity Me Not, she begins the piece with the instruction "Stark; stilted." ${ }^{, 79}$ When the tempo accelerates in $\mathrm{m} .25$, she specifies that the increased speed comes "With gaining emotion." ${ }^{80}$ The $\mathrm{B}^{1}$ section is "Passionate." ${ }^{81}$ In Thou Famished Grave, the inscriptions are even more expressive. The Introduction should be "Joyous;

\footnotetext{
${ }^{79}$ Garrop, Pity Me Not, 1.

${ }^{80}$ Ibid., 3 .

${ }^{81}$ Ibid., 5.
} 
laughing in the face of death." "Joyous; dancing," SATB have similar markings, usually including specific human emotion. While some composers write only a description of the tempo itself with familiar Italian words like andante and presto, Garrop adds a bit of her own character into her pieces with her colorful and emotional descriptions.

Garrop also chooses to change the meter frequently. As opposed to fitting the music to a single meter, possibly using accents or tenutos to delineate strong beats instead of employing the downbeat, Garrop fits the meter to her music. Non-standard meters such as 5/4 and 7/8 appear often. Sometimes the meter will change for only a measure before returning to the original time signature or moving to a new one. Garrop explained, "If I feel like words need to be stretched to really make the meaning of the text come across, I'm not going to let the meter get in the way of that." 87 Occasionally, the rhythmic motive $\$$. ? seen in Pity Me Not will also appear, though the motive is more frequently inverted in the singers' parts.

Ending pieces or sections of pieces on an open octave or fifth is another frequent occurrence in Garrop's music. Pity Me Not ends on the octave; Thou Famished Grave ends on the fifth. The same approach appears quite often in the pieces for mixed chorus.

\footnotetext{
${ }^{82}$ Garrop, Thou Famished Grave, 1.

${ }^{83}$ Ibid., 2.

${ }^{84}$ Ibid., 6.

${ }^{85}$ Ibid., 8.

${ }^{86}$ Ibid., 9.

${ }^{87}$ Garrop, interview.
} 
When using a soloist, Garrop usually writes the other parts specifically as background. Whispers for this use are common, as in Pity Me Not.

As in both pieces for treble chorus, Garrop often chooses to offset one or two parts against the others by having them enter on the text one or a few beats later. In "I will put chaos into fourteen lines," she builds the voices upon each other in a similar way to the D section in Thou Famished Grave.

Even with all of these similarities, Garrop intends each piece to be unique. "I'm not interested in getting to the final concert when they're all done and having five of them sound like I used the same source material and went along with different text," she remarked when speaking about the choral works as a whole. "So for me, part of the fun and the challenge of putting this together is to make sure each one is as unique as possible. ${ }^{98}$ In this, she succeeds. Though small motives and techniques like the changing of meter or tempo descriptions may appear in more than one piece, each piece has its own character and language that it uses to tell the story.

${ }^{88}$ Garrop, interview. 


\section{EIGHT \\ CONCLUSION}

Edna St. Vincent Millay took piano lessons from her mother in the early years of her life, and though she did not pursue music as a career, it would affect her poetry. " I was eager to learn,' she wrote later, 'for I loved music more than anything in the world except my mother." ${ }^{89}$ The musicality in her poetry may be a part of the reason that Stacy Garrop is so fascinated with her sonnets.

Garrop's works for treble chorus and piano may be short in length, but they are complex. Many musical elements come together to tell the story of the text she has chosen to set. In Pity Me Not, the rhythm, pitch, and timbre of the piano work together to express the poet's anger and frustration. Dynamics swell and the vertical density intensifies to bring the distraught lyrics to life. The shifting minor tonalities represent the sadness of the poet and the instability of her unfaithful lover. In Thou Famished Grave, one story is told but it has two sides. Each section presents a different aspect of the poet's perspective. The minor portions, low and meditative, describe the poet's understanding that she cannot evade death in the end. But the poet is determined to live a life unburdened by the fear of death, and Garrop shows it in the vibrant, major passages. All of these musical elements combine to help her appropriately capture the restless nature of the text.

After all, it is the text that provides basis for the story. Garrop has taken it and provided another facet of storytelling with her music. Her compositions give musicians a profound way to reach their audiences on emotional and intellectual levels, and she has

\footnotetext{
${ }^{89}$ Milford, 25.
} 
honored Edna St. Vincent Millay by ensuring that her music is comprehensible even to listeners with no musical background, though they may not be able to quantify the elements that affect them. Though other projects have required her to temporarily halt the composition of her last two sonnet settings for SATB, it can be hoped that she will finish them and share her own emotional connections to Millay's poetry in the form of her music.

As of this writing, Garrop's various sets for SATB have been performed, but no one has yet endeavored to analyze and write about them. Her works for treble choir and piano are only one small aspect of her catalogue, and the sonnet settings in particular deserve to be studied individually and as a whole work. Perhaps, when they are complete, an enterprising musician will make the effort to do so. 


\section{APPENDIX A \\ AN INTERVIEW WITH STACY GARROP}

From a telephone interview, February 26, 2010:

I'm interested in your personal music history. When were you first introduced to the world of music? When and how did you decide you wanted to pursue composition?

I actually began piano right around my fifth birthday. The very first thing I remember is waiting for the piano teacher to show up. She didn't show up that day; I think her car broke down or something. It was very funny that my first memory of waiting to start music was that the person didn't appear.

Past that point, though, I had piano lessons up through undergrad. After I started playing piano, we had choirs. I grew up in California, and where I grew up, we didn't necessarily have the best funding for the arts. So we didn't have recorders in schools or an elementary orchestra, and I don't know if there was one in junior high. But we did have choirs. So I started singing in choir I think in the second grade. I sang up through sixth. I didn't sing in my middle school, and I'm wondering if we just didn't have one. But then in high school I got right back into choir, and I was in the choir for three and a half years there.

At the same time, I had friends that were in the marching band. The first year I wanted to join the marching band, it must have been my sophomore year that I joined. I played orchestra bells which were unwieldy and heavy and just awful, but it was close to a keyboard so it was easy to play. Somewhere between my sophomore and junior year, I took up the saxophone, so I played saxophone for the next two years in marching band.

I think it was also in my junior year that there was an AP music theory course.

For as bad as our music education was in California, my high school at least had this AP class. That class was being taught by a jazz trumpeter and improv teacher. He told us to go home and write a piece of music, and that basically started my whole career because I went home and wrote a little waltz about a guy I liked. (chuckle) I think at first there was a duet, then came the waltz, and then after that I kept writing piece after piece even though he was no longer assigning them.

Some friends of my family noticed I was composing. They knew a local composer named H. David Hogan, and they hooked me up with him. I began studying privately with him by the middle of that junior year. That teacher happened to be one of the founding members of the Walden School for young composers, which is still vibrant and going today. It's a great little summer camp for composers for kids nine to eighteen and right before they go to college. They give you classes in music theory, composing, and a lot of different subjects. He got me going to Walden the summer after my junior year, and by the end of the summer I knew I wanted to be a composer. I kept studying with him throughout my senior year. I went to Walden one more time after that, but I also applied to undergraduate schools as a composer.

What's so funny about all of that is that it happened in such a short amount of time. If you'd asked me at the beginning of my junior year what I wanted to study in college, I don't know what I would have said. Maybe I would have thought science, but 
once I discovered composing, that was it. It's been interesting because there have been so many composers that I've met either in school or people that are auditioning for Roosevelt (where I teach now) that might have been doing something else for a while and somewhere in undergrad they discovered composing. I thought I was late, starting composing at sixteen, and it's only because when I went to the Walden School during the summers there'd be kids there that'd been composing since they were twelve. So it's all in perspective.

\section{Did your composition professors influence your composing?}

I don't know how much they really influenced the exact style, but I think what was so necessary about my teachers is that they all helped me shape my technique. I guess one way to tell is that I don't know if I sound like any of them. If you look at the list, I started at Michigan after my high school and studied with George Balch Wilson, Michael Daugherty and Leslie Bassett. Then I went to the University of Chicago and studied with Shulamit Ran and John Eaton for a quarter, and then Andrew Imbrie who was a visiting professor at the time. Then at Indiana was Eugene O'Brien, Frederick Fox and Claude Baker. They're all very different composers, but I think what I took from all of them is learning why they do what they do, and how to shape my technique to be the strongest no matter what style I choose. My style might change from piece to piece. Certainly, the style I write in my choir music is very different than the instrumental pieces.

What made you start composing instrumental music? What made you try choral? Do you consider yourself primarily a choral composer, instrumental composer, or both?

Most of the things I wrote in high school up through college were instrumental, but I did do a lot of text setting for singers, too. The thing that is striking about it is that I can't believe I got through three universities without writing a single choir piece. I've been on the crusade at Roosevelt to get all of my kids thinking about this much sooner. The first choral piece did not emerge until I entered the Dale Warland singer competition called Choral Ventures. They would choose four composers and commission them to write a short piece which they would then premiere at a reading session. Then they would choose one composer to get a big commission. I didn't get the big commission, but they commissioned me to write a short piece, and that was the very first Millay sonnet (What lips my lips have kissed).

I think I have three categories, and I think a lot of composers end up having a couple different categories. For me, I feel like I'm split pretty much evenly between choral, chamber ensemble and orchestral. For instance, I'm composer in residence of the Albany Symphony this year. They've played one piece already and they commissioned me to write two more movements of something, so I'm getting that part done. But at the same time, I had a piece to write for the Southland Chamber Singers during the summer, and before that was a big chamber piece, and the next thing after, now that I'm finishing the orchestra piece, is another chamber piece, so I feel like I'm going back and forth pretty much evenly between the three worlds. 


\section{Do you have a particular method of composing? Where do you start?}

It depends on the piece. If it's a strictly instrumental piece, sometimes I have a story that goes to it, sometimes I don't. For instance, the piece that I was just finishing for Albany is about mythological female characters. One of them is about the sirens: as these ships go past an island, the sirens call out. That's a definite story. So that story becomes the framework for the piece, and then from that point I decide on the language, meaning what kind of intervals, what kind of scales I want to use, how do I want to use the instruments.

A choir piece is probably the most extreme example because when I write for a chamber ensemble and soloist, the soloist can be fed pitches by the instruments, and my language can go out a lot further. When it comes to choral writing, even with the piano I try to be a lot more careful and a lot more tonal so that the choir will have an easier time. I don't write the easiest music, so I want them to have as many possibilities to stay on track.

When I write the piece, what I do first is look at the text and figure out the rhythm of the text. I have all these sheets in this Millay book where it's just the text with the rhythm and note heads written out. From that, I figure out what the meter is. So before it even gets set to music, those stages are done. I also look at that and figure out what is the formal structure that the words are suggesting. With Millay and these fourteen line sonnets, sometimes it's a 4-4-4-2 pattern in the way she breaks down her lines; sometimes it's 6-4-4. I figure out what kind of form that suggests. So all that information is gathered; then I go to the piano and start figuring out what I actually want to do with the notes.

When it comes to text, the most important thing is the understandability of the text. There have been so many times that I've been at concerts where I can't understand what the singers are singing, and it could just be because the emphasis is on the wrong syllable of the words, or there's so much counterpoint with people singing different lines of text at the same time. So that's giving me a lot of opportunity to think about what's important to me, and that's the clarity of the text-at least the first time around. Once I start to repeat things I don't care so much, because I figure the audience has already heard it once and their brain can fill in the rest of what I want them to think of.

\section{How have you chosen which poems go into each set?}

When I began after the Warland singers commission, I got really excited about reading all of these sonnets by Millay, and I bought her collected sonnets book. I was supposed to actually set two sonnets for them, for the reading session, but the one sonnet was over four minutes, so there wasn't going to be enough time for them to workshop both. But somehow, in reading over that sonnet, I thought, "Well, you know what? I'm going to go ahead and set that one anyway." I don't know at what point shortly thereafter my mind just decided, "Well, why don't I set a whole bunch more?" But I began reading them over, and perhaps I was just having trouble limiting it down to one or two that I liked. I literally have pages and pages of configurations of sonnets about how I could put them together into different sets. Sometime within that year, after the original Warland piece, I then contacted the Millay estate and explained that I wanted to do this big project, 
and they've been great about giving me permission all along the way for the different sonnets.

Looking at some of the titles of these [sets], there's one about war and mankind. The Sonnets of War and Mankind is the third group right now. She spends maybe about twenty sonnets or more talking about war and its effects, so I wanted to have a set that got at that part of what she discusses. But then she also has over a hundred about love, so then you have to start to figure out how you can group those together. Most of them are about love, but I try to make each title of each piece "Sonnets of" and then I list some adjectives, and each adjective describes whatever song is in the set. I try to gather them around a thought like love or war but sometimes it doesn't work out that smoothly, like Sonnets of Beauty of Music. As long as it makes sense. And sometimes you're trying to tell an overall story. There's one set called the Sonnets of the Fatal Interview, and that was a particular book of sonnets. In that one I was trying to tell the story that she told in the actual book. But that's the only one I ever worried about.

When Pity Me Not was commissioned, why didn't you stray from Millay?

I think because it was such a new project for me, and I got so excited about taking on this big, multi-set project that the thought of leaving Millay's world for a while was not something I wanted to do yet. In the last couple of years I've not had the time to do any more sonnet sets of Millay; I've set two Hebrew texts and now one Latin text. Now it doesn't seem to bother me so much, but I also feel like I'm not nearly as driven in the project as I was in those early years.

Did you already have "Pity me not because the light of day" in mind?

It's showing up on these lists that I made. That one as well as Thou Famished Grave both show up early. When I look from page to page of these lists, I was trying so hard to figure out different ways they could be put together, but those two were ones that were not fitting well into any set. And then I realized: what if they were their own set?

Did you specifically want to use the piano for the two settings?

I think when Paul wanted me to write the piece, we probably thought that adding the piano would provide the bass range that the women otherwise would be missing. I think that's the reasoning, but I'm having trouble remembering that part. I think that was probably why. It also allows me to be a little freer with what I want to do with pitches, because I know the piano can feed pitches to the group.

In Pity Me Not, what sort of character did you want the piano to have?

The piano is representing the anger and frustration that the choir is feeling but can't openly express. If you look at the dynamics, the range, the rhythm, and the starkness of the character, it feels to me like a woman who is screaming in frustration but on the surface has to remain utterly calm. The utterly calm part is the choir.

The piano frequently plays a sixteenth-dotted-eighth rhythm that is often inverted in the singers' lines. Was there a specific reason for using the rhythm? 
I don't think I consciously linked it to the singers, but at the same time, because the singers were using so many sixteenth-notes, it would make sense that the two would overlap in how I was thinking about them. In general, whenever you have those dottedeighth-sixteenth or the sixteenth-dotted-eighths, that's the angular motion playing into the stark character of the piece, the angry character of the piece.

"And you no longer look with love on me" (m. 21) is very quick; is this agonizing thought being forced out, as though speed will deaden or shorten the pain?

This is one of those mundane answers. I was trying to match the earlier text setting that had happened. So look at $\mathrm{m} .14 \mathrm{or} \mathrm{mm} .17-18$ where there are a lot of other sixteenths. I didn't want to slow down the motion so much. It would have been totally plausible to stretch "no longer look with love." I could have stretched that easily, and make that work too. But there's something about the rapid-fire way of delivery of all these sixteenth notes that I thought it would be nice to bring that back before I moved on to the next section.

In Thou Famished Grave, was there a specific reason for your choice of a 5/4 meter for parts of the piece?

That actually was not only a consideration of the text and how that was going to set well. I was waiting for the right opportunity to set Thou Famished Grave. I got very busy during this series of years, so I didn't have time to just turn out extra pieces. When the PWC contacted me, I said, "You know what? I've been wanting to do this other movement to match Pity Me Not for a long time." They thought, "Yeah, that's a great idea." So this particular one is both a dance with death and a dance to evade death. This woman is saying, "I know you're going to get me some day, but you're not going to get me now, and I'm going to enjoy life every moment I can until you get me." So she's dancing to celebrate life and there's a weird dance of death, like the Shostakovich mode. So the $5 / 4$ is really $3 / 4$ plus $2 / 4$, so there's a little sense of a waltz going on.

Is that why you started the piece in 3/4 or was that mostly about the text?

I think that was mostly text, in that I wanted the choir to be doing this call and answer or stretto. That had nothing to do with the actual 5/4 part yet.

The meter in $m .29$ switches to 6/4. Why?

I remember working on that particular measure. If I was counting in $5 / 4$, it felt like the word "heroes" was being rushed. And "heroes" is such an important word. I always try to analyze what is the most important word or words in a sentence and then make sure those words get the most rhythmic value when I set the text. So in that sentence, I thought "heroes" was the most important. "Beget" is important, but maybe not as much as heroes. So that's why I ended up stretching it.

\section{What is the significance of switching back and forth between major and minor?}

Whenever we get to what you might call the chorus, which is the "thou famished grave" part, that's the part where she's saying, "You can't get me," and she's succeeding. 
In that way it's major because she's winning. And the minor is perhaps where she realizes she's dancing with death and knows that she's not going to be able to evade him forever. So there's definitely this idea of life versus death that was playing into that with the major and minor.

\section{Most 5/4 measures are built as 3+2. Why is "Till I be old" given a $2+3$ feel?}

It was about text. I felt like the word 'be' should not be emphasized. It's always nice to shake things up a little bit. "I am too happy here" was all very straightforward with everything happening on every beat. I wanted to shake it up a little bit before going on to the next section.

\section{Why the 4/4 time in measures 94, 97, etc.?}

That was to accommodate the "even in the" text. I wanted "end" to happen on a strong beat, so it couldn't be on beat five, and nothing in the 'even in the' felt like it was more important than anything else, so those needed to be even quarter notes. And once again it shakes up the pattern. If you think about how Beethoven or Brahms, as they get closer to a cadence, they might take a four measure phrase and cut it to a two measure, to a one measure or to a half a measure phrase: they're shaking up their patterns. I feel like these are ways I'm shaking up mine.

\section{Why the comma in $m .108$ ?}

This is the end of the piece, the big climax in a sense, but I also wanted the choir to get a chance to let them breathe with the phrase. Because the piano's not playing, they have the freedom to take this a little bit differently, to take a big breath if they want instead of a really fast breath, especially because of what they have coming up. I don't expect anyone to hold m. 108 through the end of the piece on one breath. That's the last pause before they plow into the finale, or the final measures. It was a chance to let them have a little space, let the conductor give a pause in the music, and get a really big breath.

You cut off "many a splendid-" (m. 37) and interject, "I will not come anear," back into minor. Why not continue alternating? Why did you choose to break the text?

I would have to actually go back and look at the musical material a little deeper to confirm this, but I suspect that I didn't want to spend any more time, that the piece wouldn't be able to handle it with the keys I was going through. So the 'many a splendid year' is alternating between the A major and the F\# major, and I didn't want to spend too long on that before going on to the $\mathrm{Bb}$ minor since we're cycling through keys. This is a case where after the overlap 'many a splendid year' (the sopranos sing that and then the altos come in and then the sopranos again), they don't need to finish off the word 'year'; the audience already knows what's been filled in. I felt like to me it was more interesting to cut it off abruptly and go onto the next thing with the change of harmony below. 
Why did you switch to sharps in $m .71$ ?

The reason for that one is what happens in $\mathrm{ms} 72$. At that point I'm in $\mathrm{C \#}$ minor. This is the type of thing they would never be able to pull off without a piano, the amount of changes this particular movement goes through. I always remember from my choir days seeing these really awkward leaps, like a diminished $3^{\text {rd }}$ or an augmented $2^{\text {nd }}$, and I'm always trying to be very conscientious about the linear approach that I give to singers for notes. For whatever reason, I thought that from $\mathrm{C}$ to $\mathrm{C} \#$ to $\mathrm{D} \#$ to $\mathrm{E}$ would be a more logical approach than if I'd gone $\mathrm{D}$ b to $\mathrm{E}$, to $\mathrm{E}$ natural.

The last measure is made up of almost entirely rests. Is this meant to indicate that the sound will continue to ring after the cut-off, or was it simply because you wanted to indicate a clean release?

It was for the clean cut-off. Looking at it now, though, I'm thinking choirs do tend to pause after a piece anyway, there's no point in all those rests! I could easily have put that eighth note back one eighth into the previous measure with the same pressure accent. For me the most important part is making sure the choir crescendos and really puts a little more pressure on that last note before they release. I tend to think that if you show that on a downbeat, it might come out a little cleaner and precise than if you show it on the last eighth possible in a measure.

I noticed a theme: you change meter frequently instead of fitting your music to one specific time signature. Is this a principle that you follow or just a technique?

It's mostly just trying to fulfill the needs of the text. If I feel like words need to be stretched to really make the meaning of the text come across, I'm not going to let the meter get in the way of that.

Are there any other sonnets you're interested in setting that won't be part of the cycle, like the ones for women?

Not really. I've got two more SATB sets to go to finish the cycle. I have this big project called the Book of American Poetry that's for baritone and sextet, and each movement is a different American poet. It involves ten poets so far and I'm going to do another ten next year. I actually used one of the sonnets that I'd been planning to use for the SATB arrangement because I liked it so much and I'm not getting around to finishing the set. I wanted to use the sonnet anyway. So that one's independent now. I could go back and give it a choral setting too, but that's tricky because once I hear something a particular way, I'm not sure I'm going to be able to go back and re-imagine it in an a cappella setting without using the same sort of material. That'll be interesting to see.

I've only approached your pieces for SATB on a surface level, but I am interesting in hearing about your vision for the complete work. Do you know what you will do after they are finished? What's next?

I'd love to finish them. I only need two more to complete the whole the set. It's mostly because my schedule just got so busy that I haven't been able to get my attention back on it. But my goal would be to finish off the last two sets and have a concert where 
they all get done at once. This is a composer's dream, so I don't know if it'll happen or not! But put them all in a concert and record them all and get them onto a single CD. The problem I'm dealing with now is a standard CD length right now is under 80 minutes, so I really have to be careful about how many more I put in and what their lengths are.

\section{Anything else you'd like to add?}

For any piece that has multiple sections, in this case all of these different sonnets, I'm really trying to make sure that every single sonnet has a different character from the others. I'm not interested in getting to the final concert when they're all done and having five of them sound like I used the same source material and went along with different text. So for me, part of the fun and the challenge of putting this together is to make sure each one is as unique as possible.

I'm also going to miss having the opportunity or reason to read over Millay's sonnets the way I have been. It was very useful to read enough of her sonnets, to read a couple of different biographies at the same time, and really try to get into her head, about what her thought process was when she was working on these. That part's been fun. She had such a remarkable life. 


\section{APPENDIX B \\ SUPPLEMENTARY DATA AND ANALYSIS}

Pity Me Not

Item one: pitch in linear form

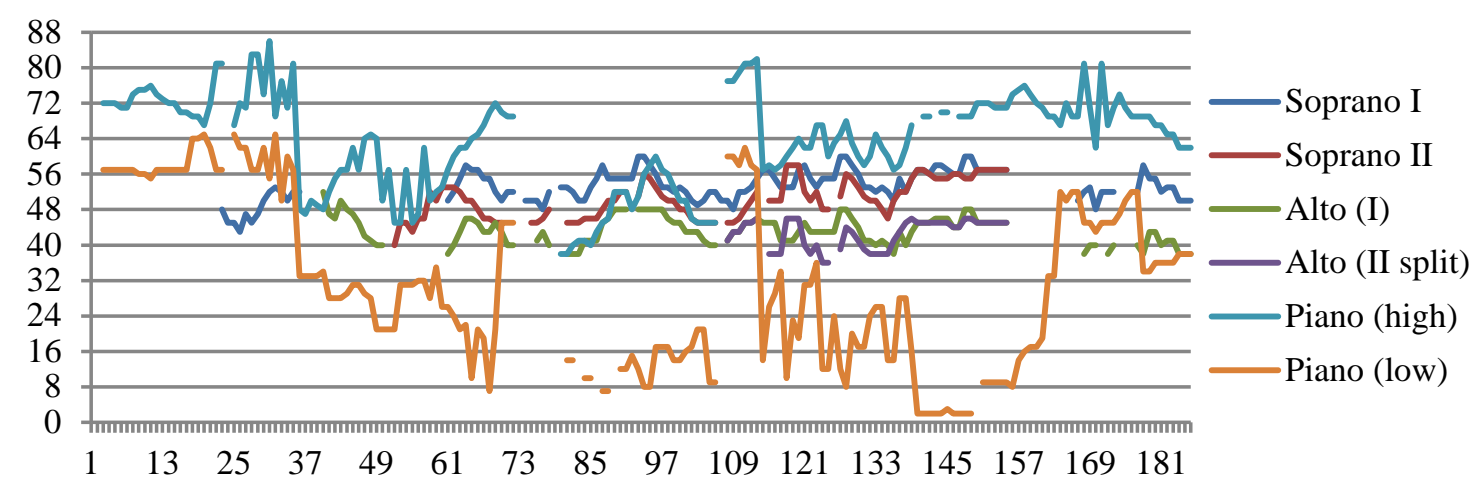

$\mathrm{X}$-axis: beats

Y-axis: pitches; $\mathrm{A}_{0}$ equals $1, \mathrm{C}_{8}$ equals 88

The piano's high line traces the highest notes played in the right hand. The piano's low line traces the lowest notes played in the left hand.

Details worth noting:

is In the Introduction, the notes in the piano start very high for both hands.

\& In the A section (beginning on beat 21), each vocal part trades off singing the melody.

is Beats 71 and 77 are the only moments of complete silence in the entire piece.

cs In the B section (beginning on beat 78), the right hand of the piano mixes with the vocal lines, while the left hand plays low. Rests are also visible in the left hand. Compare this to the $\mathrm{B}^{1}$ section (starting on beat 109), where the right hand plays higher than the voices and the left hand jumps frequently. Without looking at a density graph, the thickness of this section is already apparent.

is The climax (beats 138 to 153 ) is surprisingly simple when looking at the vocal parts. It ends on an octave. The piano's clustered chords are not evident on the graph.

is During the coda, the left hand of the piano ascends to mix with the singers.

is The last notes are octaves apart, like the end of the climax. 
Pity Me Not

Item two: volume/dynamics

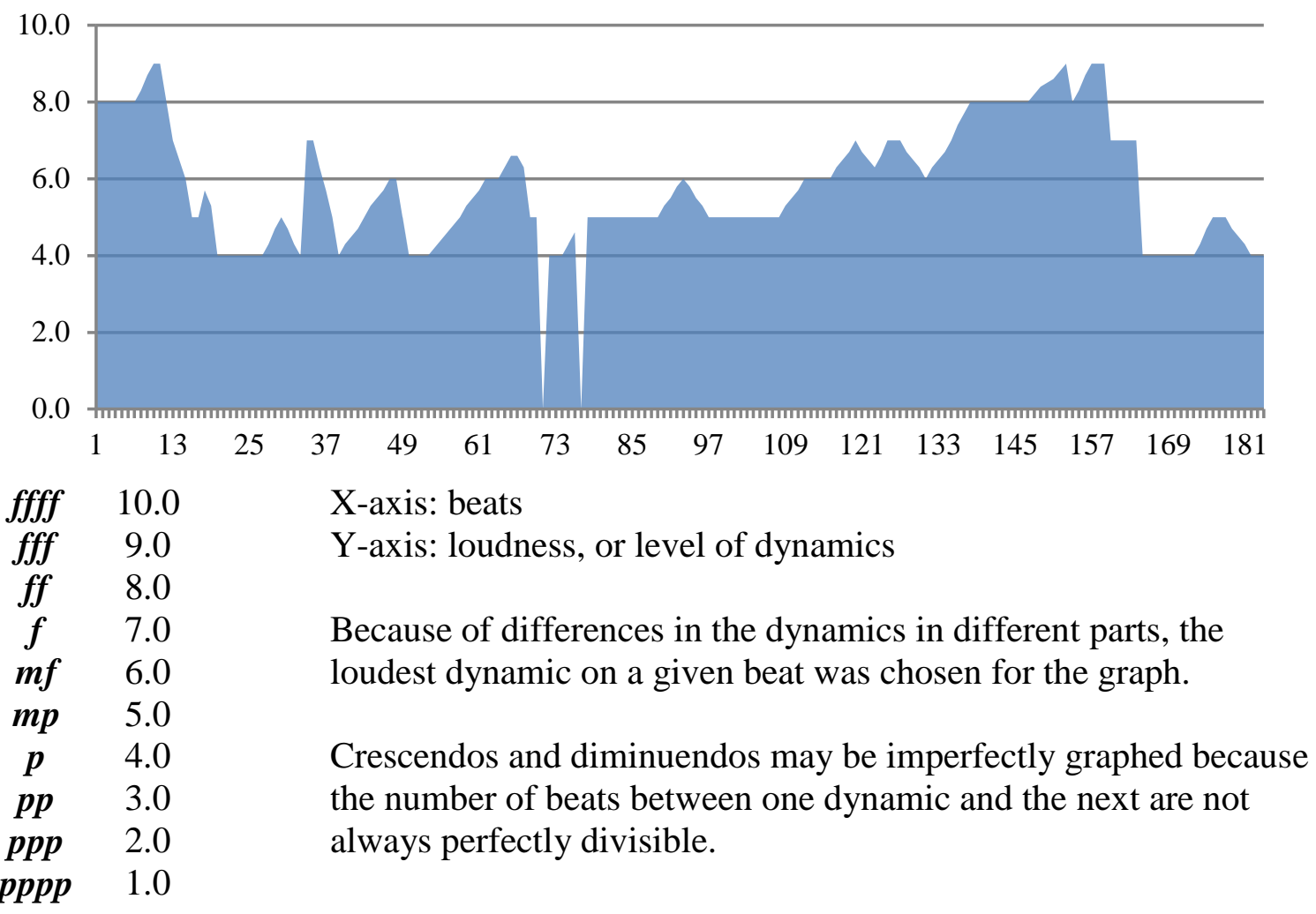

Details worth noting:

is The two rests on beats 71 and 77 are extremely evident on this graph.

Furthermore, the dynamic of the notes between the rests is piano with a slight crescendo, so the rests are easily heard.

is The slow build to the fff climax is clear. It begins roughly at the beginning of the $\mathrm{B}^{1}$ section (beat 109). After the loud climax, the quiet coda is even more dramatic. 
Pity Me Not

Item three: vertical density

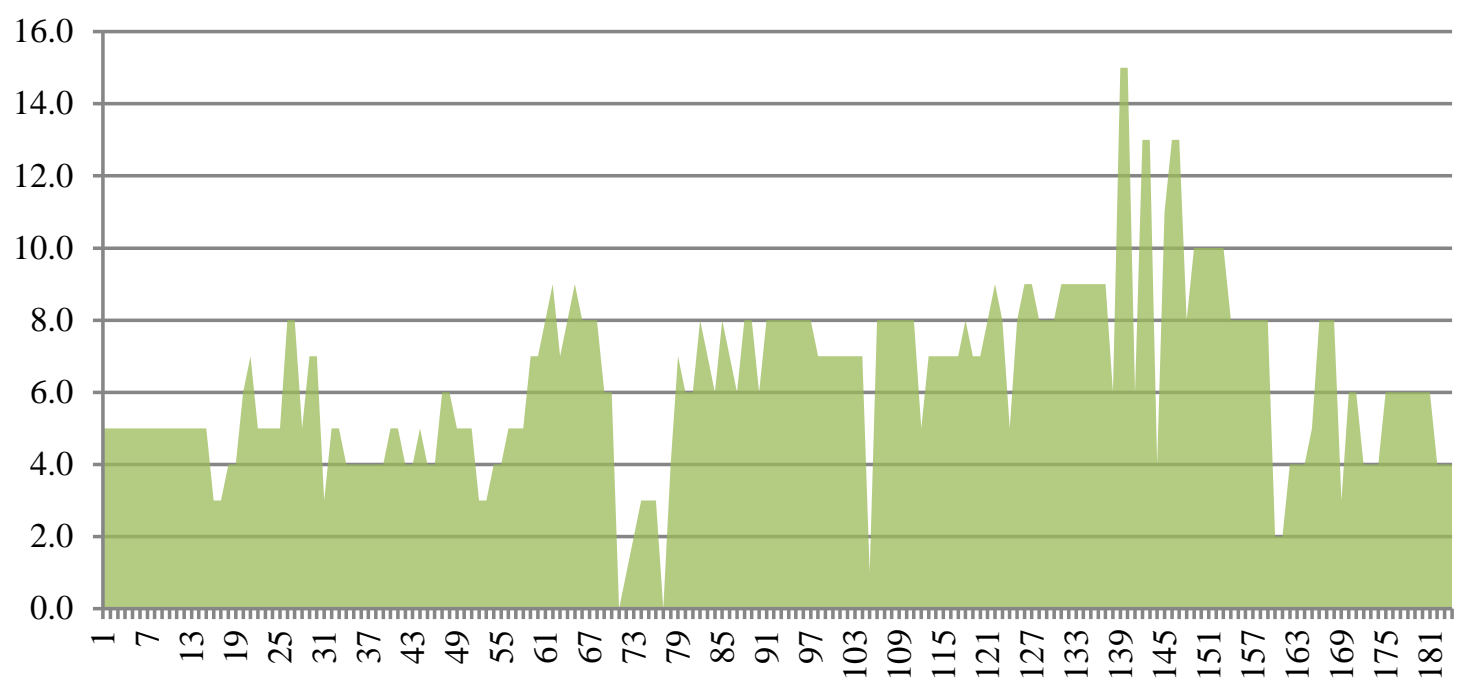

X-axis: beats

Y-axis: number of pitches occurring at once

Details worth noting:

is The interlude in mm. 23-24 has very few notes occurring: it begins with one voice and builds to three. This can be seen by the horizontal line that starts at the 0 notes (the rest).

\& Beat 105 is the beginning of the $\mathrm{B}^{1}$ section, where the first sopranos sing one beat alone.

is The downbeat of m. 50, beat 160, has only two notes in the piano.

is Beat 139 is the second beat in m. 43, the first measure of the climax. It has the most notes per beat at 15 . The next two spikes show the rest of the climax, particularly when the pianist plays the thick clustered chords on beat 2 of each measure.

as Otherwise, the piece generally stays between four to nine notes per beat. Since the piece has only two pervasive timbres, voice and piano, its texture is relatively uncomplicated. 
Pity Me Not

Item four: horizontal density
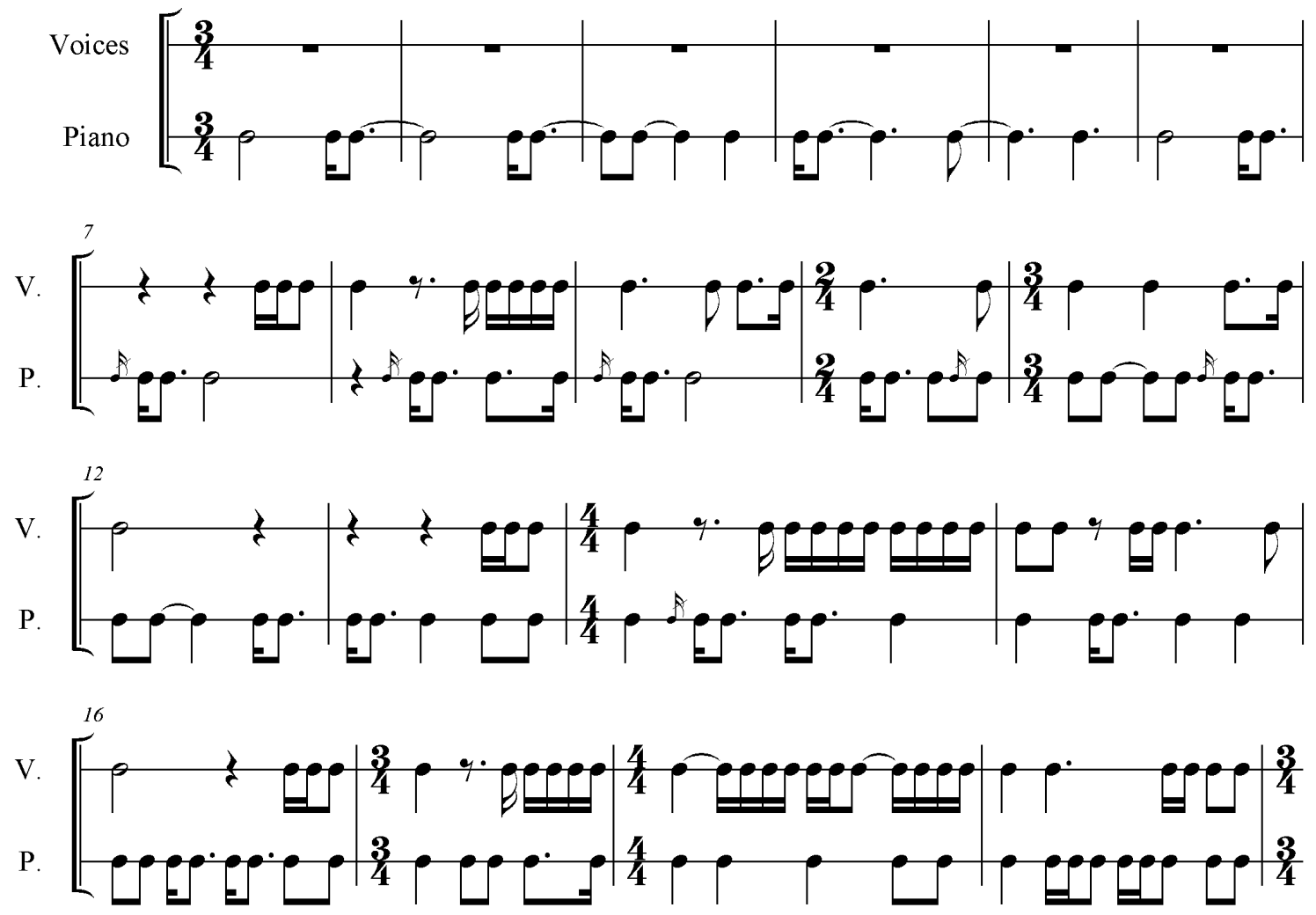

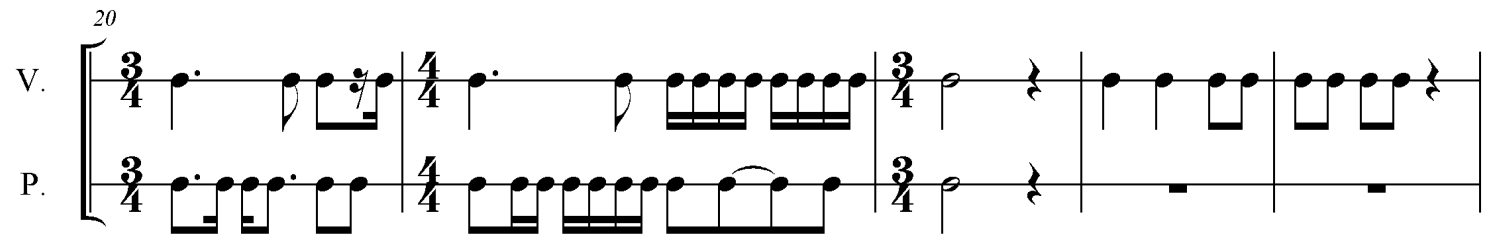
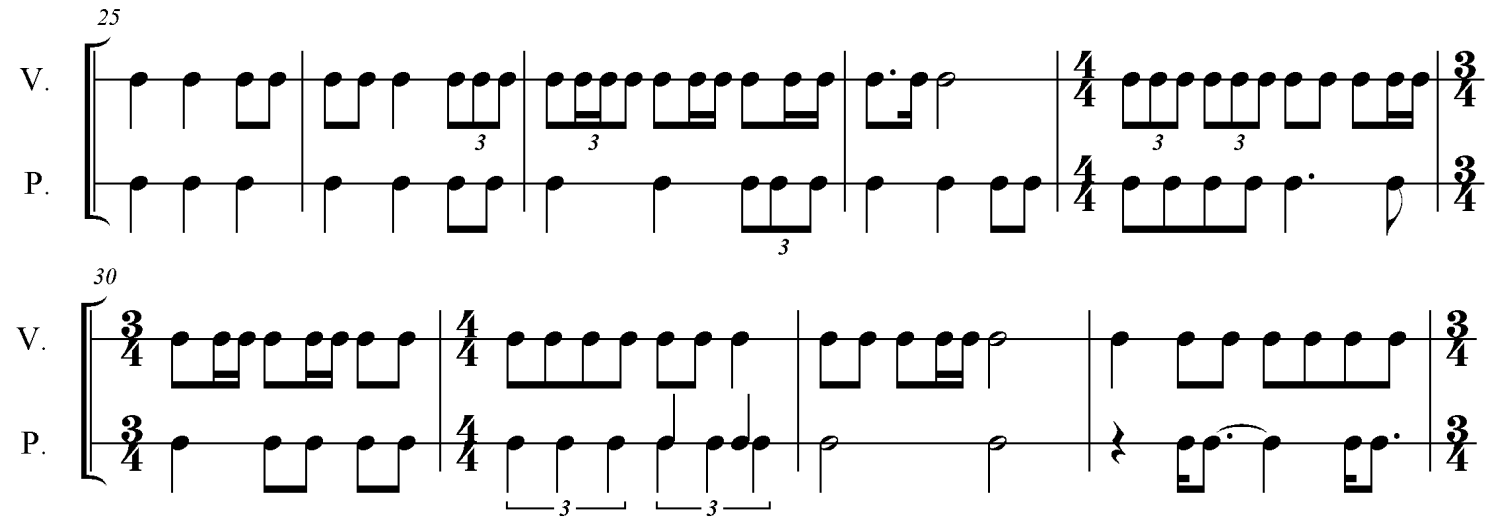

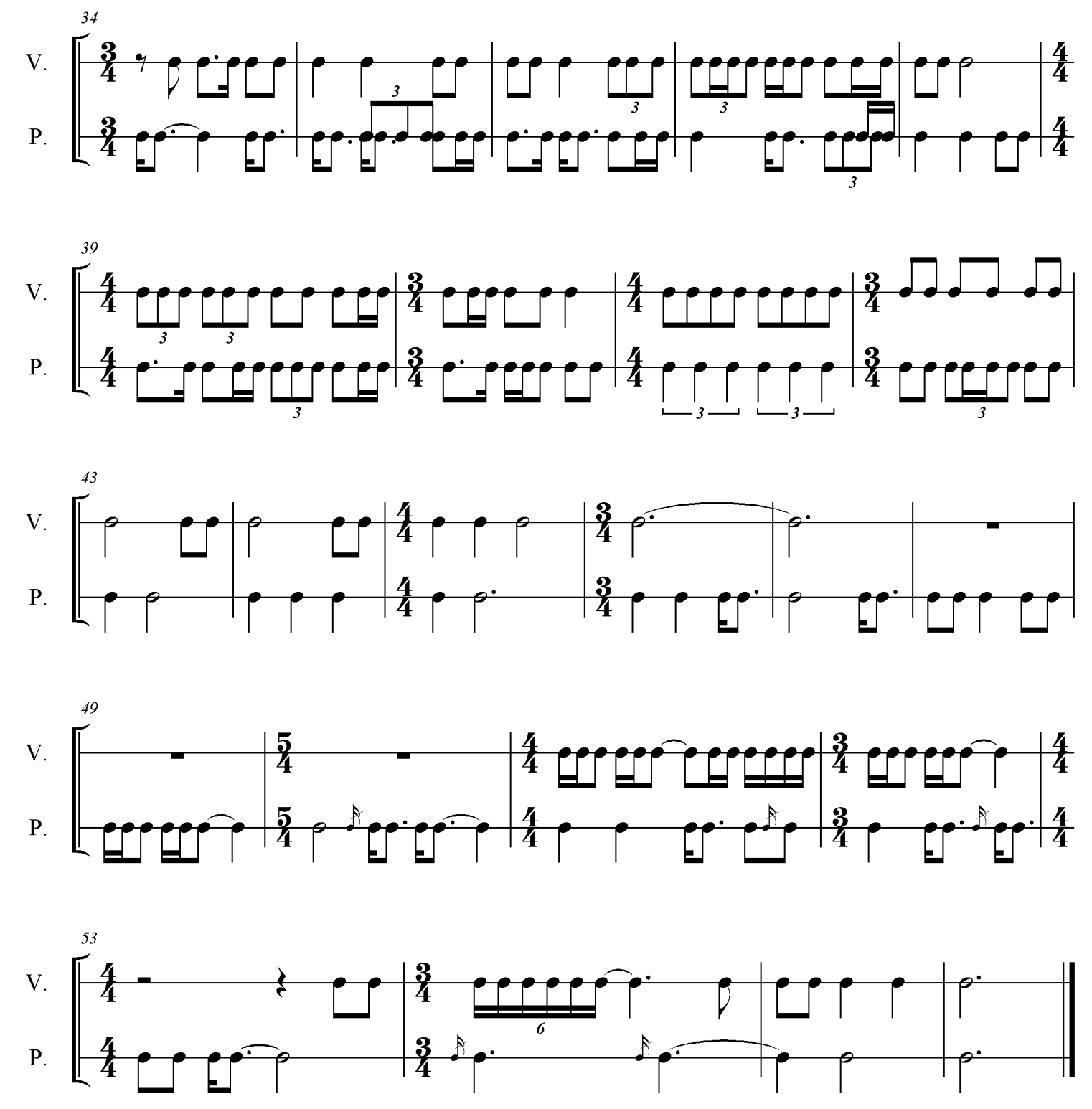

Note: Horizontal density is not the same as rhythm. Horizontal density is a determination of new pulses heard. Vocal and piano lines should be considered together for a complete picture.

Details worth noting:

es The .\$.) motive appears many times in the piano, sometimes with an additional grace note before for additional excitement.

is Triplets are almost exclusively used in the B and $\mathrm{B}^{1}$ sections (mm. 23-45), but not in A or the Coda. 


\section{Thou Famished Grave}

Item one: pitch in linear form

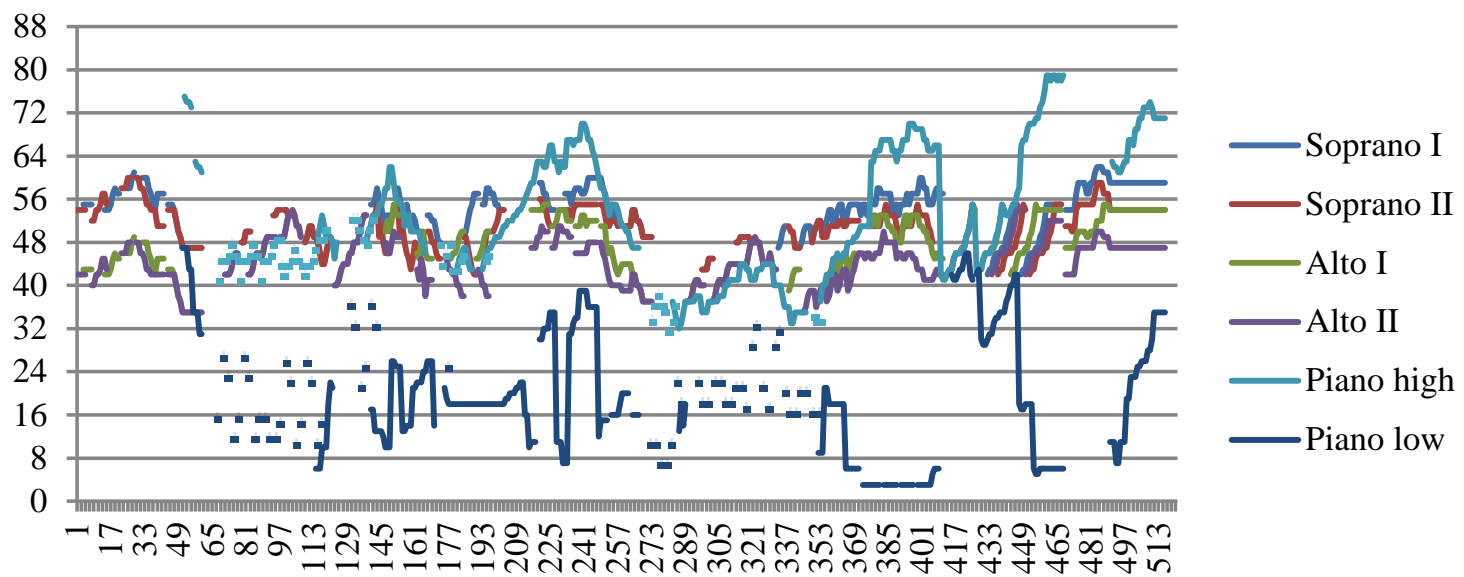

$\mathrm{X}$-axis: beats

Y-axis: pitches; $\mathrm{A}_{0}$ equals $1, \mathrm{C}_{8}$ equals 88

The piano's high line traces the highest notes played in the right hand. The piano's low line traces the lowest notes played in the left hand.

Details worth noting:

is In the Introduction, the Soprano Is and IIs echo each other, as do the Alto Is and IIs. In general, the vocal parts sing similar patterns throughout the piece.

is During the $\mathrm{A}$ and $\mathrm{A}^{1}$ sections (easily identifiable by the dots in the left hand), the right hand's highest notes are intermixed with the singers.

cs During the B section (beat 216 to 269), the piano part becomes more melodic and less disjointed. The top notes of the right hand briefly ascend above the sopranos, but the score confirms that the rest of the right hand's notes are still mingling with the singers.

is The repeated melodic pattern in the D section (beat 412) is particularly beautiful when graphed. Even when the piano parts move away from the vocalists' register, they continue to somewhat follow the melodic pattern. The two hands are furthest apart here in preparation for the climax.

is The final notes are almost symmetrical: a total of three octaves with a fifth in the middle. 


\section{Thou Famished Grave}

Item two: volume/dynamics graph

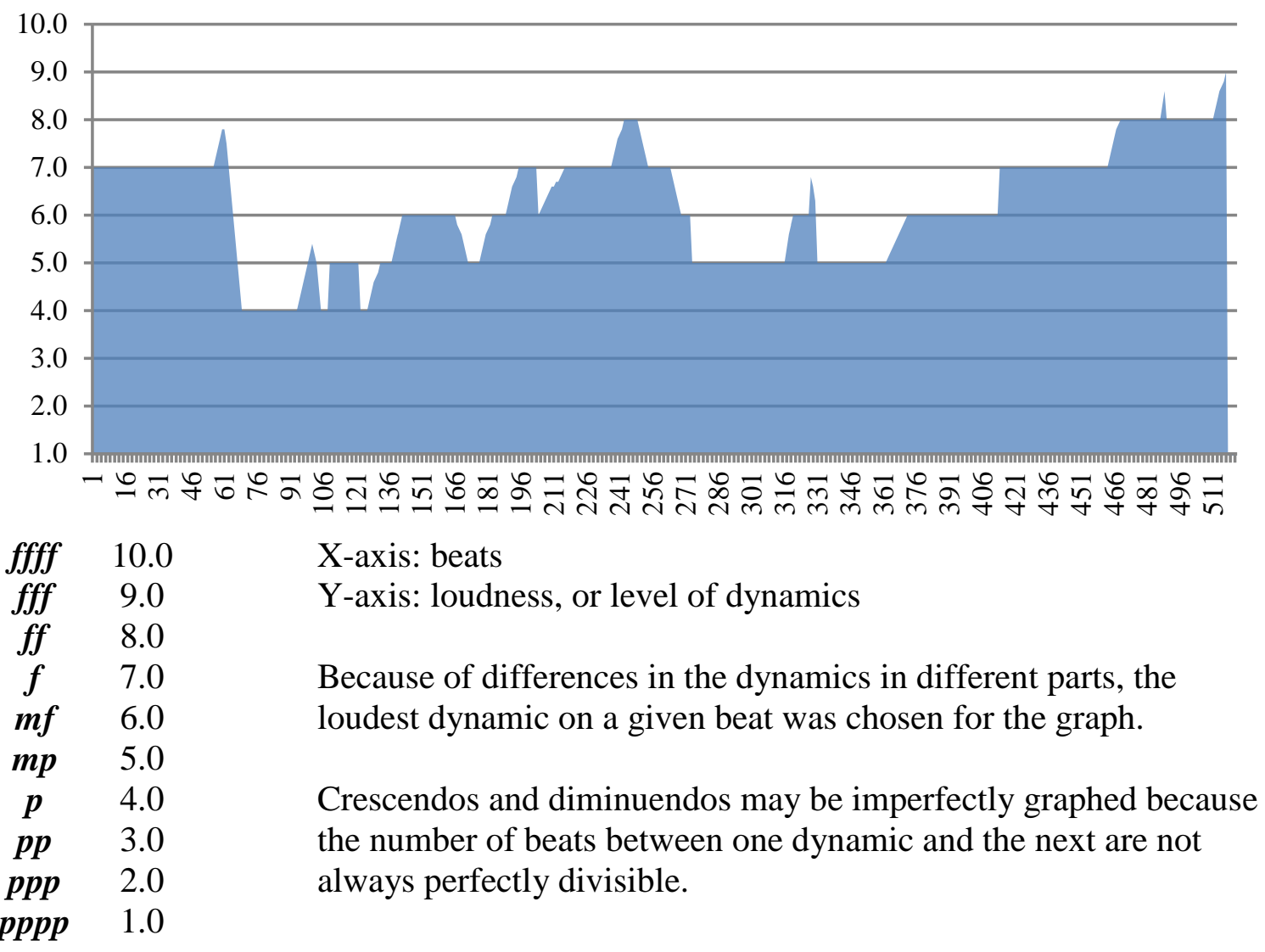

Details worth noting:

is The highest dynamic is at the end. Garrop chooses to save the climax for the very end of the piece. The next highest dynamic occurs on beat 243 during the B section.

is The $\mathrm{A}$ and $\mathrm{A}^{1}$ sections are the quietest portions of the music. Interestingly, the "Introspective" $\mathrm{A}^{1}$ section is slightly higher in volume than the "Dancing fearlessly" A section.

es Similar to Pity Me Not, the gradual increase in dynamic to the climax is evident. 


\section{Thou Famished Grave}

Item three: vertical density graph

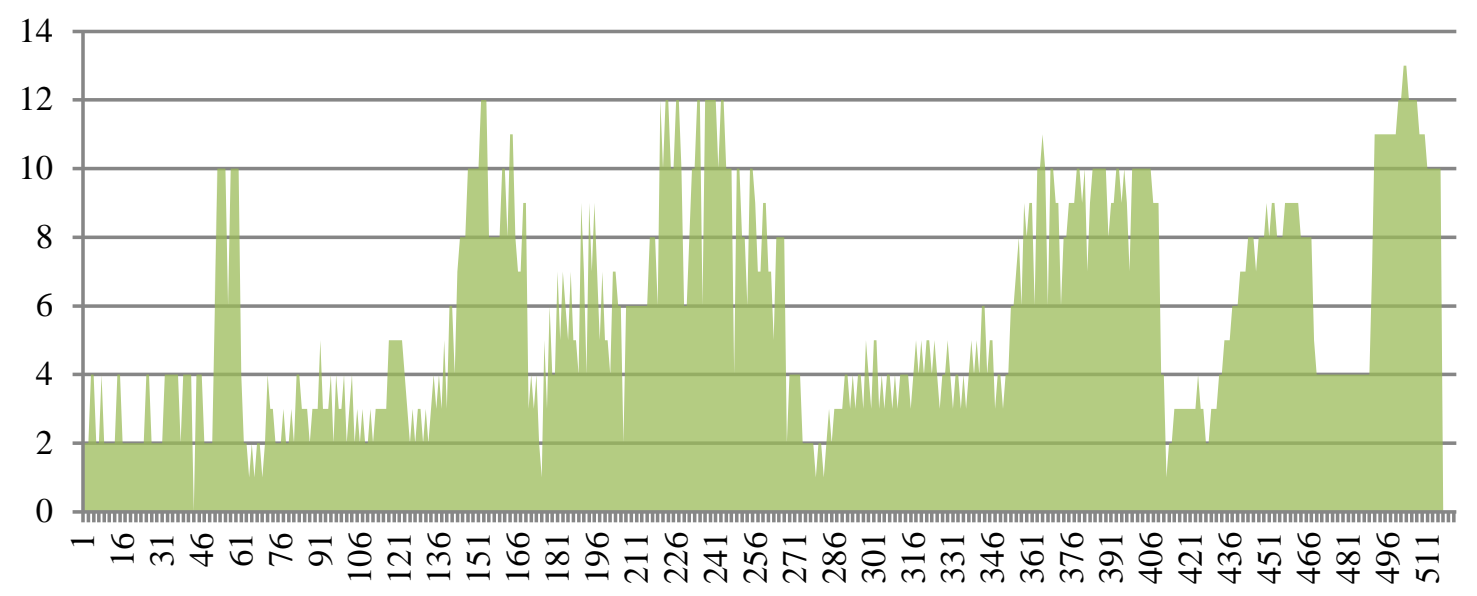

X-axis: beats

Y-axis: number of pitches occurring at once

Details worth noting:

is The periods of higher vertical density occur when the piano is playing chords. Therefore, the beginnings of the sparse $A$ (beat 51 to 215) and $A^{1}$ (beat 269 to 371) sections are low on the graph. As the music moves out of those sections and into the next, the density thickens.

is The single rest in the piece is barely noticeable on beat 43. Otherwise, the piece rarely contains less than two notes at a time. 


\section{Thou Famished Grave}

Item four: horizontal density
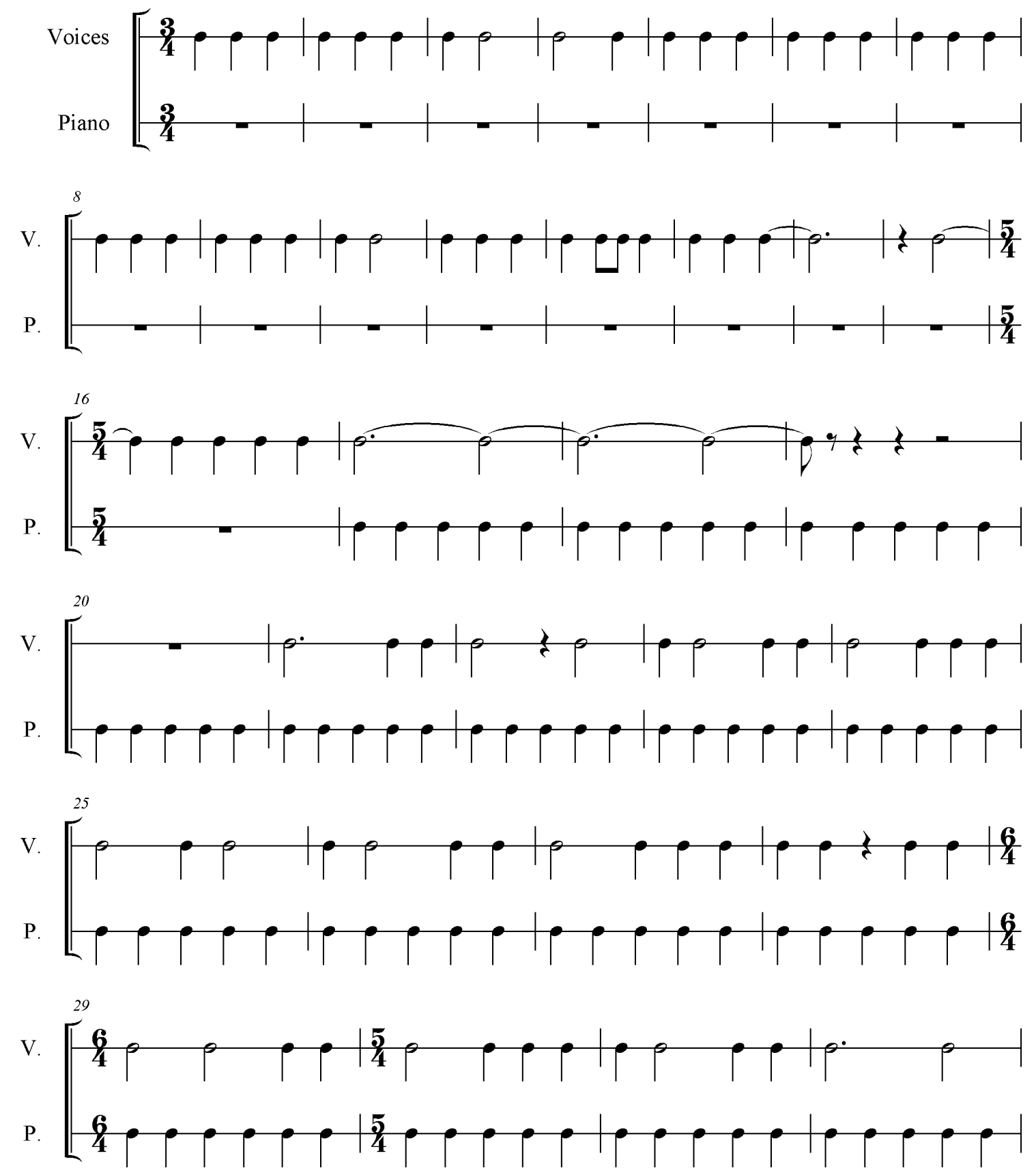

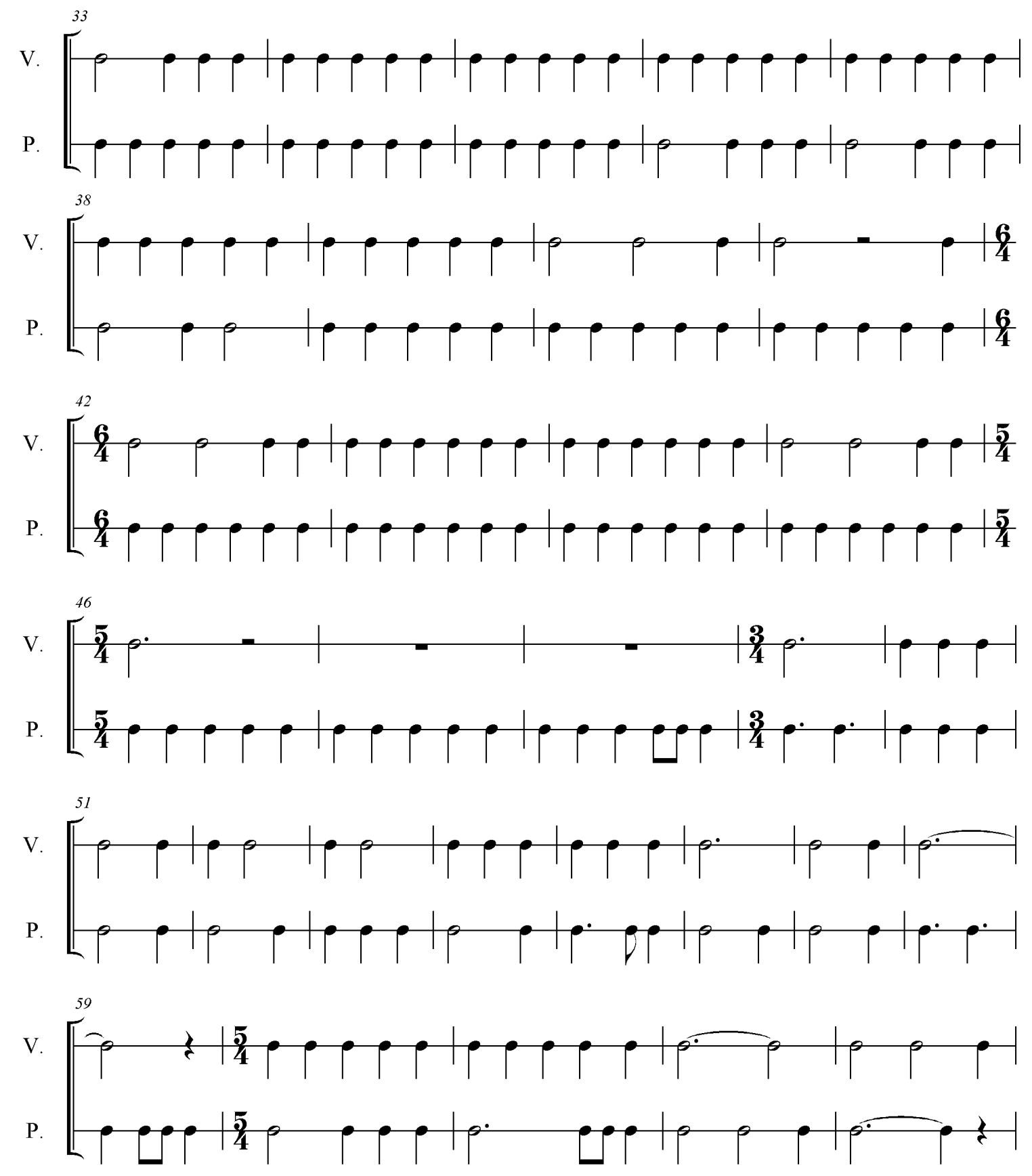
$\mathrm{V}$.
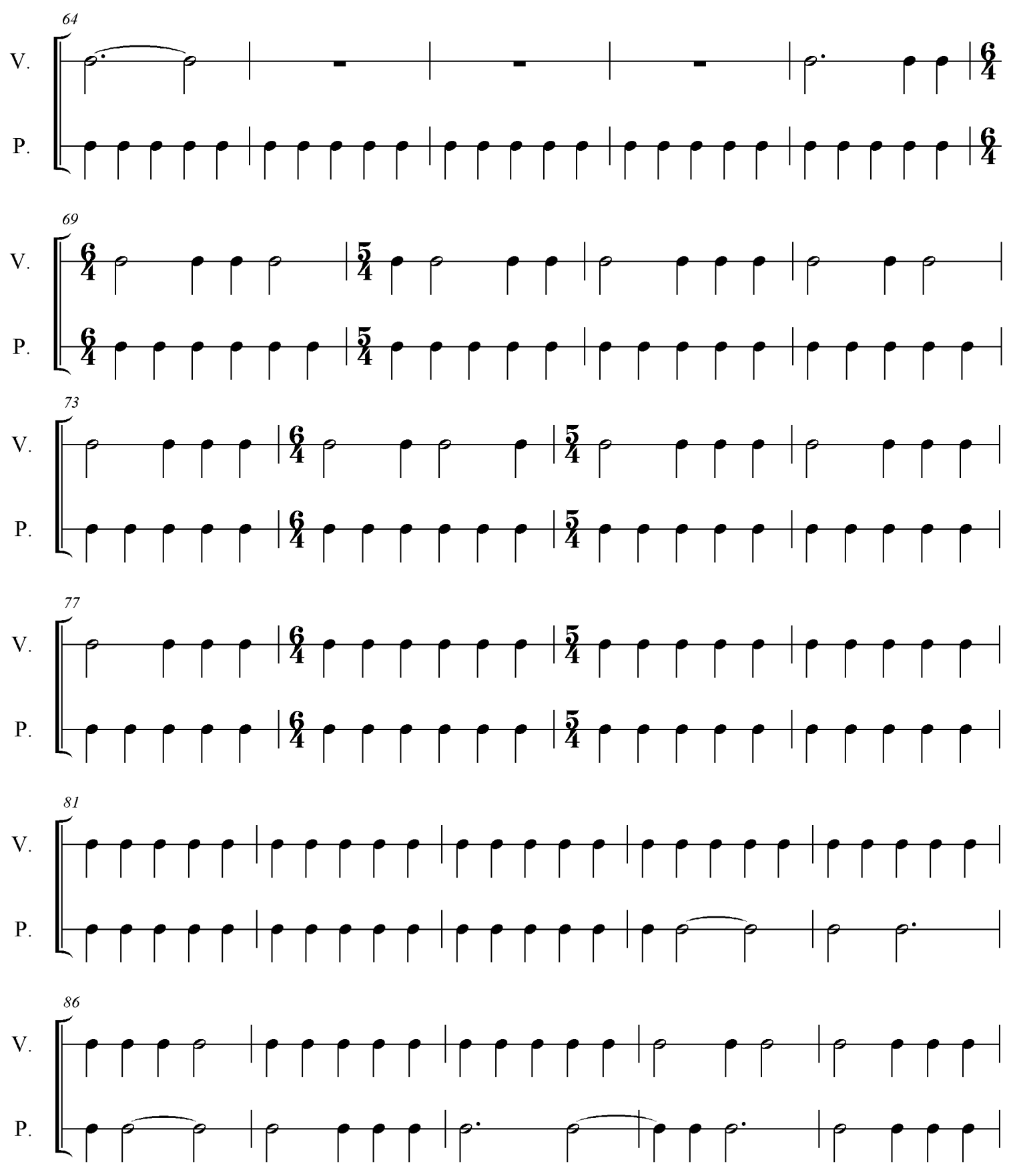

109 

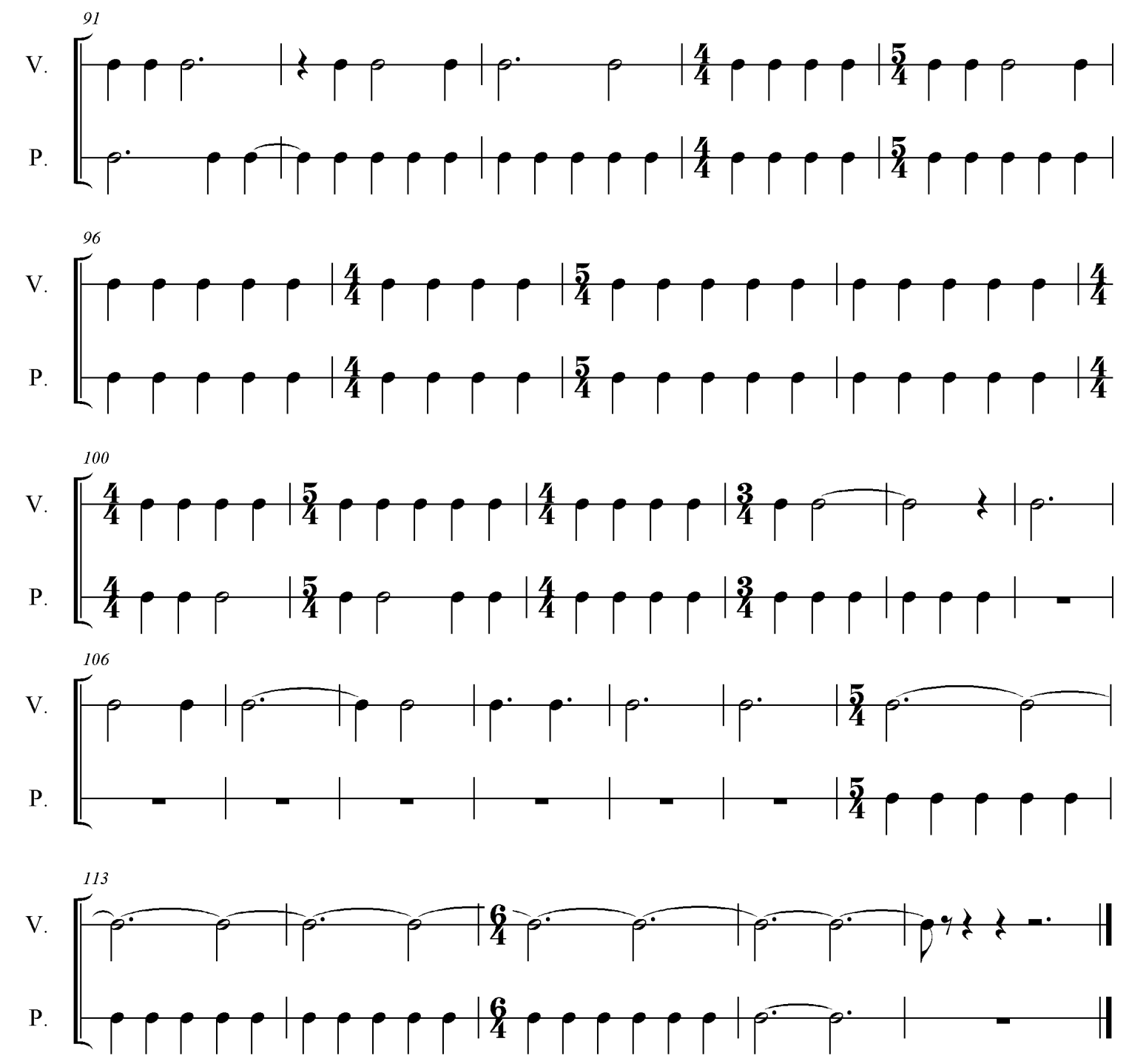

Note: Horizontal density is not the same as rhythm. Horizontal density is a determination of new pulses heard. Vocal and piano lines should be considered together for a complete picture.

Details worth noting:

is Much of the piece has a consistent quarter note rhythm between the vocal and piano lines.

\& During the climax (m. 105 to the end), many beats do not have a new pulse.

Because this is different than the quarter note rhythm pervasive in the rest of the piece, this section creates more tension and interest. 


\section{BIBLIOGRAPHY}

Belet, Brian. "Theoretical and Formal Continuity in James Tenney’s Music." Contemporary Music Review 27, Part 1 (2008): 23-46.

Carter, Tim. "Word-painting." Grove Music Online, Oxford Music Online. "Wordpainting."

http://www.oxfordmusiconline.com.libaccess.sjlibrary.org/subscriber/article/grov e/music/30568 (accessed February 20, 2010).

Cooke, Deryck. The Language of Music. Oxford: Oxford University Press, 1959.

Fuller, John. The Critical Idiom. Edited by John D. Jump. Vol. 26, The Sonnet. London: Methuen \& Co. Ltd., 1972.

Garrop, Stacy. Pity Me Not. Chicago: Stacy Garrop, 2002. Used with permission.

Garrop, Stacy. Thou Famished Grave. Chicago: Inkjar Publishing Company, 2006. Used with permission.

Groves, Peter L. ELS Monograph Series. Edited by Robert M. Schuler. Vol. 74, Strange Music: The Metre of the English Heroic Line. Victoria, B.C.: English Literary Studies, 1998.

Hyer, Brian. "Tonality." Grove Music Online, Oxford Music Online, http://www.oxfordmusiconline.com.libaccess.sjlibrary.org/subscriber/article/grov e/music/28102 (accessed October 20, 2009).

Lewis, Pericles. The Cambridge Introduction to Modernism. New York: Cambridge University Press, 2007.

Milford, Nancy. Savage Beauty: The Life of Edna St. Vincent Millay. New York: Random House Trade Paperbacks, 2001.

Spiller, Michael R. G. The Development of the Sonnet: An Introduction. London: Routledge, 1992.

Tomlinson, Charles. The Sonnet: Its Origin, Structure, and Place in Poetry. Folcroft, PA: The Folcroft Press, Inc., 1970.

Wigmore, Richard. "Contralto." The Oxford Companion to Music, edited by Alison Latham, Oxford Music Online, http://www.oxfordmusiconline.com.libaccess.sjlibrary.org/subscriber/article/opr/t 114/e1596 (accessed February 20, 2010). 
Wigmore, Richard. "Soprano." The Oxford Companion to Music, edited by Alison Latham, Oxford Music Online,

http://www.oxfordmusiconline.com.libaccess.sjlibrary.org/subscriber/article/opr/t 114/e6341 (accessed February 20, 2010). 